\title{
Accurate GPS Time-Linked Data Acquisition System (ATLAS) User's Manual
}

\author{
Dale Berg \& Jose Zayas \\ Wind Energy Technology Department \\ Sandia National Laboratories \\ Albuquerque, NM 87185-0708
}
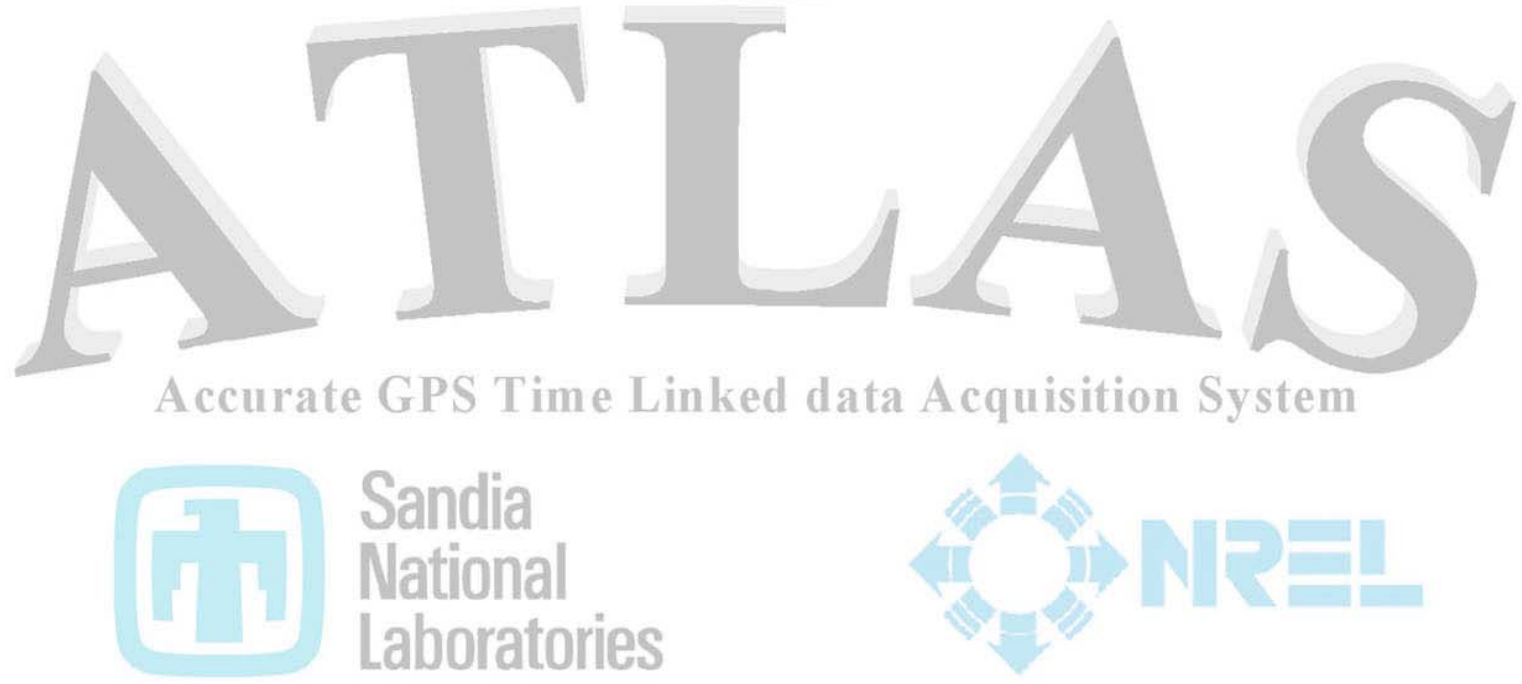

Albuquerque, New Mexico 87185 and Livermore, California 94550 
Issued by Sandia National Laboratories, operated for the United States

Department of Energy by Sandia Corporation.

NOTICE: This report was prepared as an account of work sponsored by an agency of the United States Government. Neither the United States Government, nor any agency thereof, nor any of their employees, nor any of their contractors, subcontractors, or their employees, make any warranty, express or implied, or assume any legal liability or responsibility for the accuracy, completeness, or usefulness of any information, apparatus, product, or process disclosed, or represent that its use would not infringe privately owned rights. Reference herein to any specific commercial product, process, or service by trade name, trademark, manufacturer, or otherwise, does not necessarily constitute or imply its endorsement, recommendation, or favoring by the United States Government, any agency thereof, or any of their contractors or subcontractors. The views and opinions expressed herein do not necessarily state or reflect those of the United States Government, any agency thereof, or any of their contractors.

Printed in the United States of America. This report has been reproduced directly from the best available copy.

Available to DOE and DOE contractors from

U.S. Department of Energy

Office of Scientific and Technical Information

P.O. Box 62

Oak Ridge, TN 37831

Telephone: (865)576-8401

Facsimile: (865)576-5728

E-Mail: reports@adonis.osti.gov

Online ordering: http://www.DOE.gov/bridge

Available to the public from

U.S. Department of Commerce

National Technical Information Service

5285 Port Royal Rd

Springfield, VA 22161

Telephone: (800)553-6847

Facsimile: (703)605-6900

E-Mail: orders@ntis.fedworld.gov

Online ordering: http://www.ntis.gov/ordering.htm 
SAND2001-1289

Unlimited Release

Printed May 2001

\title{
Accurate GPS Time-Linked Data Acquisition System (ATLAS) User's Manual
}

\author{
Dale Berg \\ Jose Zayas \\ Wind Energy Technology \\ Sandia National Laboratories \\ P.O. Box 5800 \\ Albuquerque, NM 87185-0708
}

\begin{abstract}
The Accurate Time-Linked data Acquisition System (ATLAS) is a small, lightweight, time-synchronized, robust data acquisition system that is capable of acquiring simultaneous long-term time-series data from both a wind turbine rotor and ground-based instrumentation. This document is a user's manual for the ATLAS hardware and software. It describes the hardware and software components of ATLAS, explains how to install and execute the software, presents a detailed set of instructions on assembling an ATLAS for a particular application, and includes an extensive list of troubleshooting procedures.
\end{abstract}




\section{Frontispiece}

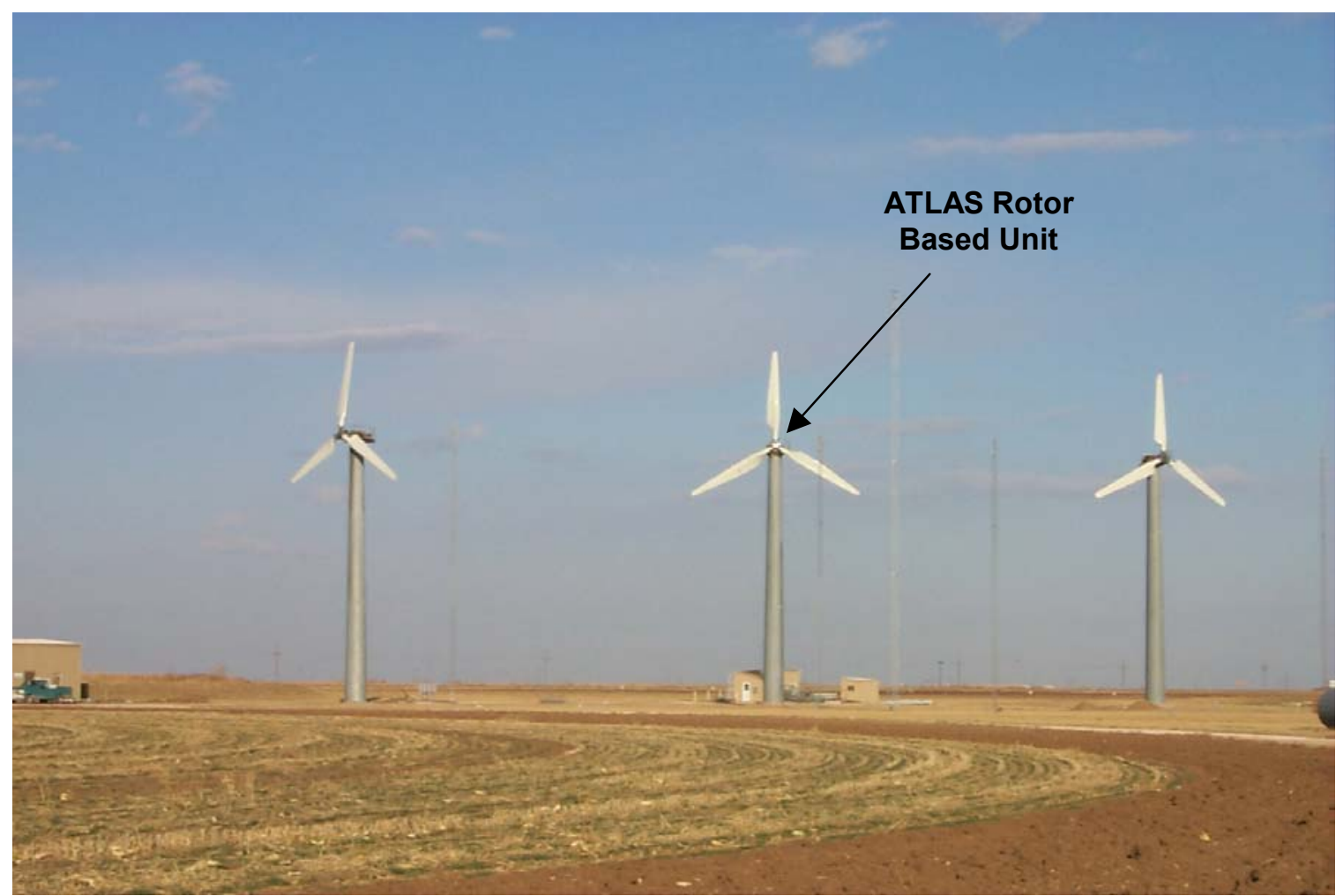

Micon 65 Turbines in Bushland, Texas, Equipped with the Accurate GPS Time-Linked data Acquisition System (ATLAS) 


\section{ATLAS USER'S MANUAL}

Dale Berg and Jose Zayas

Wind Energy Technology

Sandia National Laboratories, Albuquerque, NM 
This page intentionally left blank. 


\section{Acronyms}

1PPS one pulse per second

ADAS

Advanced Data Acquisition System

AGND

analog ground

ATLAS

Accurate GPS Time-Linked data Acquisition System

DAM

Data Acquisition Module

DAS

DCLK

Data Acquisition Subsystem

DCS

digital clock

DGND

data communication subsystem

DMM

digital ground

ESD

digital multimeter

GBCU

GBU

electrostatic discharge

GND

ground-based computer unit

GPS

ground-based unit

NREL

ground

ODBC

Global Positioning Satellite

PATSyM

National Renewable Energy Laboratory

open database connectivity

PCM

Programmable Accurate Time Synchronization Module

PLD

pulse code modulated

PROM

programmable logic device

RAM

programmable read-only memory

RBU

random access memory

SDAS

rotor-based unit

SNL

Smart Data Acquisition System

TSS

Sandia National Laboratories

TTL

UPS

timing synchronization subsystem

transistor/transistor logic

UTC

uninterruptible power supply

universal time clock 
This page intentionally left blank. 


\section{Foreword}

This user's manual provides sufficient information for scientists, engineers, and technicians to install, operate, and maintain an Accurate GPS Time-Linked data Acquisition System (ATLAS).

Various NOTES, CAUTIONS, and WARNINGS are used throughout this manual to emphasize important and critical instructions and should be heeded under the following conditions:

\section{NOTE}

Operating procedures, conditions, etc., that are essential to highlight.

\section{CAUTION}

Operating procedures, practices, etc., which, if not strictly observed, will result in damage to, or destruction of, equipment.

$$
\text { WARNING }
$$

Operating procedures, practices, etc., which, if not strictly observed, will result in personal injury or loss of life. 
This page intentionally left blank. 


\section{Contents}

Page

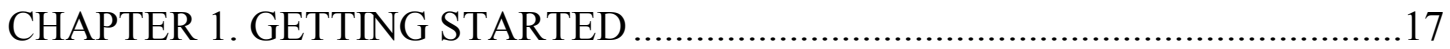

1.1 Installing and Configuring the ATLAS Software .........................................19

1.1.1 Set Up the Ground-Based Computer Unit.....................................20

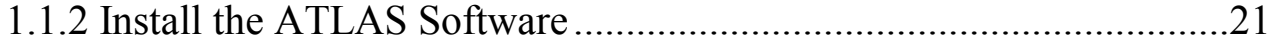

1.1.3 Quick Check ..........................................................................25

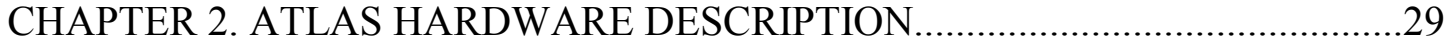

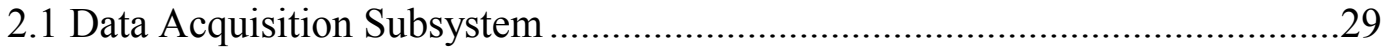

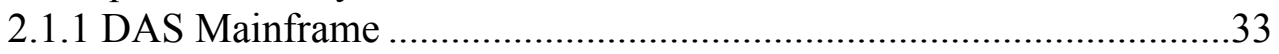

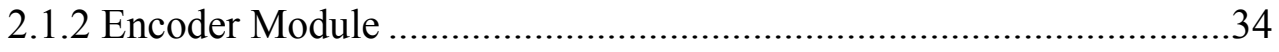

2.1.3 Instrumentation Modules......................................................................35

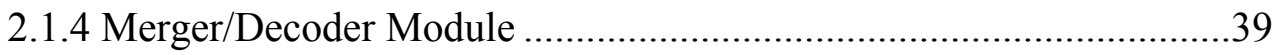

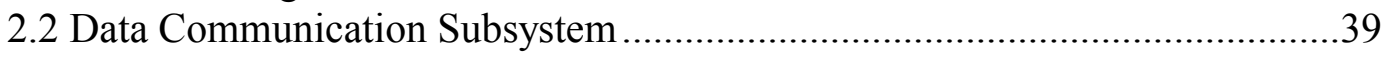

2.3 Programmable Accurate Time Synchronization Module................................41

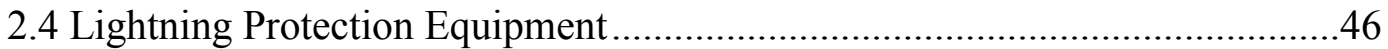

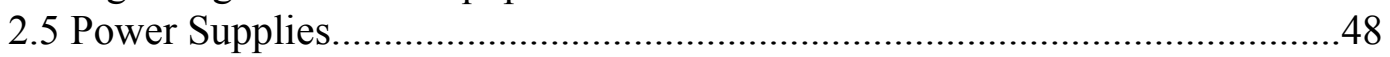

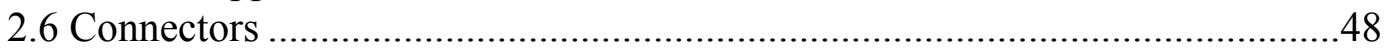

2.7 ATLAS Application-Specific Configuration ..............................................49

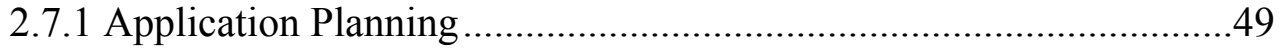

2.7.2 General Fabrication Notes ...........................................................53

2.7.3 Ground-Based Unit Assembly....................................................5

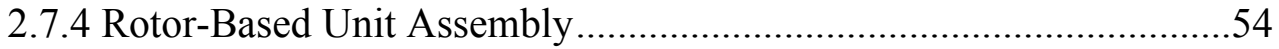

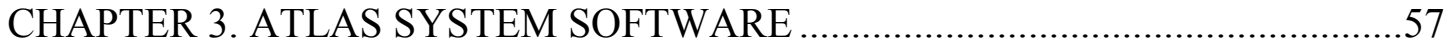

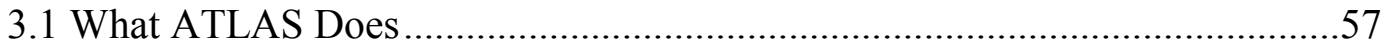

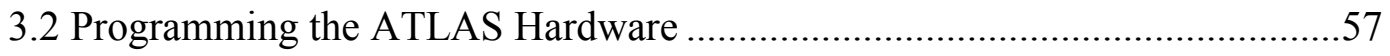

3.2.1 Launching the ATLAS Software ...............................................57

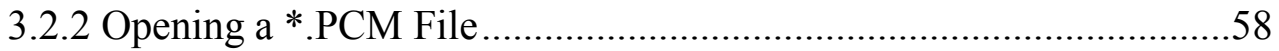

3.2.3 Creating a New *.PCM File ......................................................5

3.2.4 Other Software Features ........................................................... 73

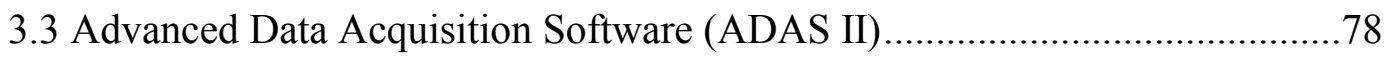

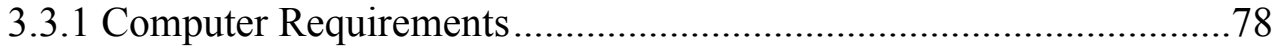

3.3.2 Launching ADAS II................................................................. 78

3.4 Smart Data Acquisition System .............................................................. 82

3.4.1 Smart Data Acquisition System Overview ....................................82

3.4.2 Smart Data Acquisition System Computer Requirements .................82

3.4.3 Smart Data Acquisition System Status Window .............................83

3.4.4 Smart Data Acquisition System Statistics .....................................83

3.4.5 Smart Data Acquisition System Configuration ................................83

3.4.6 Smart Data Acquisition System Database .......................................86

3.4.7 Smart Data Acquisition System Post-Processing ............................86

3.4.8 Smart Data Acquisition System and Power Failures........................87

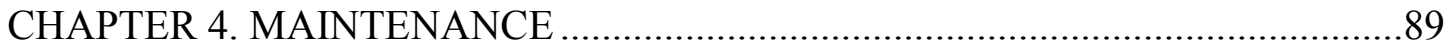

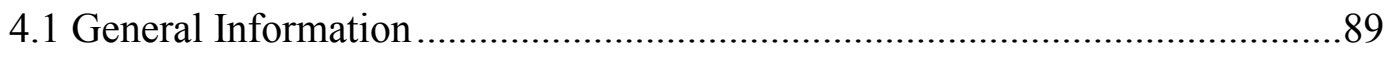




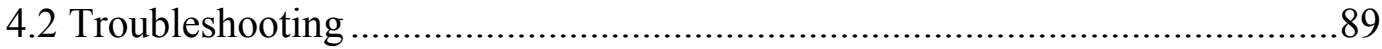

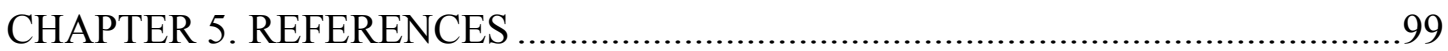

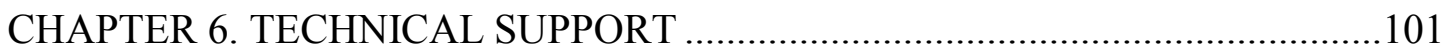

APPENDIX A: CITEL PROTECTION DEVICES SPECIFICATION

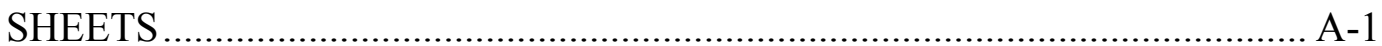

APPENDIX B: GBU WIRING SCHEMATICS.................................................

APPENDIX C: RBU WIRING SCHEMATICS ....................................................

APPENDIX D: ESTIMATING MICROPRO POWER REQUIREMENTS ............ D-1

APPENDIX E: GBU PHOTOGRAPHS ..................................................................

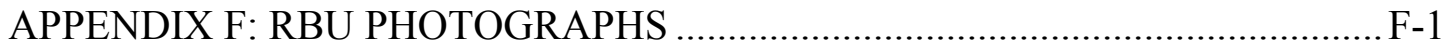

APPENDIX G: CONFIGURING MODEMS ...................................................... G-1 


\section{Figures}

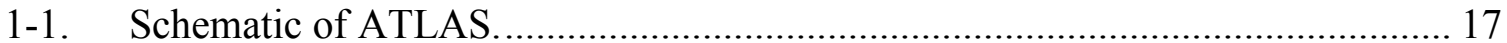

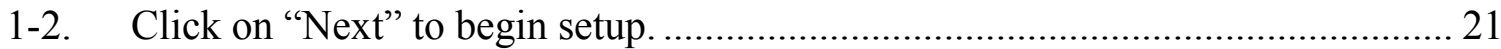

1-3. Read the Warnings and Click on "Next" to Continue with the Setup................. 22

1-4. If the Default Destination is Appropriate, Click "Next." If not, click on

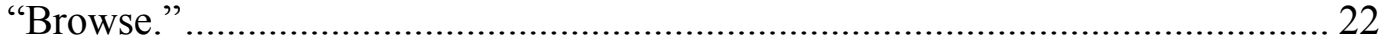

1-5. If You Want to Change Directories, Click “Browse.”............................................ 23

1-6. Specify your Name and Company......................................................................... 23

1-7. ATLAS will Create a Program Folder and an Icon Which will Appear in Your Start bar. If you want to rename the folder, you may do so. ................................. 24

1-8. ATLAS Displays the Information You Have Entered.......................................... 24

1-9. Cables and Connectors Associated with ATLAS. .............................................. 25

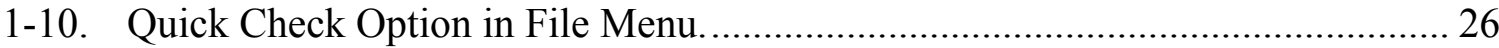

1-11. This is the ATLAS Data Acquisition Window................................................... 26

1-12. If ATLAS Finds a Problem During Quick Check, the Button Turns Red. ........... 28

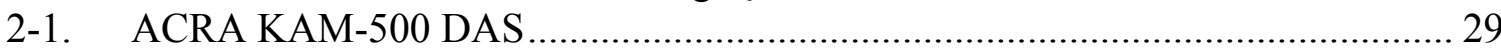

2-2. This is a Picture of What the DAMS Look Like..................................................... 31

2-3. KAM-500 Power Supply Connector Pin Assignment. .......................................... 34

2-4. KAM-500 Encoder Pin Assignment. .................................................................. 35

2-5. MicroPro/KAM-500 Digital Input Card Pin Assignment..................................... 36

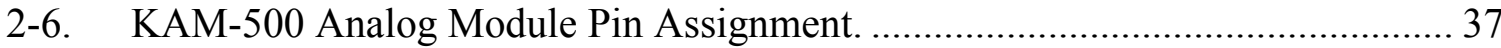

2-7. KAM-500 Strain-Gauge Module Pin Assignments. ............................................. 38

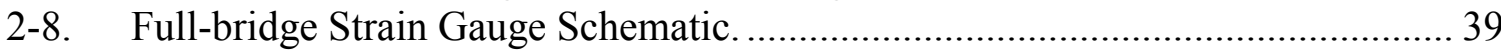

2-9. KAM-500 Merger/Decoder Pin Assignment ...................................................... 40

2-10. The Programmable Accurate Time Synchronization Module ............................... 42

2-11. GPS Receiver/Antenna Configuration............................................................. 44

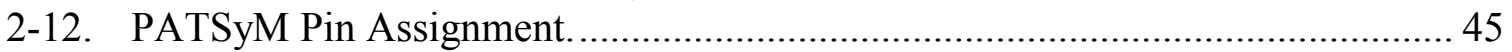

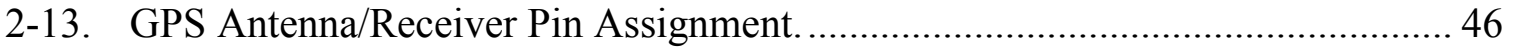

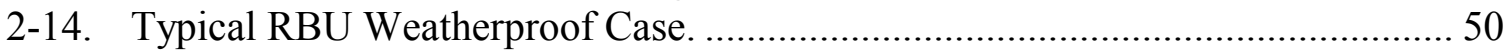

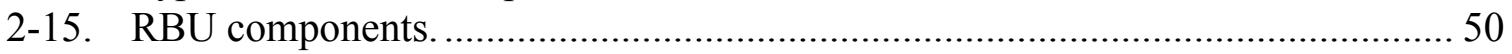

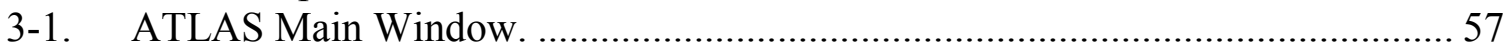

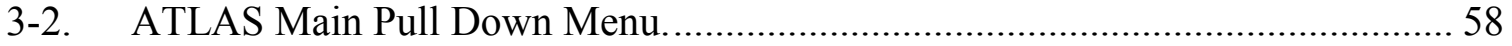

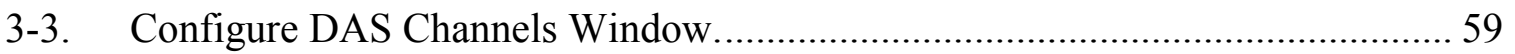

3-4. ATLAS 9-Slot Systems Configuration. …………………………………........ 59

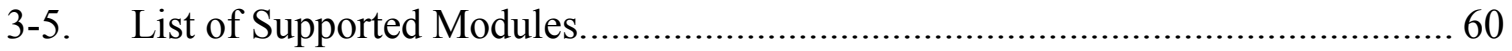

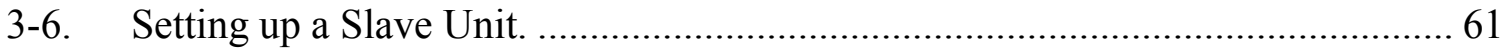

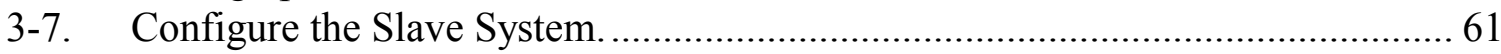

3-8. Slave Unit in Slot 6 has been Properly Configured................................................. 62

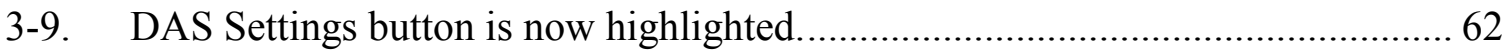

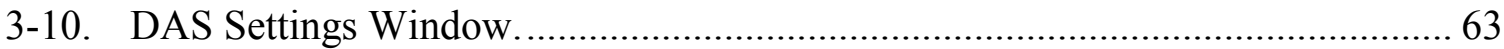

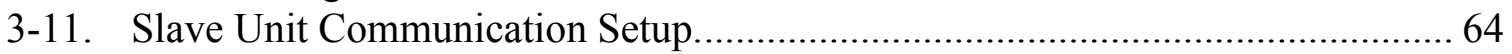

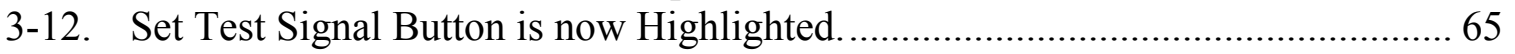

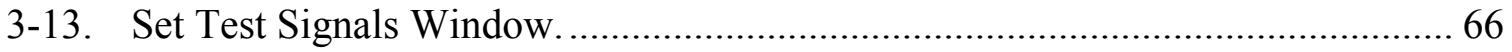




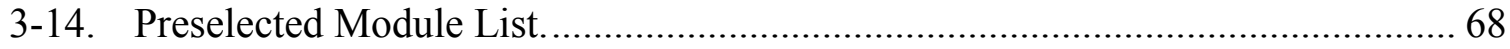

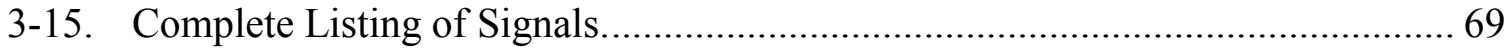

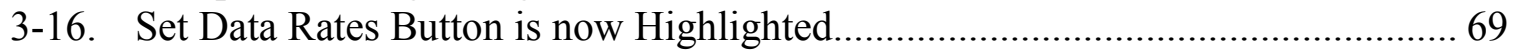

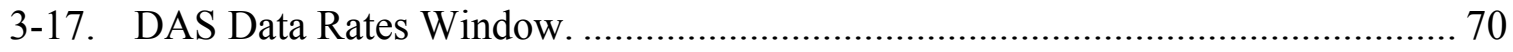

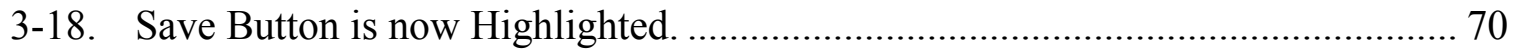

3-19. PCM Editor and Program Button are Highlighted............................................... 71

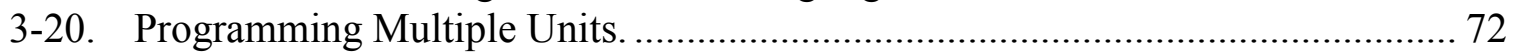

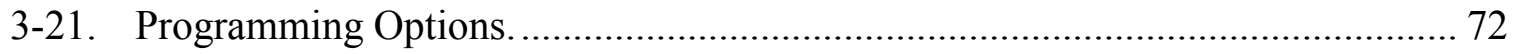

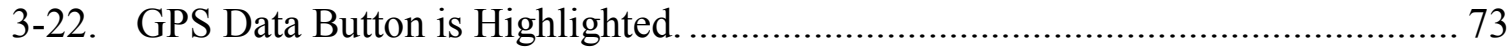

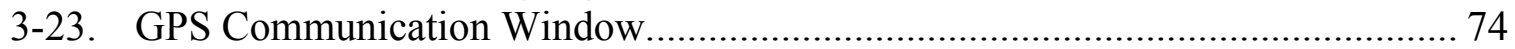

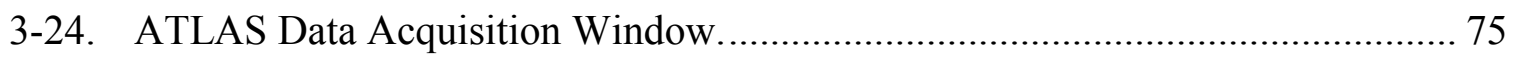

3-25. ATLAS Data Acquisition Window Sections. ..................................................... 76

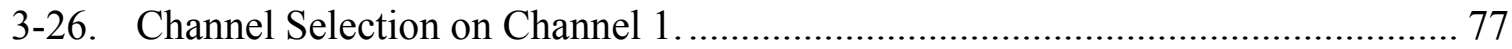

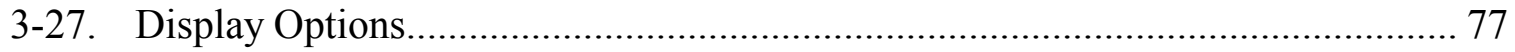

3-28. ADAS II Software Main Menu.............................................................................. 79

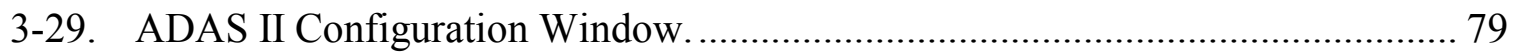

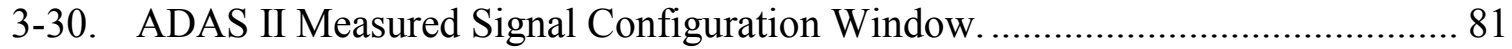

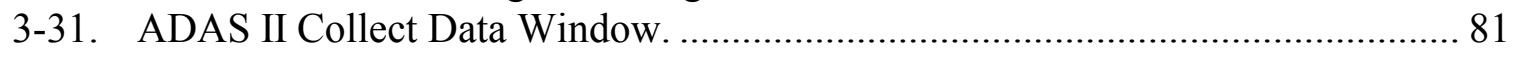

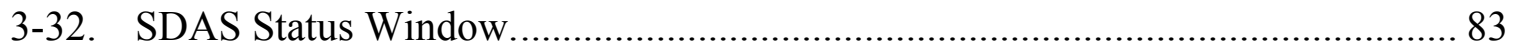

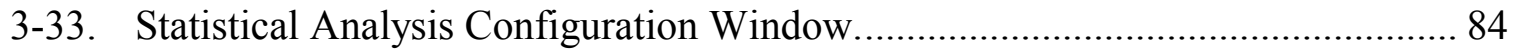

3-34. SDAS Default Cross Channel Statistics Window................................................ 85

3-35. Cross Channel Statistics Configuration Window. ................................................ 85

3-36. Rainflow Analysis Configuration Screen.......................................................... 86

3-37. Channel Versus Channel Plot Showing Four Strain-Gauge Channels Plotted

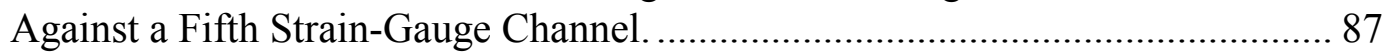

4-1. Diagnostic/Troubleshooting Cable Schematic.................................................. 97 


\section{Tables}

$\underline{\text { Page }}$

1-1. ATLAS Hardware Components .................................................................... 20

1-2. Minimum Computer Requirements to Run ATLAS and ADAS II...................... 21

2-1. Digital Signal-Conditioning Module Characteristics...................................... 31

2-2. High-Level Analog Serial-Conditioning Module Characteristics........................ 31

2-3. Strain-Gauge Signal-Conditioning Module Characteristics .............................. 32

2-4. Merger/Decoder Module Characteristics .......................................................... 33

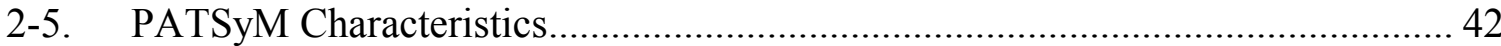

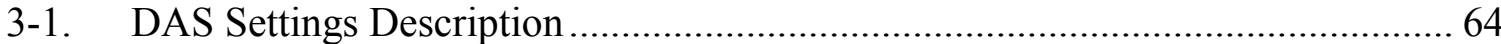

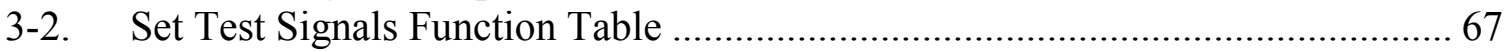

4-1. Troubleshooting Problems/Solutions for ATLAS …......................................... 90

4-2. Troubleshooting Problems/Solutions for PATSyM ........................................... 95 
This page intentionally left blank. 


\section{Chapter 1. Getting Started}

The Accurate Global Positioning Satellite (GPS) Time-Linked data Acquisition System (ATLAS) is a small, lightweight, time-synchronized, robust data acquisition system that is capable of acquiring simultaneous long-term time-series data from both a wind turbine rotor and ground-based instrumentation. These data are then post-processed to provide a complete set of data on wind turbine performance under specific wind speeds, turbulence levels, and temperatures. ATLAS consists of various hardware components with a personal computer and software to interface with the user, control the hardware, and store and process the data.

Figure 1-1 illustrates the various components of a typical ATLAS installation.

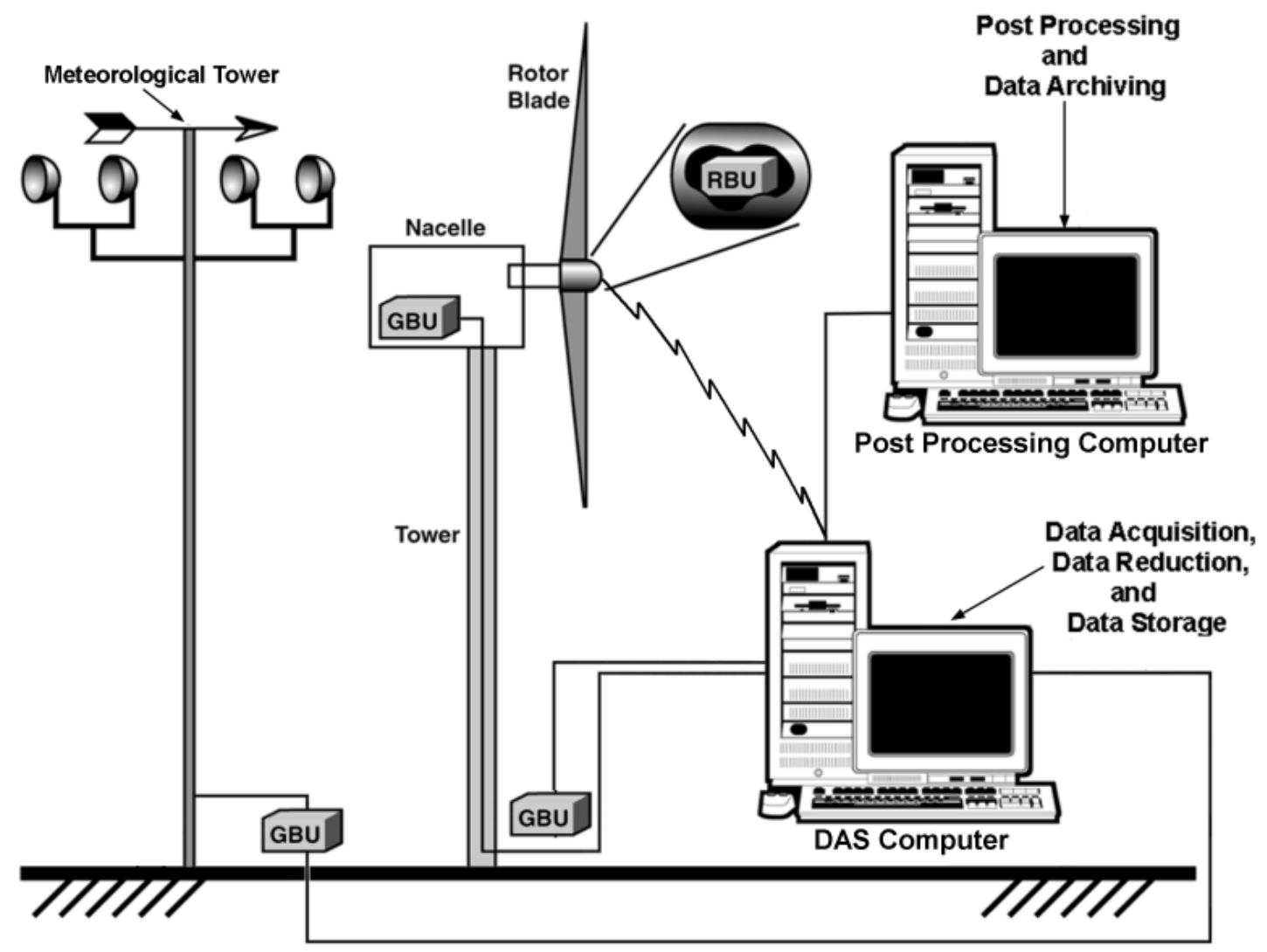

Figure 1-1. Schematic of ATLAS.

A data acquisition subsystem (DAS) is the hardware unit that actually acquires the data, utilizing plug-in data acquisition modules (DAMs) to interface with the sensors. The optional data communications subsystem (DCS) utilizes telemetry to provide communications between the various components of ATLAS, while the programmable accurate time synchronization module (PATSyM) utilizes the GPS to ensure data is acquired at precisely the same time by each DAS. These components are packaged into three types of units, each containing a number of the subsystems listed above: 
1. A rotor-based unit (RBU) typically consists of

- One DAS

- One DCS (optional)

- Typically consisting of two modems, one for bidirectional RS-232 communications and the other for transmitting data to the ground

- One PATSyM

- Including one GPS antenna and receiver

- One or more DAMs

- One power supply

- Lightning protection equipment (optional)

Additional information on RBU components and assembly may be found in Section 2.7.4.

2. A ground-based unit (GBU) typically consists of

- One DAS

- One DCS (optional)

- Typically consisting of two modems, one for bidirectional RS-232 communications and the other for transmitting data to the "Master" (the main GBU) or to the system computer.

- One PATSyM

- Including one GPS antenna and receiver

- One or more DAMs

- One power supply

- Lightning protection equipment (optional)

One GBU is designated the Master GBU, while all the others are "Slave" GBUs and operate under control of the Master GBU. The Master GBU accepts data streams from the RBU and the Slave GBUs, merges those streams with the data it acquires, and sends the resultant data stream to the system computer. If the RBU is utilizing a DCS to transfer data to the Master GBU, the Master GBU must include a data-link modem to receive that data. Data transfer between the Slave and the Master GBUs and between the Master GBU and the system computer is normally accomplished with a hardwire or fiber-optic link, but it may also be via modem.

Additional information on GBU components and assembly may be found in Section 2.7.3 of this manual.

3. A ground-based computer unit (GBCU) (the system computer) consists of

- One PC-type computer

- One DCS (optional)

- Typically consisting of two modems, one for bidirectional RS-232 communications and the other for receiving data from the Master GBU 
- One PCMCIA decoder card (Pocket Decoder)

- One RS-232 bidirectional modem (optional)

- ATLAS software

- Advanced Data Acquisition System (ADAS) II software

- Smart Data Acquisition System (SDAS) software (optional)

If the Master GBU utilizes a DCS to transfer data to the GBCU and to perform RS-232 communications, the GBCU must contain a DCS to receive that data and perform the RS-232 communications with the Master. If the RBU utilizes a DCS, the GBCU must contain an RS-232 modem (not a complete DCS) to communicate with the RBU.

As indicated above, in addition to the hardware, ATLAS contains three distinct software programs. The ATLAS software interacts with the user to determine the configuration of each DAS and programs each DAS to perform the data acquisition. The ADAS II software performs calibrations, retrieves the data acquired by all of the DAS units, and displays and stores that data. The SDAS software post-processes that data to yield more detailed statistics and analyses.

ATLAS features include the following:

1. Data acquisition from a virtually unlimited number of high-level analog and straingauge channels,

2. Simultaneous data acquisition from all channels,

3. Long-term, continuous data acquisition at throughput rates of up to 200,000 data points per second (2000 channels at 100 samples per second, 200 channels at 1000 samples per second, etc.),

4. Hardware programming and control via personal computer,

5. Programmable filtering and gain on each analog and strain-gauge channel, and

6. Bridge completion circuitry and programmable bridge excitation levels for all straingauge channels.

More detailed descriptions of the ATLAS hardware components are provided in Chapter 2.

\subsection{Installing and Configuring the ATLAS Software}

The ATLAS software installation and configuration procedure consists of the following primary operations:

1. Installing the ATLAS software. 
2. Executing and configuring the ATLAS software for the first time.

3. Checking the communication between the computer and each DAS.

The ATLAS components that are required for a typical installation are listed in Table 1-1.

Table 1-1. ATLAS Hardware Components

\begin{tabular}{|c|l|l|}
\hline Item & \multicolumn{1}{|c|}{ Component } & \multicolumn{1}{c|}{ Quantity } \\
\hline 1 & DASs & Two or more \\
\hline 2 & GPS antenna/receiver & Two or more \\
\hline 3 & DAMs & Two or more \\
\hline 4 & PATSyM & Two or more \\
\hline 5 & DCS & $\begin{array}{l}\text { Two, if using telemetry data and communications } \\
\text { links for the RBU. Additional pairs if using } \\
\text { telemetry links for some or all GBUs. } \\
\text { Zero, if using hardwire connections between the } \\
\text { RBU and the Master GBU, between the Slave } \\
\text { GBUs and the Master GBU, and between the } \\
\text { Master GBU and the GBCU. }\end{array}$ \\
\hline 6 & PCMCIA Decoder Card & $\begin{array}{l}\text { One (to be installed in a PCMCIA adapter }- \text { most } \\
\text { laptop computers have this, but you may need to } \\
\text { add one if you're using a desktop computer). }\end{array}$ \\
\hline 7 & Miscellaneous cables & Number, length, connectors vary \\
\hline 8 & ATLAS Software Disk & One CD \\
\hline
\end{tabular}

\subsubsection{Set Up the Ground-Based Computer Unit}

The GBCU is the nucleus of the ATLAS. It is the platform on which your interface software runs and on which the data is stored and processed.

The computer requirements necessary to run the ATLAS and ADAS II software packages are given in Table 1-2.

ATLAS utilizes an application-specific type II PCMCIA card to decode the data stream. All laptop computers come with a PCMCIA adapter installed. If a desktop PC without an adapter will be used for ATLAS, purchase and install the PCMCIA adapter in the computer before installing the ATLAS software (adapters from Antec seem to work well and are readily available). Insert the DAS PCMCIA decoder card (the Pocket Decoder) in the adapter and be sure that it is properly seated. 
Table 1-2. Minimum Computer Requirements to Run ATLAS and ADAS II

\begin{tabular}{|l|l|}
\hline \multicolumn{1}{|c|}{ Parameter } & \multicolumn{1}{c|}{ Particulars } \\
\hline Processor & Pentium 166 MHz (minimum) \\
\hline Operating Systems & $\begin{array}{l}\text { Windows }{ }^{\circledR} \text { 95 or 98 (Windows }{ }^{\circledR} \text { NT version will be } \\
\text { available May 2001) }\end{array}$ \\
\hline $\begin{array}{l}\text { Random access } \\
\text { memory (RAM) }\end{array}$ & 64 megabytes (minimum) \\
\hline Mass storage & 15 megabytes, plus more for data storage. ${ }^{*}$ \\
\hline Monitor resolution & $800 \times 600$ (required) $1024 \times 768$ (preferred) \\
\hline PCMCIA Adapter & PCMCIA Type II (minimum) \\
\hline
\end{tabular}

* For example: 47 channels, 10 minutes, at $30 \mathrm{~Hz}=$ approximately 10 megabytes.

\subsubsection{Install the ATLAS Software}

To install the ATLAS software, insert the supplied ATLAS CD into the CD drive on the GBCU and click on "Start" on your desktop. Select "Run" and use "Browse" to locate and select "SETUP.EXE" on the CD. Click on "OK" and follow the instructions on the screens as they appear. Figures 1-2 through 1-4 show the initial installation screens.

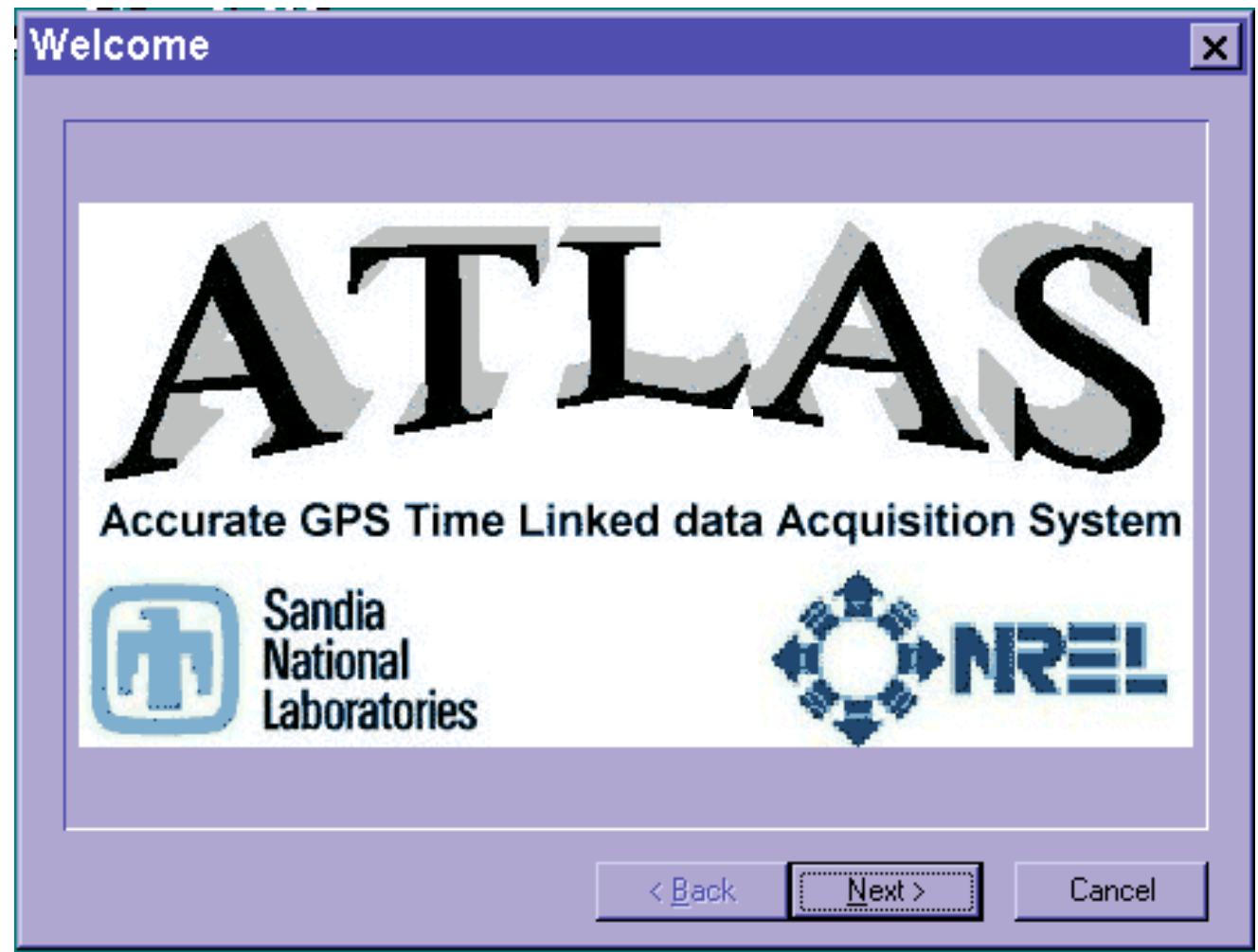

Figure 1-2. Click on "Next" to begin setup. 


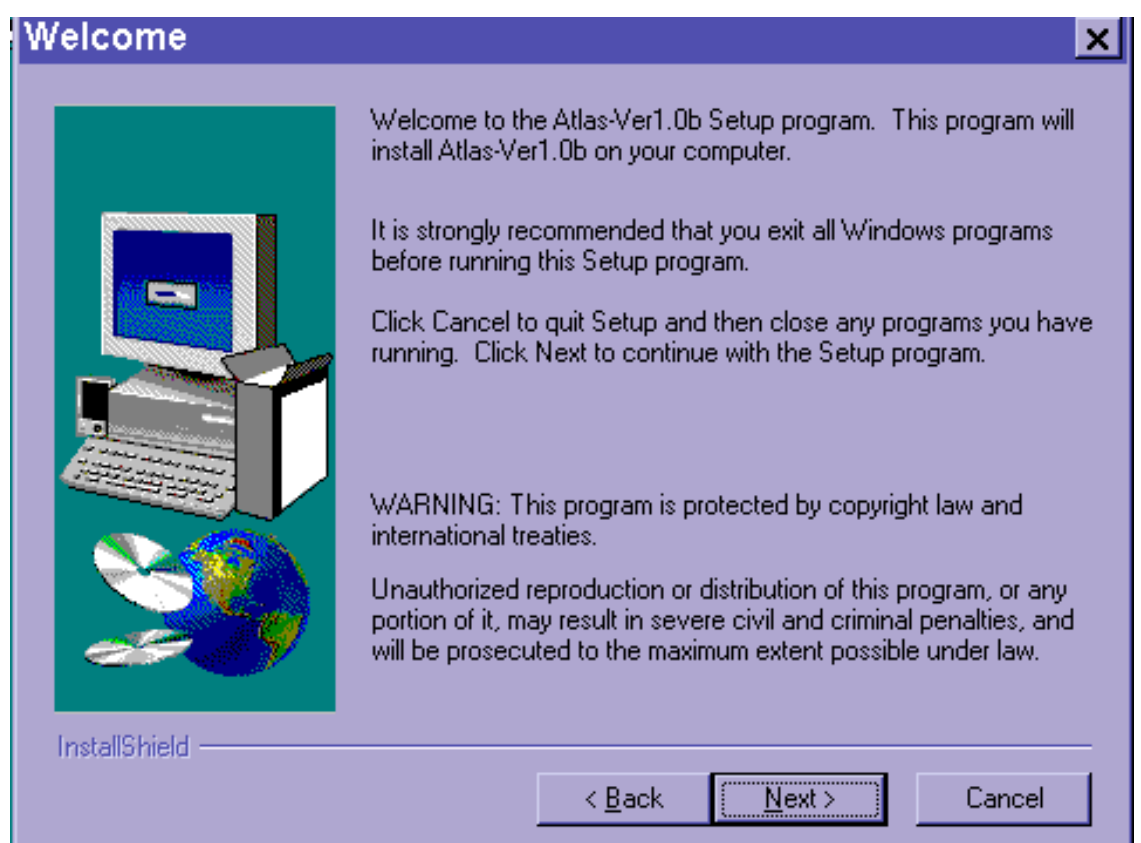

Figure 1-3. Read the Warnings and Click on "Next" to Continue with the Setup.

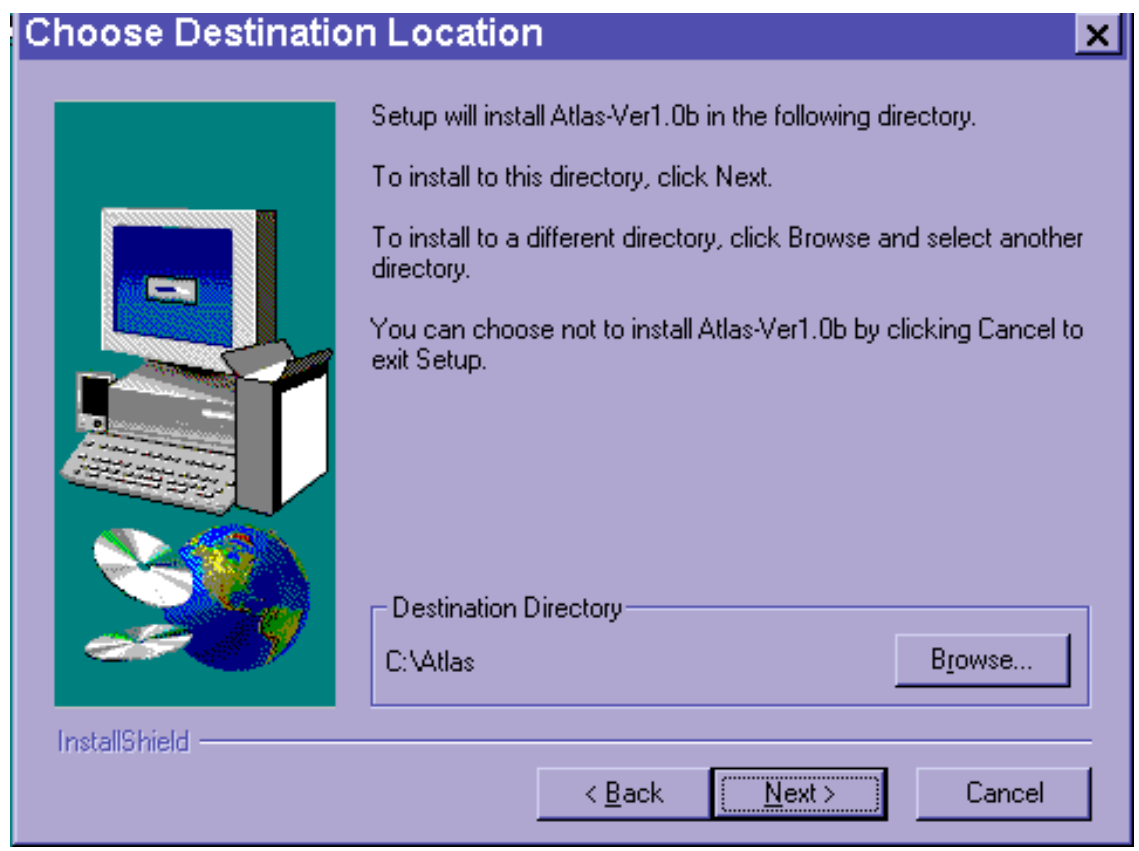

Figure 1-4. If the Default Destination is Appropriate, Click "Next." If not, click on "Browse."

If you do not want to install the program in the recommended directory, choose Browse and select the disk location where ATLAS should be installed. See Figure 1-5 for an example of the directory list.

Figures 1-6 through 1-8 detail the rest of the installation process. After all of the files have been copied to your computer, ATLAS is ready to run for the first time. 


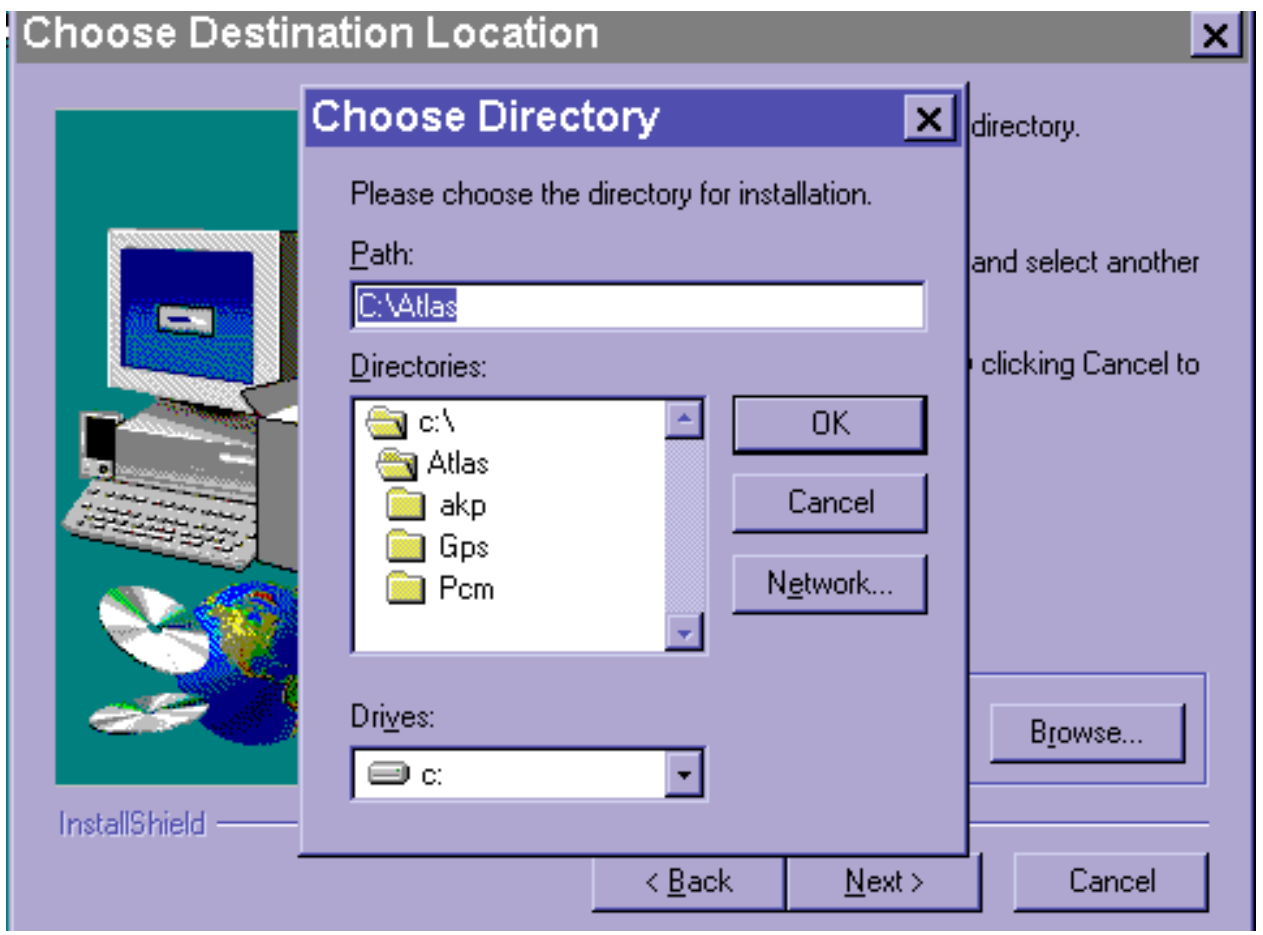

Figure 1-5. If You Want to Change Directories, Click "Browse." ATLAS will ask you to choose a directory. After you have chosen a directory, click "OK" and then "Next."

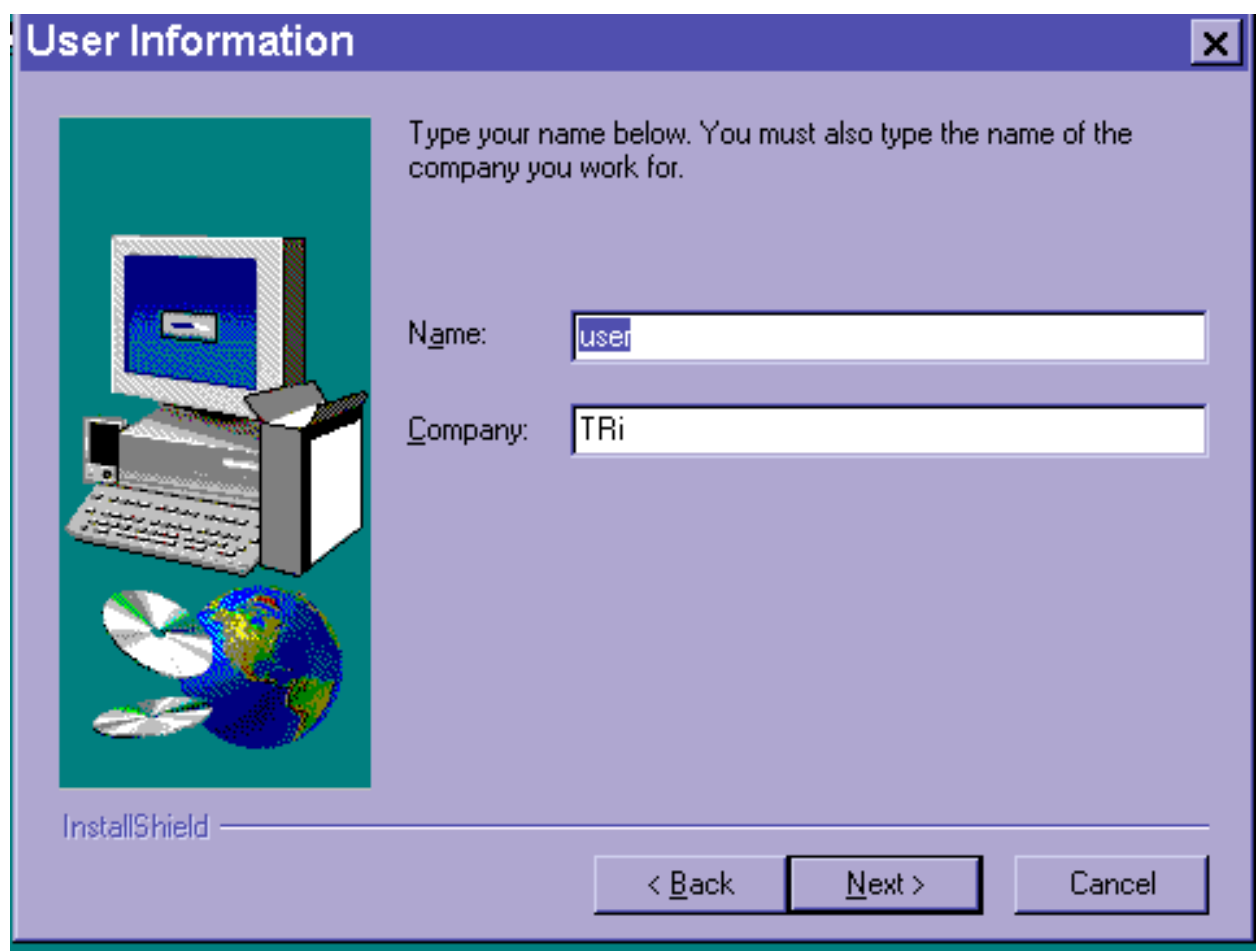

Figure 1-6. Specify your Name and Company. 


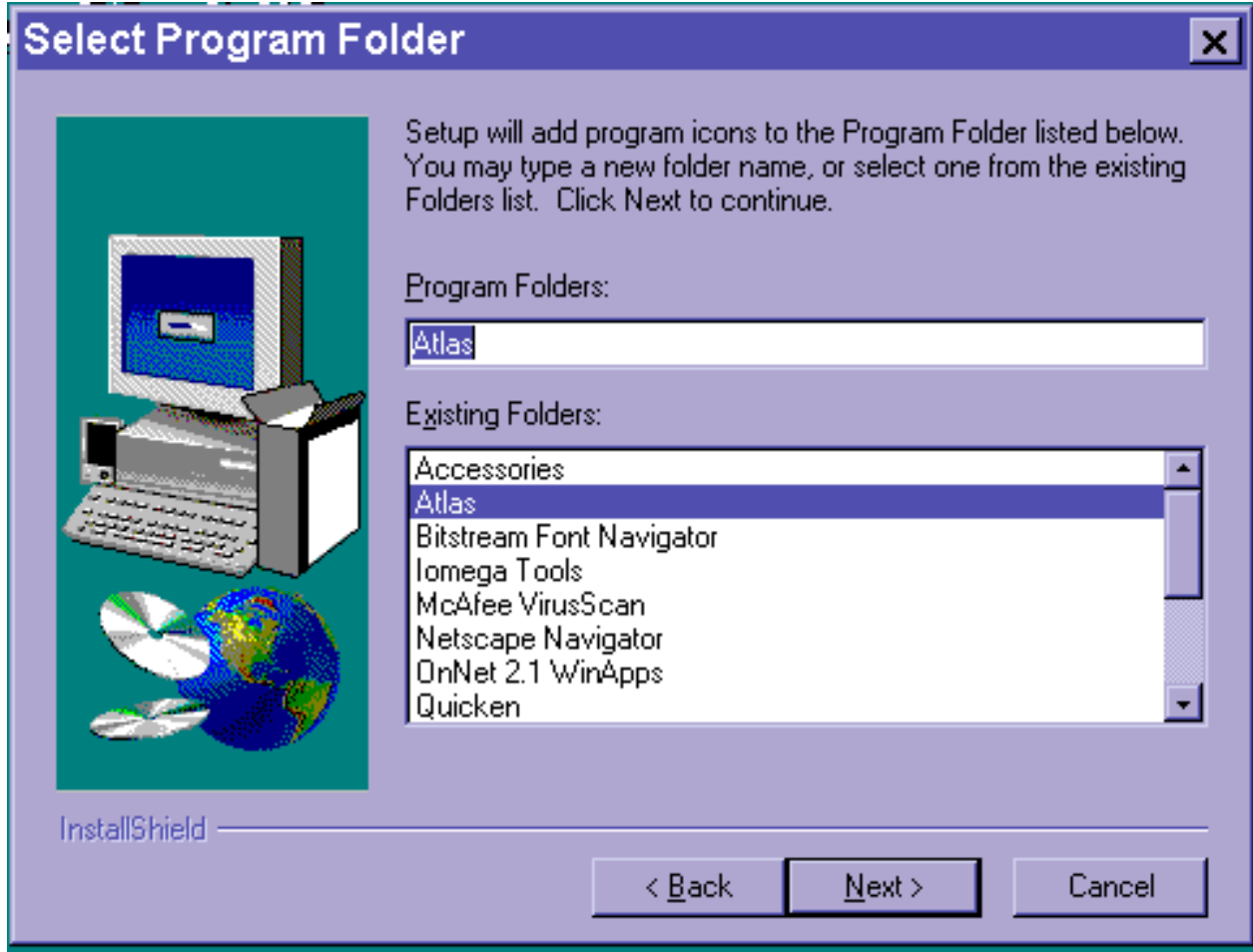

Figure 1-7. ATLAS will Create a Program Folder and an Icon Which will Appear in Your Start bar. If you want to rename the folder, you may do so.

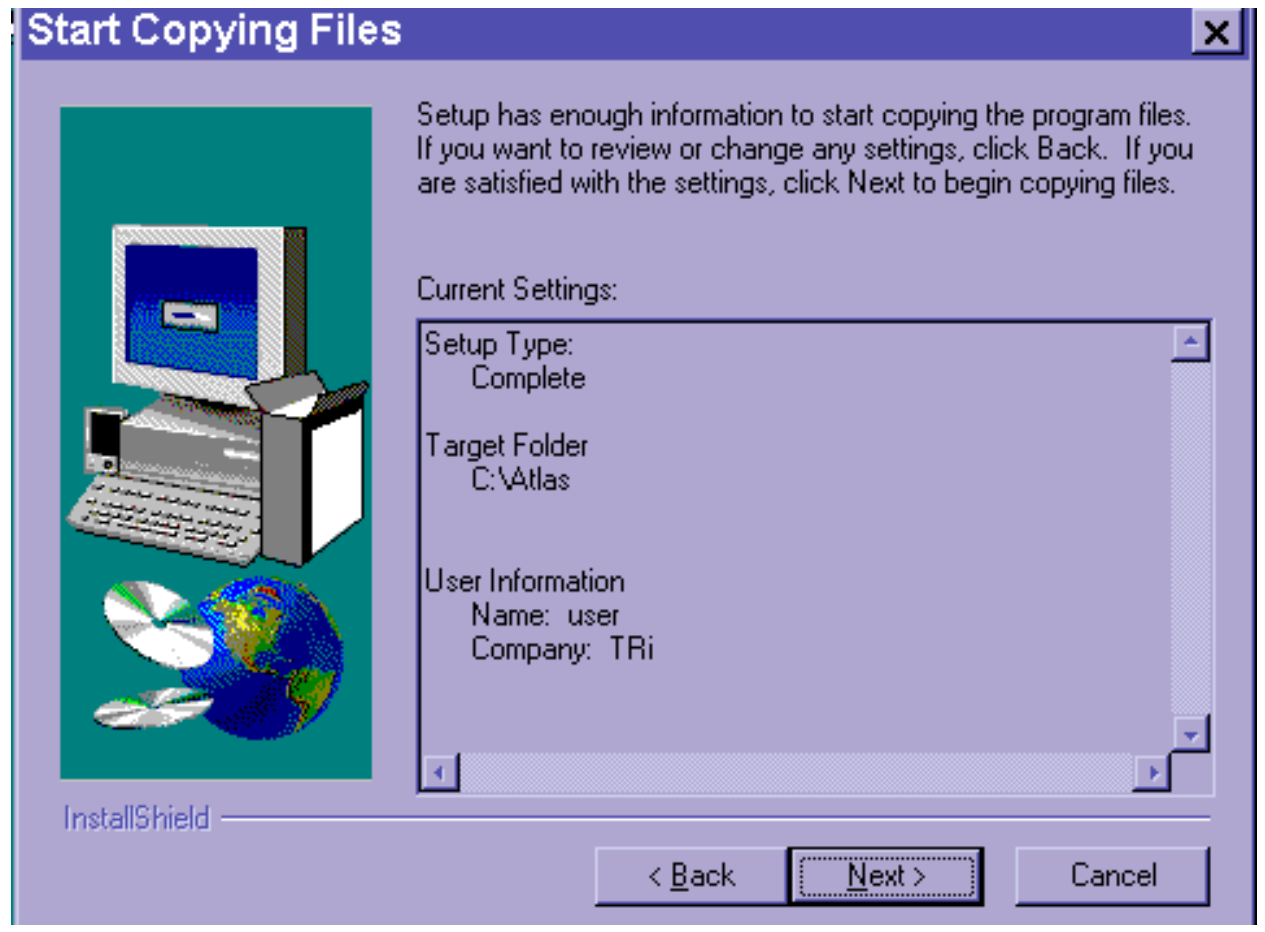

Figure 1-8. ATLAS Displays the Information You Have Entered.

If everything is correct, click "Next" to begin installing the files. If it is not correct, click "Back," correct the information, and then click "Next." 


\subsubsection{Quick Check}

The ATLAS software can now be used to perform a simple check of the hardware to confirm that the communications links between the computer and the DASs are working properly.

\section{NOTE}

Quick Check only checks the functioning of the PCMCIA decoder card and the encoder for each DAS unit - it does not check every aspect of the hardware.

Figure 1-9 shows the various cables and connectors associated with ATLAS.

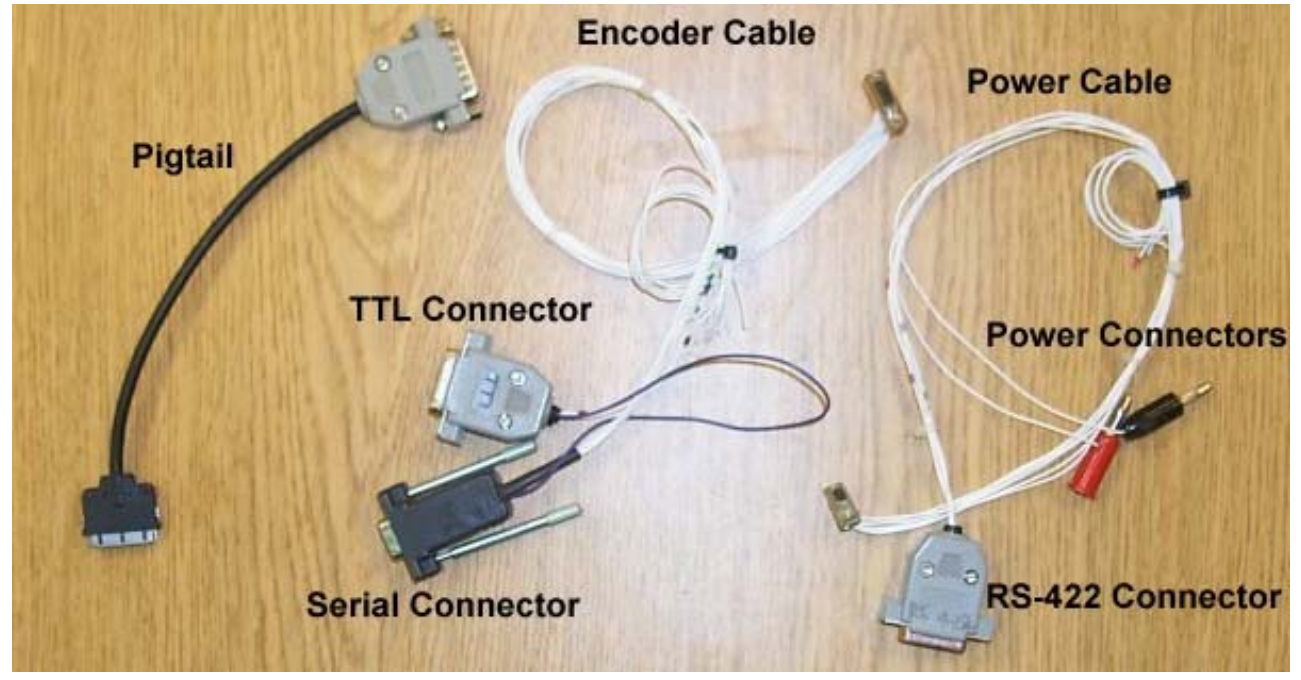

Figure 1-9. Cables and Connectors Associated with ATLAS.

Connect the hardware using the supplied cables as follows:

1. Connect the serial connector of the encoder cable to the computer serial port.

2. Connect the "pigtail" cable to the PCMCIA decoder installed in the computer.

3. Connect the RS-422 connector of the power cable to the 15-pin pigtail connector.

4. Connect the power cable to the DAS and connect the power connectors of that cable to a 12 -VDC power supply capable of supplying at least $500 \mathrm{~mA}$. The actual power supply voltage can be anywhere in the range of 9 to $36 \mathrm{VDC}$.

Execute ATLAS, go to "File" and select "Quick Check," as shown in Figure 1-10. Quick Check will program the DAS with a dummy configuration file. After the DAS has been programmed, click on the "Acquire" button to launch the acquisition program. The ATLAS Data Acquisition window shown in Figure 1-11 should appear. If the "Link" 


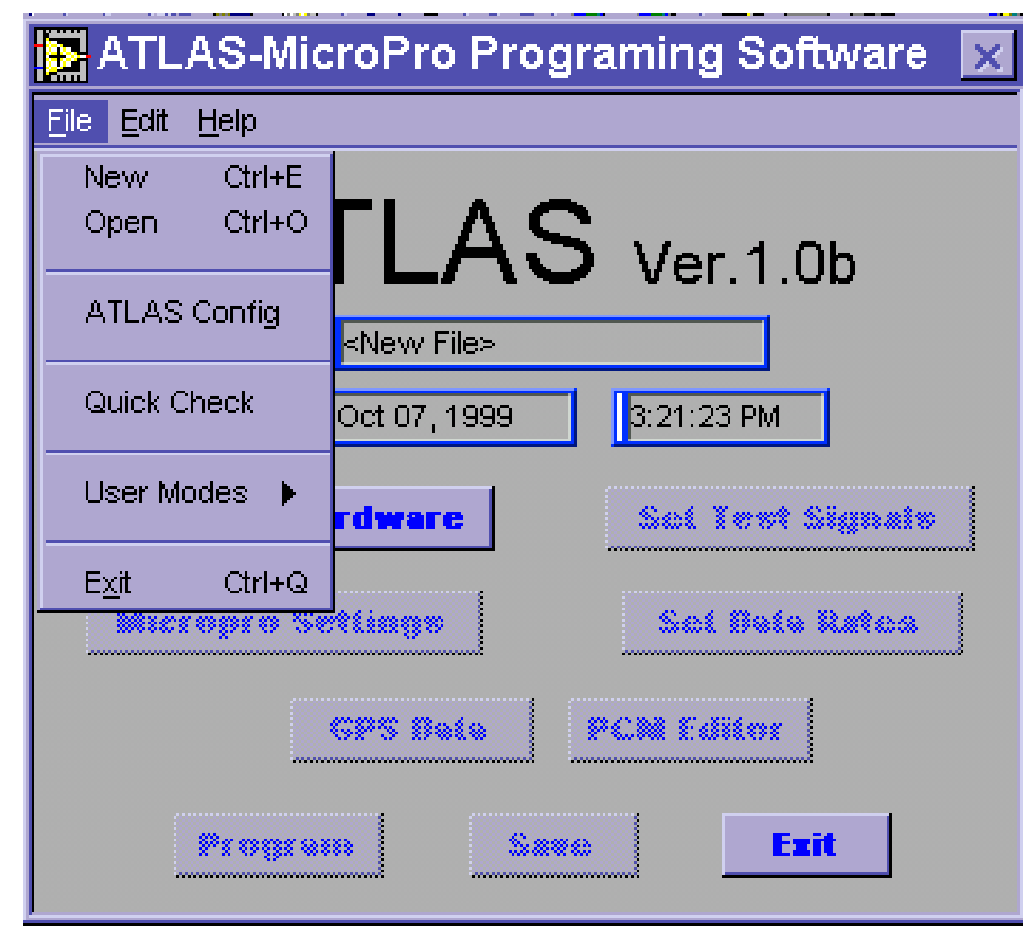

Figure 1-10. Quick Check Option in File Menu.

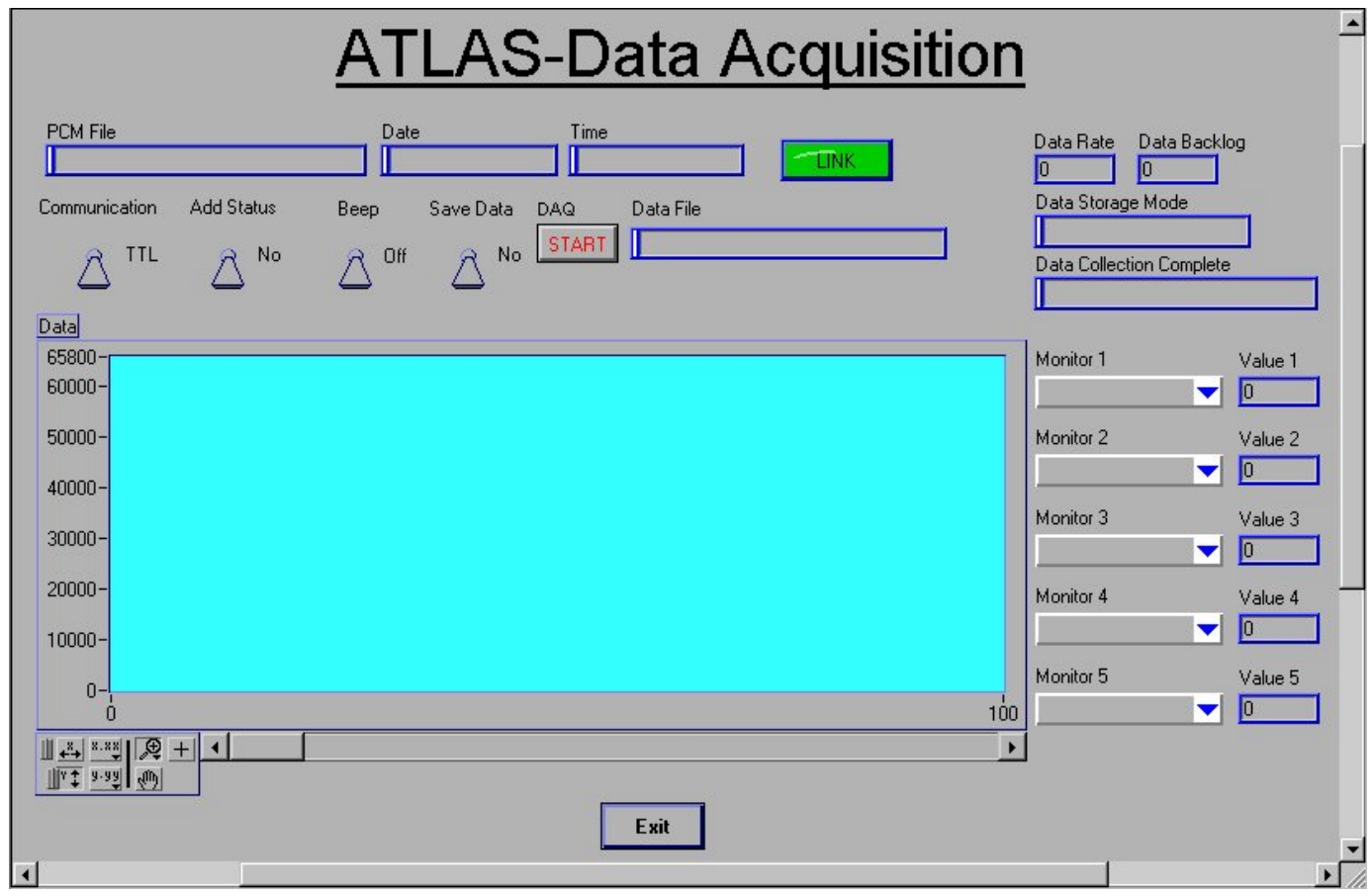

Figure 1-11. This is the ATLAS Data Acquisition Window. Note the green "Link" light. 
light is green, the DAS is working properly. Click on "Exit" to go back to ATLAS main window. Repeat the instructions in Section 1.1.3 for all your DAS units.

If the "Link" light is red, as shown in Figure 1-12, there is a problem that must be resolved. Make sure the power supply is on, the serial and data cables are securely connected to the DAS, the pigtail adapter is firmly inserted into the PCMCIA card, and the PCMCIA card is firmly inserted into the computer adapter. There's no need to turn off the power while checking these. If ATLAS still shows "No Link," click on "Exit" to return to the ATLAS main menu, and select "Acquire" again.

If ATLAS still shows "No Link," the DAS, one or more of the cables, or the decoder may be damaged. Click on "Exit" to return to the ATLAS main menu, turn off the DAS power supply, and attach a different DAS with the power and encoder cables (do not disconnect them from the computer). Then go to "File" and select "Quick Check" again. If the "Link" light is still red, the problem is most likely in the computer equipment (the PCMCIA adapter, the PCMCIA decoder card, or the cables). Try swapping out each of these components in turn and rerunning Quick Check to resolve the problem.

If the second DAS gives a green "Link" light, the second DAS is functioning properly and the problem is in the initial DAS unit. Set the initial DAS aside for now and continue to check out the rest of the DAS units. Click on "Exit" to return to the ATLAS main menu, turn off the DAS power supply, and attach a different DAS with the power and encoder cables (do not disconnect them from the computer). Then go to "File" and select "Quick Check" again. All the DAS units for which the "Link" light is green are functioning properly. Once all the DAS units are checked out, click on "Exit" to return to the ATLAS main menu, then click on "Exit" to terminate the ATLAS program.

If one or more DAS units do not link up, follow the instructions given in Section 4.2, Troubleshooting, to resolve the problem(s).

Once all DAS units are checked out and are linking properly, proceed with assembly of the RBU and GBUs that will be used for the particular application. Information on building these units can be found in Chapter 2 . 


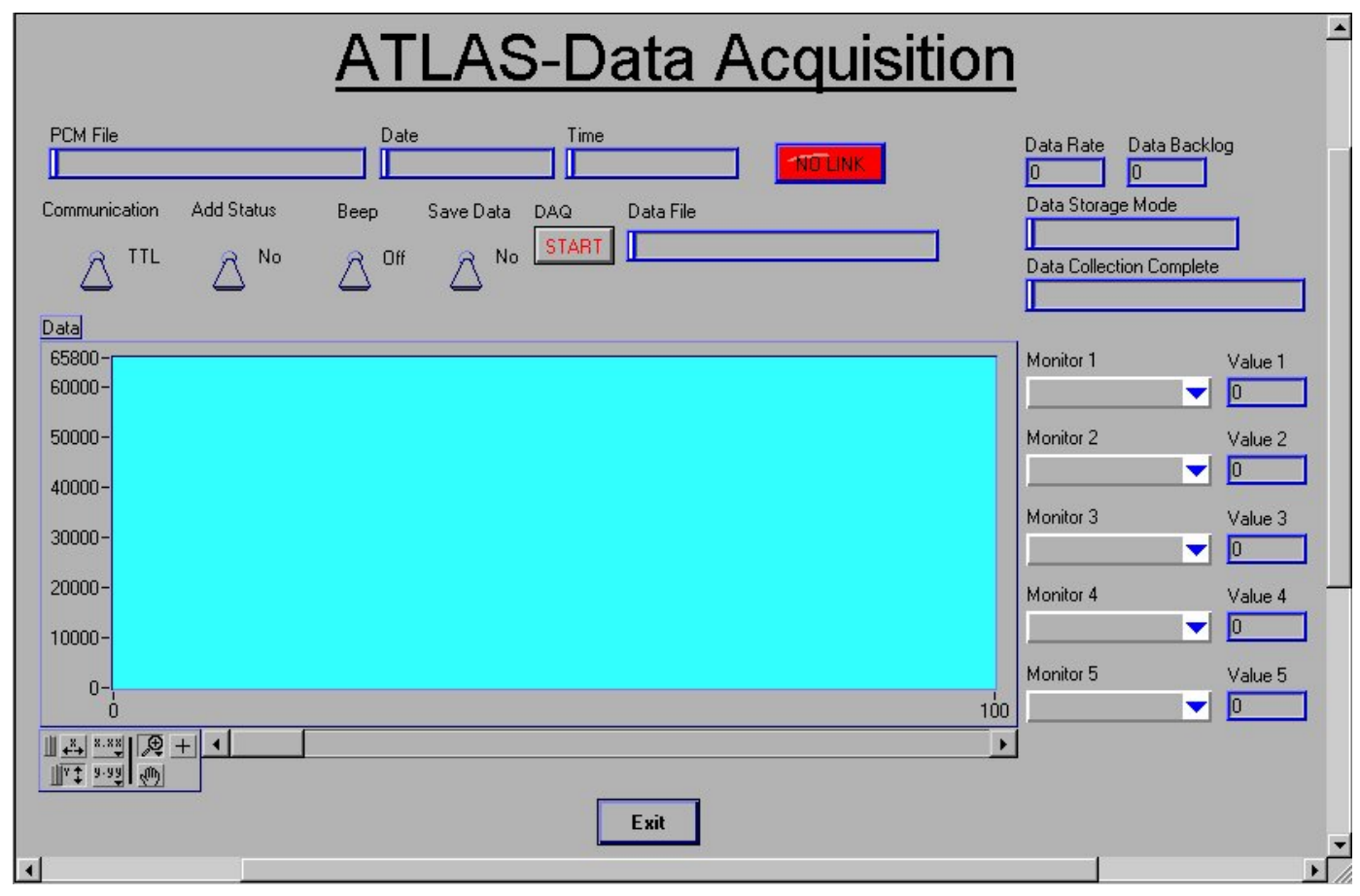

Figure 1-12. If ATLAS Finds a Problem During Quick Check, the Button Turns Red. 


\section{Chapter 2. ATLAS Hardware Description}

ATLAS utilizes several hardware subsystems to obtain continuous, time-synchronized data from a wind turbine rotor, tower, nacelle, and associated meteorological instrumentation over extended periods of time. These subsystems are assembled in applicationspecific configurations for each turbine application. The various pieces of hardware and the process of assembling the ATLAS are described in the following sections.

\subsection{Data Acquisition Subsystem}

ATLAS uses a commercially-available DAS known as the ACRA Control KAM-500. This hardware, a sample of which is shown in Figure 2-1, was sold in the U.S. as the Nicolet MicroPro for several years, but it is now sold around the world by ACRA Control Inc. ${ }^{1}$

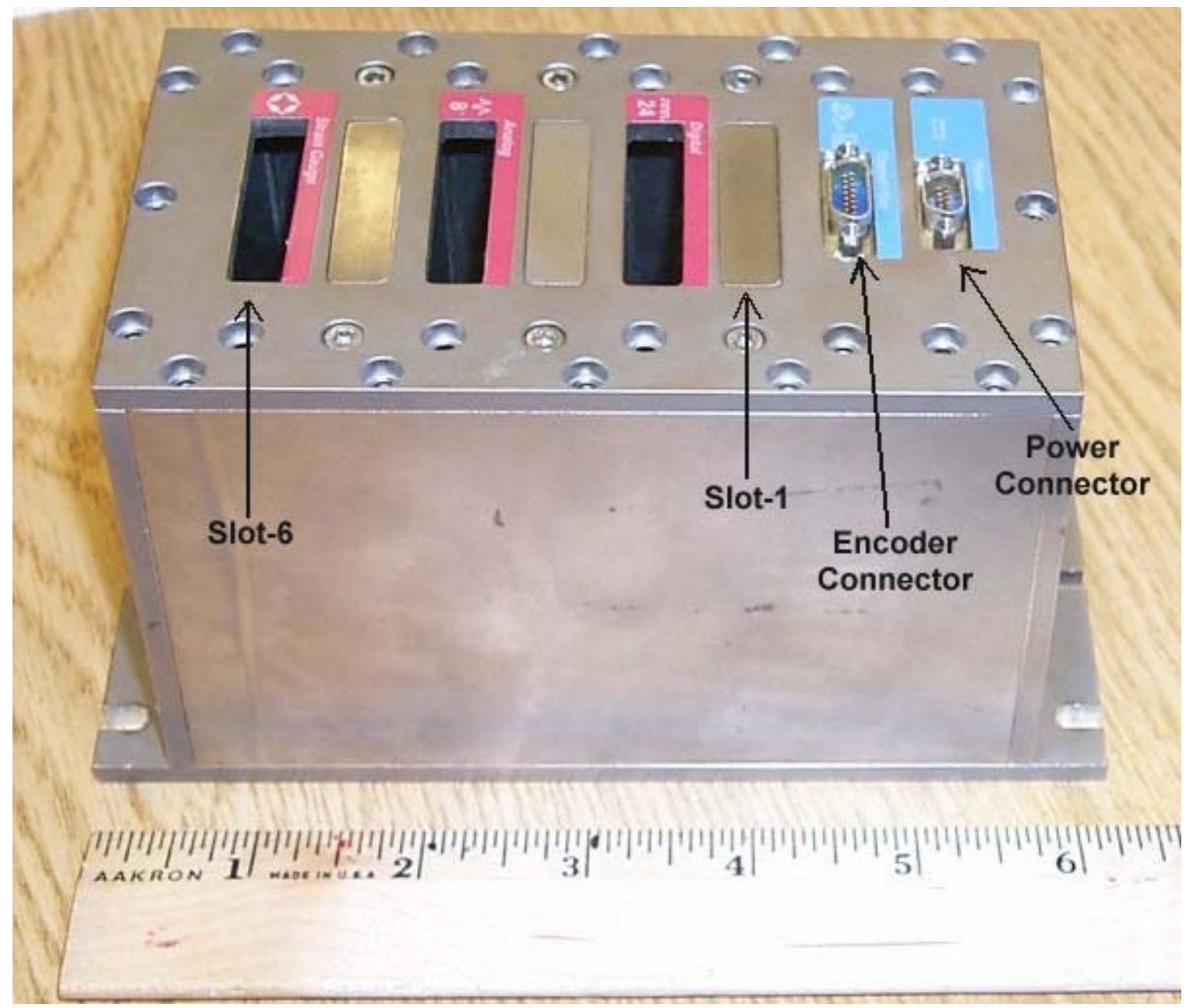

Figure 2-1. ACRA KAM-500 DAS

${ }^{1}$ ACRA Control, Inc., Landscape House, Landscape Road, Dublin, Ireland. 
The KAM-500 is a small, rugged, modular, lightweight DAS with a relatively low power consumption that is designed for remote operation in harsh environments. Its operational temperature range is from $-40^{\circ}$ to $+85^{\circ} \mathrm{C}\left(-40^{\circ}\right.$ to $\left.+185^{\circ} \mathrm{F}\right)$, and it can withstand $100-\mathrm{g}$ shock loads. The basic unit, or mainframe, includes one or more power supplies and a data encoder module that controls the DAS and outputs the acquired data in a pulse-code modulated (PCM) digital data stream. The unit operates on 12 VDC input power (voltage must be between 9 and $36 \mathrm{VDC}$ ), and power consumption can range from 5 to approximately $35 \mathrm{~W}$ depending on the numbers and types of data channels being acquired. KAM-500 mainframes are available in four configurations, with 3, 6, 9, or 13 user slots available.

Each user slot of the KAM-500 mainframe accepts a single DAM. Each DAM plugs into a connector on the back plane of the mainframe (see Figure 2-2 for examples of DAMS). The DAM obtains power and control information from the mainframe and furnishes the mainframe with digitized sensor information obtained by the DAM. Data are acquired simultaneously from all channels on all DAMs, and the precise acquisition time can be specified by a user-supplied synchronization pulse. Standard instrumentation modules for the KAM-500 include digital, high-level analog, strain-gauge, accelerometer, thermocouple, and serial data input. Digital, analog, and strain-gauge input module characteristics are summarized in Tables 2-1, 2-2, and 2-3, respectively. Additional information on these and other modules may be found in the KAM-500 technical manuals from ACRA Control.

ATLAS typically utilizes two or more mainframes in a Master/Slave arrangement - one mainframe is identified as the Master and the other mainframes are Slaves to that Master. In a typical Master/Slave arrangement, the Master clock drives the data acquisition of each of the Slaves so data is acquired at precisely the same time on all units. Each Slave transfers its data to the Master, and the Master merges those data streams with its own data into a single data stream for transmission to the system computer. The merger/ decoder module described in Table 2-4 is utilized to merge the data from each Slave into the Master data stream. A system needs one merger/decoder for each Slave in a system. For the ATLAS, the Master/Slave arrangement is somewhat different - the Master and the Slave data acquisitions still take place at exactly the same time, but the PATSyM clocks, rather than the Master clock, provide the timing.

As mentioned earlier, the digitized data for each mainframe (whether Master or Slave) is output as a PCM digital serial stream consisting of a continuous series of data frames. Each frame begins with a data synchronization word to ensure data integrity, followed by one data word for each data channel. Data words are typically either 12 bits or 16 bits in length, and the data synchronization word is usually twice the data word length. The PCM data stream can be transmitted in RS-422 or TTL format by hardwire, fiber-optic cable, or telemetry, in any of several PCM formats. The PCM data from a Slave is normally transmitted to the Master mainframe merger/decoder module, while PCM data from the Master is normally transmitted to the PCM decoder card contained in the system computer. 


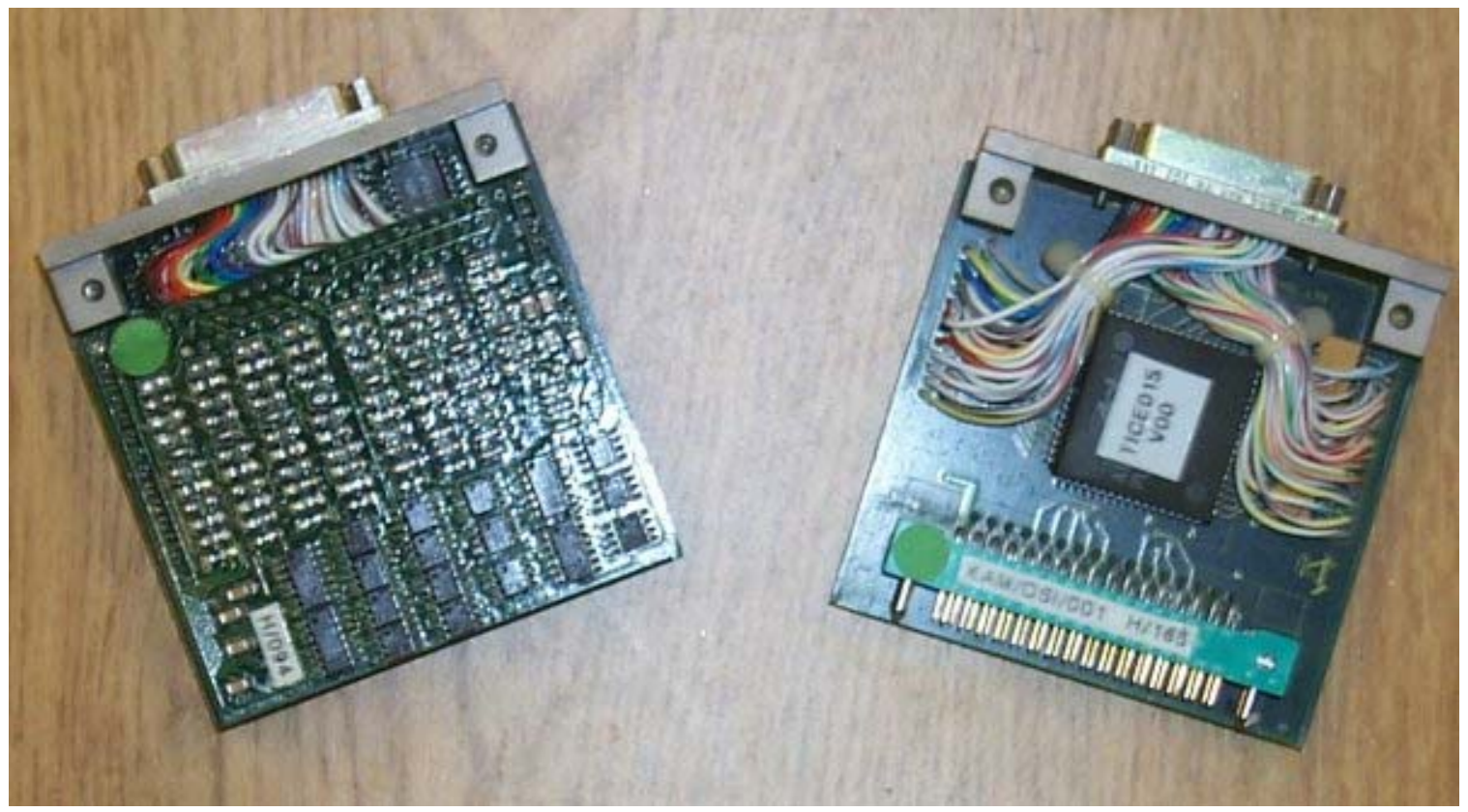

Figure 2-2. This is a Picture of What the DAMS Look Like.

Table 2-1. Digital Signal-Conditioning Module Characteristics

\begin{tabular}{|l|l|}
\hline \multicolumn{1}{|c|}{ Parameter } & \multicolumn{1}{c|}{ Particulars } \\
\hline Number of digital inputs per module & 48 bits (3 16-bit words or 4 12-bit words) \\
\hline Input voltage range & $\begin{array}{l}0-20 \mathrm{Vdc} ;<0.8 \mathrm{Vdc} \text { sensed as low (0), } \\
>2 \mathrm{Vdc} \text { sensed as high (1) }\end{array}$ \\
\hline Number of counters/timers per module & 8 \\
\hline Event counting range & $1-4095$ \\
\hline Period counter resolution & $125 \mathrm{~ns}-8 \mu \mathrm{s}$ \\
\hline Period measurement range & $125 \mathrm{~ns}-32.76 \mathrm{~ms}$ \\
\hline Frequency counter resolution & $1 \mathrm{~Hz}-100 \mathrm{~Hz}$ \\
\hline Frequency measurement range & $1 \mathrm{~Hz}-409.5 \mathrm{kHz}$ \\
\hline Current consumption (5 VDC) & $80 \mathrm{~mA}$ \\
\hline
\end{tabular}

Table 2-2. High-Level Analog Serial-Conditioning Module Characteristics

\begin{tabular}{|l|l|}
\hline \multicolumn{1}{|c|}{ Parameter } & \multicolumn{1}{c|}{ Features } \\
\hline Number of channels & 8 differential input \\
\hline A/D converter & 12 -bit A/D per channel $(0.25 \%$ resolution $)$ \\
\hline Maximum sample rate & 100,000 samples/sec per channel \\
& 500,000 samples $/$ sec aggregate \\
\hline Input ranges & $\pm 1.25 \mathrm{~V}, \pm 2.50 \mathrm{~V}, \pm 5.0 \mathrm{~V}, \pm 10.0 \mathrm{~V}$ \\
\hline
\end{tabular}


Table 2-2. High-Level Analog Serial-Conditioning Module Characteristics (continued)

\begin{tabular}{|l|l|}
\hline \multicolumn{1}{|c|}{ Parameter } & \multicolumn{1}{c|}{ Features } \\
\hline Gain & $1,2,4,8$ \\
\hline Filter & $\begin{array}{l}\text { Programmable cut-off frequency 5-pole } \\
\text { Butterworth per channel }\end{array}$ \\
\hline Offset range & $\pm 75 \%$ of input range \\
\hline Input Impedance (ON state) & $10 \mathrm{G} \Omega$ \\
\hline Input Impedance (OFF state) & $1 \mathrm{M} \Omega$ \\
\hline Current consumption (5 VDC) & $180 \mathrm{~mA}$ \\
\hline Current consumption (+12 VDC) & $90 \mathrm{~mA}$ \\
\hline Current consumption (-12 VDC) & $90 \mathrm{~mA}$ \\
\hline
\end{tabular}

Table 2-3. Strain-Gauge Signal-Conditioning Module Characteristics

\begin{tabular}{|l|l|}
\hline \multicolumn{1}{|c|}{ Parameter } & \multicolumn{1}{c|}{ Features } \\
\hline Number of channels & 8 differential \\
\hline A/D converter & 12 -bit A/D per channel $(0.25 \%$ resolution $)$ \\
\hline Maximum sample rate & 100,000 samples per sec per channel \\
& 500,000 samples per second aggregate \\
\hline Input ranges & $\pm 2.5 \mathrm{mV}, \pm 5.0 \mathrm{mV}, \pm 10.0 \mathrm{mV}, \pm 20 \mathrm{mV}$ \\
\hline Gain & $500,1000,2000,4000$ \\
\hline Filter & Programmable cut-off frequency 5-pole \\
& Butterworth per channel \\
\hline Offset range & $\pm 75 \%$ of input range \\
\hline Bridge excitation voltage & $\pm 1.25 \mathrm{~V}, \pm 2.50 \mathrm{~V}, \pm 5.0 \mathrm{~V}, \pm 7.5 \mathrm{~V}$ \\
\hline Bridge type & $1 / 4 \mathrm{bridge}, 1 / 2$ bridge, or full bridge (factory set) \\
\hline Bridge resistance & $120-1000 \Omega$ \\
\hline Input Impedance $(\mathrm{ON}$ state) & $10 \mathrm{G} \Omega$ \\
\hline Input Impedance (OFF state) & $1 \mathrm{M} \Omega$ \\
\hline Current consumption $(5 \mathrm{VDC})$ & $180 \mathrm{~mA}$ \\
\hline Current consumption (+12 VDC) & $90 \mathrm{~mA}$ \\
\hline Current consumption (-12 VDC) & $90 \mathrm{~mA}$ \\
\hline
\end{tabular}


Table 2-4. Merger/Decoder Module Characteristics

\begin{tabular}{|l|l|}
\hline \multicolumn{1}{|c|}{ Parameter } & \multicolumn{1}{c|}{ Particulars } \\
\hline Frame Format & Up to 8 formats may be defined \\
\hline Bit Rate & Up to 1 Mbps \\
\hline PCM Codes & BI $\phi$-L or NRZ-L \\
\hline PCM Polarity & True/Inverse \\
\hline DCLK Polarity & True/Inverse \\
\hline Word Length & $1-16$ Bits \\
\hline Syncword Length & $10-32$ Bits \\
\hline Syncword Mask & Any bits in syncword \\
\hline Minor Frame Length & $2-256$ Words \\
\hline Most Significant Bit Transfer & First/Last \\
\hline Current Consumption (5 VDC) & $100 \mathrm{~mA}$ \\
\hline
\end{tabular}

The GBCU contains a PCMCIA-format PCM decoder, an essential part of the DAS. This device decodes the PCM data stream coming from the Master DAS into individual data words and places those words into computer memory for later retrieval and manipulation by software, such as the ATLAS software or the ADAS II data acquisition and data storage software (both discussed in Chapter 3).

Each DAS mainframe is programmed by the GBCU using the ATLAS software, described in Chapter 3. You can specify the Master/Slave configuration information, data channel selections, data sampling rates, filter cut-off frequencies, channel gains and offsets, bridge excitation voltages, PCM format, and communication formats with the ATLAS software. This information can be transferred to each mainframe via hardwire or radio RS-232 link (separate from the RS-422 or TTL data link described above) at any time to actually program the various DAS units. Programming a mainframe interrupts data acquisition for that unit, but the unit resumes acquisition immediately upon completion of programming.

\subsubsection{DAS Mainframe}

The KAM-500 mainframe consists of a power supply and the slots to receive the various modules. The power supply cannot be removed from the mainframe. It contains a single 9-pin power connector; the pin assignment is shown in Figure 2-3.

User-supplied DC power must be connected to pins 1 and 2. Although the input power should be nominally 12 VDC, it may actually be anywhere in the range of 9-36 VDC. The KAM-500 passes the input power through a DC/DC converter and regulates it to generate clean internal power with a voltage ripple of less than $\pm 50 \mathrm{mV}$. Pins 3, 4, 7, and 8 output the DAS PCM datastream in RS-422 mode, pins 5 and 6 output regulated \pm 12 VDC to power external devices, and pin 9 is a connection to the common digital ground for the KAM-500. 


\begin{tabular}{|c|c|c|}
\hline \multicolumn{3}{|c|}{ 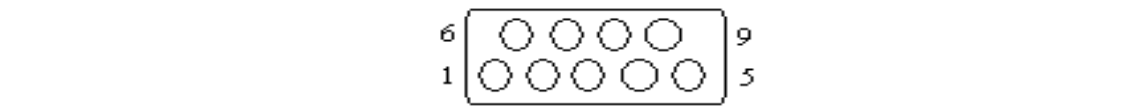 } \\
\hline Pin \# & Pin Name & Pin Description \\
\hline 1 & Vin & DC (+) power supply input \\
\hline 2 & AGND & Power supply ground \\
\hline 3 & RS-422 TX+ & RS-422 PCM stream, output (+) \\
\hline 4 & RS-422 TX- & RS-422 PCM stream, output (-) \\
\hline 5 & Vcc Out $(+12 \mathrm{~V})$ & $\mathrm{DC}(+)$ output to power external devices \\
\hline 6 & Vee Out $(-12 \mathrm{~V})$ & DC (-) output to power external devices \\
\hline 7 & RS-422 DataClock+ & Data clock $(+)$ signal \\
\hline 8 & RS-422 Data Clock - & Data clock (-) signal \\
\hline 9 & DGND & Digital ground \\
\hline
\end{tabular}

Figure 2-3. KAM-500 Power Supply Connector Pin Assignment.

\section{NOTE}

The DGND digital ground pin ties directly to the back plane of the mainframe and is directly connected to the DGND pin on the encoder or any instrumentation module.

\subsubsection{Encoder Module}

The KAM-500 encoder module is located in the mainframe immediately adjacent to the power supply (it is the only module that can be inserted there), and can be removed from the mainframe. It contains the "smarts" for the KAM-500, controls the data acquisition, and outputs the PCM stream in TTL format. Figure 2-4 describes the pin assignment on the 15-pin encoder connector. The format select pins (1,2, and 3) determine which of the eight possible formats is to be executed. Typically, only a single format is loaded into each DAS, so these pins should be hardwired to DGND to force the use of format 1 . If a mainframe is to run off its internal clock (not the normal mode for an ATLAS application), pins 4 and 5 are not connected and pin 6 is either disconnected or tied to DGND. If a PATSyM is used in a mainframe (as in an ATLAS configuration), pins 4 and 5 are connected to pins 11 and 12, respectively, of the PATSyM connector (see Section 2.3 for pin assignment) to provide synchronization of data acquisition, and pin 6 must be hardwired to a +5 VDC source to force the DAS to accept the input from pins 4 and 5. Pins 7-10 are not used for ATLAS and are left unconnected. Pins 11 and 12 output the PCM data stream in TTL mode. Pins 13 and 14 provide the user-interface RS-232 communications needed to program the DAS. 


\section{NOTE}

Both RS-422 and TTL PCM data streams are output by the KAM-500, regardless of whether the RS-422 or TTL communications mode is specified when programming the DAS with the ATLAS software.

\subsubsection{Instrumentation Modules}

As mentioned above, the instrumentation modules typically used in ATLAS include the digital, high-level analog, and strain-gauge modules. Figure 2-5 describes the pin assignment on the 51-pin connector of the digital input module. Pins 1-48 are treated as digital input lines. A voltage level below $0.8 \mathrm{VDC}$ is interpreted as 0 ; a voltage level of 2.0 VDC or higher is interpreted as 1. Maximum allowable voltage levels are $\pm 20 \mathrm{VDC}$. The three DGND pins are connected to the mainframe back plane and to the DGND pin of any other DAS connector.

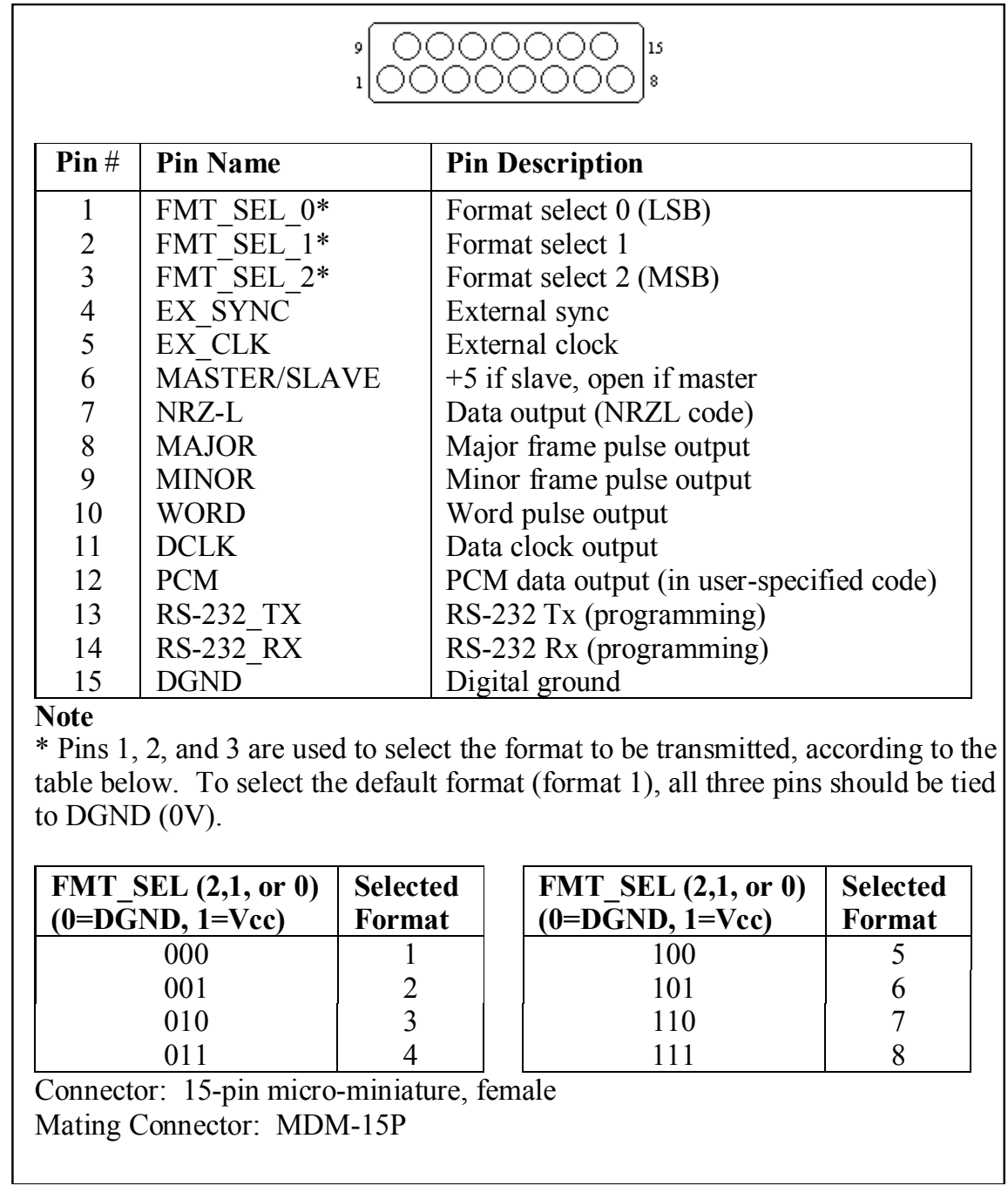

Figure 2-4. KAM-500 Encoder Pin Assignment. 


\section{CAUTION}

Voltages outside the range of $\pm 20 \mathrm{~V}$ applied to the digital input pins may damage the module.

Figure 2-6 shows the pin assignment on the 51-pin connector of the high-level analog module. The module senses the differential voltage present between two-pin pairs. This voltage must be limited to $\pm 10 \mathrm{~V}$ to be properly sensed by the card. Voltages beyond those limits will be sensed as $-10 \mathrm{~V}$ or $+10 \mathrm{~V}$. The analog ground (AGND) pin should be wired to the AGND (pin 2) on the power connector.

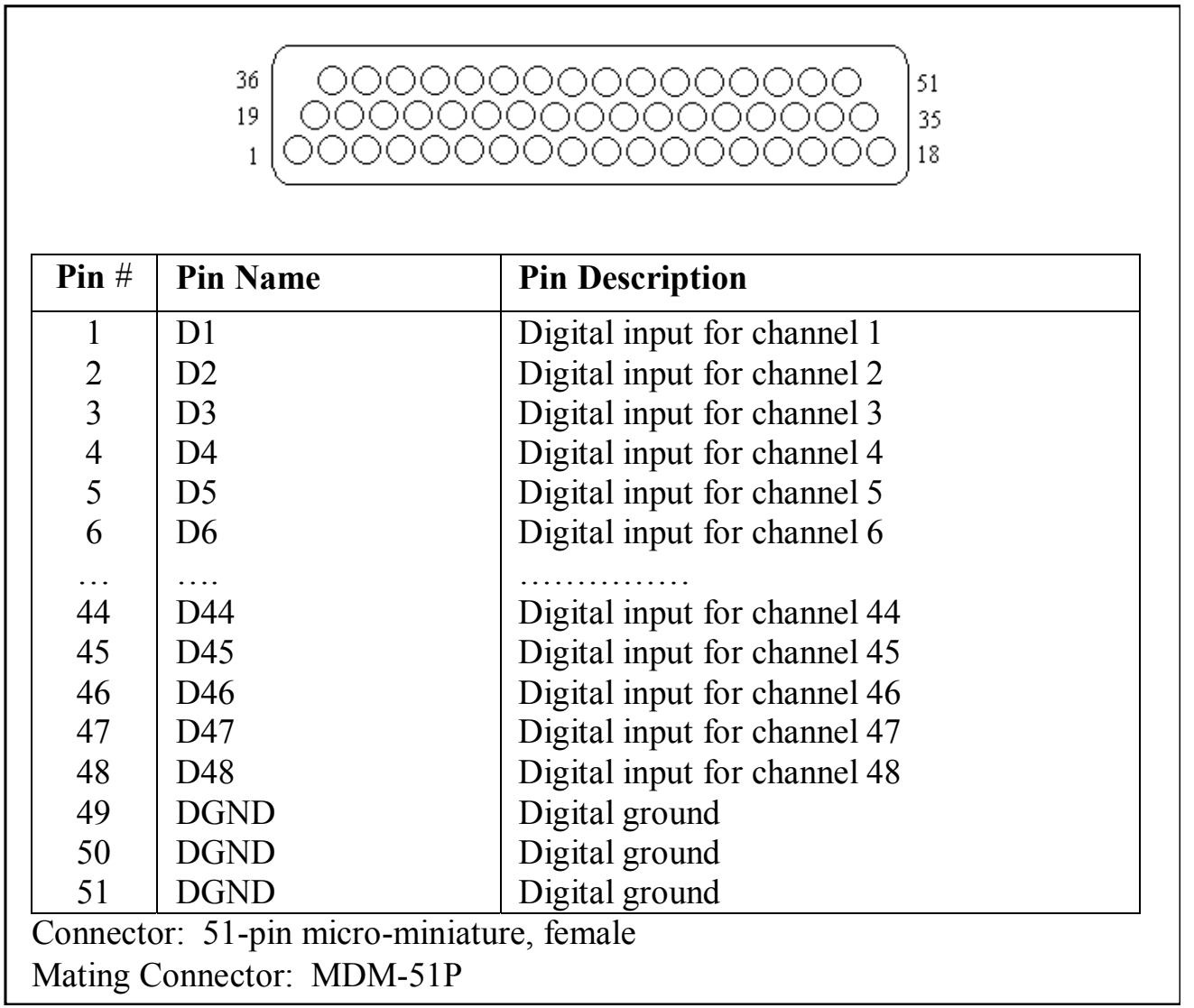

Figure 2-5. MicroPro/KAM-500 Digital Input Card Pin Assignment.

\section{CAUTION}

Differential voltages outside the range of $\pm 40 \mathrm{~V}$ may damage the module.

Figure 2-7 describes the pin assignment for the 51-pin connector of the strain-gauge module. The first 48 pins are divided into eight groups of six, each group dedicated to one channel of strain-gauge instrumentation. Figure 2-8 is a schematic diagram of a typical full-bridge strain gauge and illustrates the connection points for the six pins allocated 


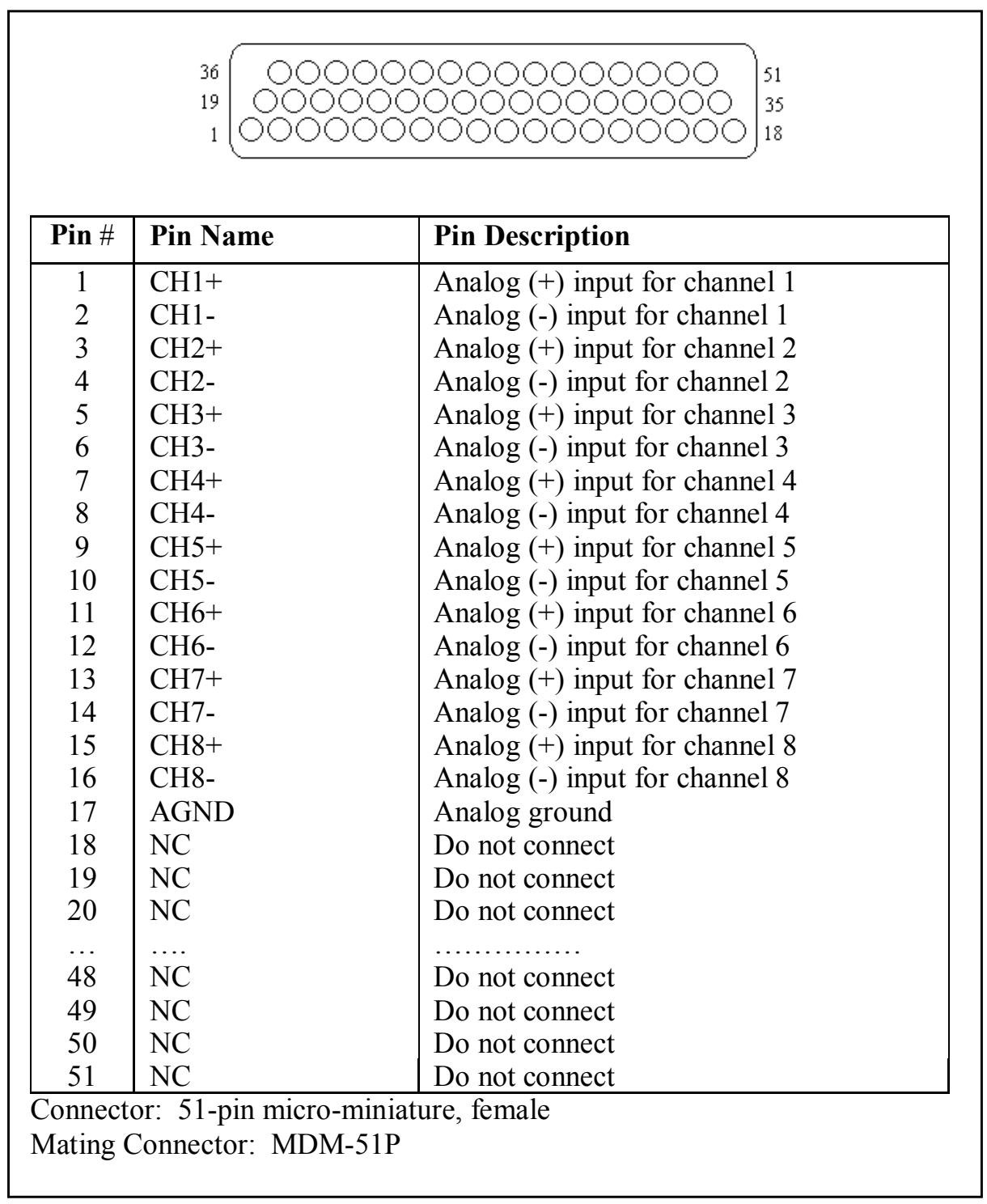

Figure 2-6. KAM-500 Analog Module Pin Assignment.

to each channel on the module. In general, pin B of each channel is tied to pin A of that channel and pin $\mathrm{D}$ is left disconnected. Thus \pm excitation is provided by pins $\mathrm{A}$ and $\mathrm{C}$ and \pm signal is sensed at pins $\mathrm{E}$ and $\mathrm{F}$. If, however, the strain gauge bridge is located over 10 feet from the DAS, run a wire from pin $\mathrm{B}$ to the + excitation connection on the bridge to sense and control the excitation voltage right at the bridge.

Pins 49 and 50 must be connected to a voltage source to provide the excitation voltage for the strain gauges sensed by this module. The voltage at these pins must be at least $20 \%$ above the highest user-specified voltage level for bridge excitation. The input excitation voltage is converted down to the user-specified excitation voltage level (set with the ATLAS software) and then output to the bridge through pins A and $\mathrm{C}$ of each channel. Pin 51 (AGND) should be tied to AGND (pin 2) of the 9-pin power connector; see Figure 2-3. 


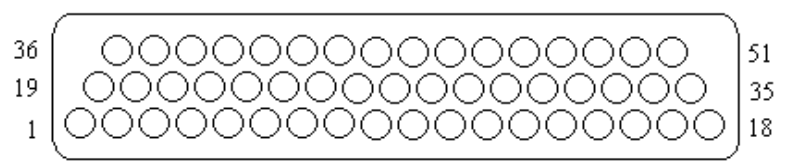

\begin{tabular}{|c|c|c|}
\hline Pin \# & Pin Name & Pin Description \\
\hline 1 & CH1 A & Constant excitation voltage for channel 1 \\
\hline 2 & $\mathrm{CH} 1 \_\mathrm{B}$ & Voltage sense for channel 1 \\
\hline 3 & CH1_C & $\begin{array}{l}\text { Continuously adjusted to keep point } E \text { at zero } \\
\text { volts for channel } 1\end{array}$ \\
\hline 4 & CH1_D & Offset resistor point for channel 1 \\
\hline 5 & $\mathrm{CH} 1 \_\mathrm{E}$ & Input signal from the bridge circuit for channel 1 \\
\hline 6 & $\mathrm{CH} 1 \_\mathrm{F}$ & Input signal from the bridge circuit for channel 1 \\
\hline 7 & $\mathrm{CH} 2-\mathrm{A}$ & Constant excitation voltage for channel 2 \\
\hline 8 & $\mathrm{CH} 2 \mathrm{~B}$ & Voltage sense for channel 2 \\
\hline 9 & $\mathrm{CH} 2-\mathrm{C}$ & $\begin{array}{l}\text { Continuously adjusted to keep point } \mathrm{E} \text { at zero } \\
\text { volts for channel } 2\end{array}$ \\
\hline 10 & $\mathrm{CH} 2 \mathrm{D}$ & Offset resistor point for channel 2 \\
\hline 11 & $\mathrm{CH} 2 \mathrm{E}$ & Input signal from the bridge circuit for channel 2 \\
\hline 12 & $\mathrm{CH} 2 \mathrm{~F}$ & Input signal from the bridge circuit for channel 2 \\
\hline 13 & CH3_A & Constant excitation voltage for channel 3 \\
\hline 14 & $\mathrm{CH} 3{ }_{-}^{-} \mathrm{B}$ & Voltage sense for channel 3 \\
\hline 15 & CH3_C & $\begin{array}{l}\text { Continuously adjusted to keep point } \mathrm{E} \text { at zero } \\
\text { volts for channel } 3\end{array}$ \\
\hline 16 & $\mathrm{CH} 3 \mathrm{D}$ & Offset resistor point for channel 3 \\
\hline 17 & $\mathrm{CH} 3{ }^{-} \mathrm{E}$ & Input signal from the bridge circuit for channel 3 \\
\hline 18 & CH3_F & Input signal from the bridge circuit for channel 3 \\
\hline \multirow[t]{6}{*}{$\cdots$} & & n.w. \\
\hline & CH8_A & Constant excitation voltage for channel 8 \\
\hline & CH8_B & Voltage sense for channel 8 \\
\hline & CH8_C & $\begin{array}{l}\text { Continuously adjusted to keep point } \mathrm{E} \text { at zero } \\
\text { volts for channel } 8\end{array}$ \\
\hline & CH8_D & Offset resistor point for channel 8 \\
\hline & $\mathrm{CH} 8{ }^{-} \mathrm{E}$ & Input signal from the bridge circuit for channel 8 \\
\hline 48 & $\mathrm{CH} 3{ }^{-} \mathrm{F}$ & Input signal from the bridge circuit for channel 8 \\
\hline 49 & V_E $\bar{X} T+$ & External $+12 \mathrm{~V}$ regulated supply \\
\hline 50 & V_EXT- & External $-12 \mathrm{~V}$ regulated supply \\
\hline 51 & AGND & Analog ground \\
\hline
\end{tabular}

Connector: 51-pin micro-miniature, female

Mating Connector: MDM-51P

Figure 2-7. KAM-500 Strain-Gauge Module Pin Assignments.

CAUTION

Amplifier output voltages (the product of the maximum input voltage times the two-stage gain) outside the range of $\pm 40 \mathrm{~V}$ may damage the module. An amplifier output voltage outside the range of $\pm 10 \mathrm{~V}$ will not be sampled correctly (the sampled value will appear as $\pm 10 \mathrm{~V}$ ). 


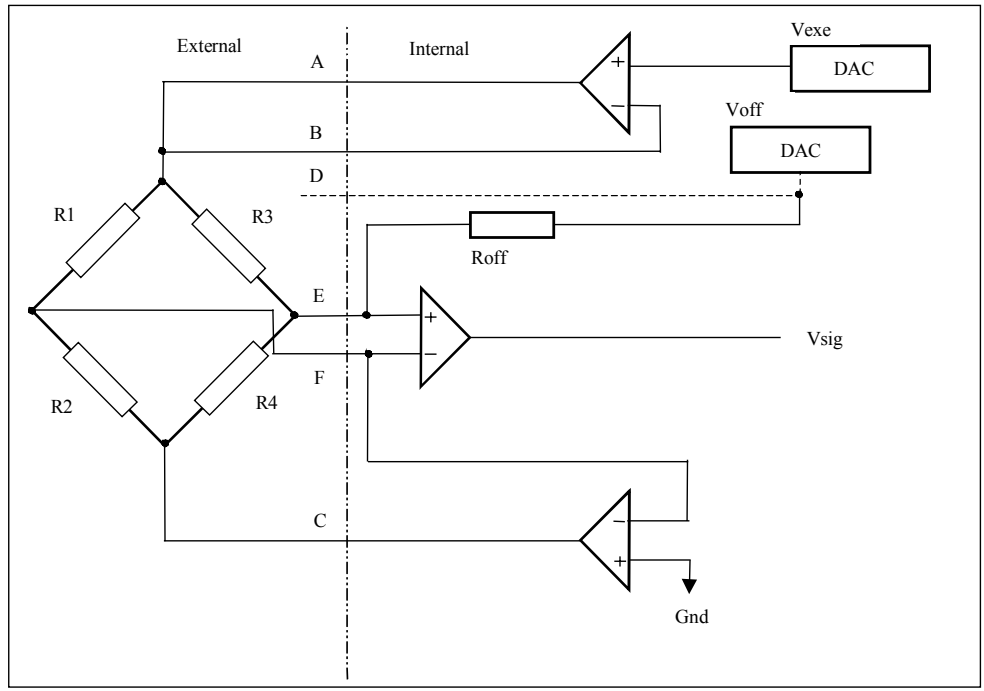

Figure 2-8. Full-bridge Strain Gauge Schematic.

\subsubsection{Merger/Decoder Module}

Figure 2-9 describes the pin assignment for the 51-pin connector of the merger/decoder module. This module is inserted in the Master DAS to merge the data stream from a Slave into the data stream output by the Master. During system programming, specify whether TTL or RS-422 communications will be used to transfer data from each Slave to the Master. This specification does not have to be the same for all Slaves. However, the connections between the Slave and the merger/decoder for each Slave depend on the communication mode for that particular Slave. If the input to a particular merger/decoder is to be TTL mode (specified when programming the communications mode for the Slave in question using the ATLAS software), connect pins 11 (DCLK), 12 (PCM), and 15 (digital ground [DGND]) from the slave encoder connector to pins 3, 1, and 2, respectively, of the merger/decoder. If the input is to be RS-422, connect pins 3 (RS-422 TX+), 4 (RS-422 TX-), 7 (RS-422 Data Clock+), 8 (RS-422 Data Clock-), and 9 (DGND) from the Slave power connector to pins 5, 6, 7, 8, and 4, respectively, of the merger/decoder.

\subsection{Data Communication Subsystem}

PCM data transfer from the Slaves to the Master and from the Master to the GBCU may be accomplished via hardwire, fiber optics, or telemetry. This data transfer occurs concurrent with data acquisition to enable data acquisition to continue over a period of hours, days, or weeks. For some applications, hardwire communications are possible between the Slaves and the Master and between the Master and the GBCU. For many applications, however, hardware communications between all the Slave units and the Master are not possible. In particular, the rotor may not include slip rings or other provisions for transferring information between the rotor and the tower or the ground, making hardwire communications with the rotor unit impossible. ATLAS includes a DCS for transferring the PCM data and enabling RS-232 communications in this situation. 


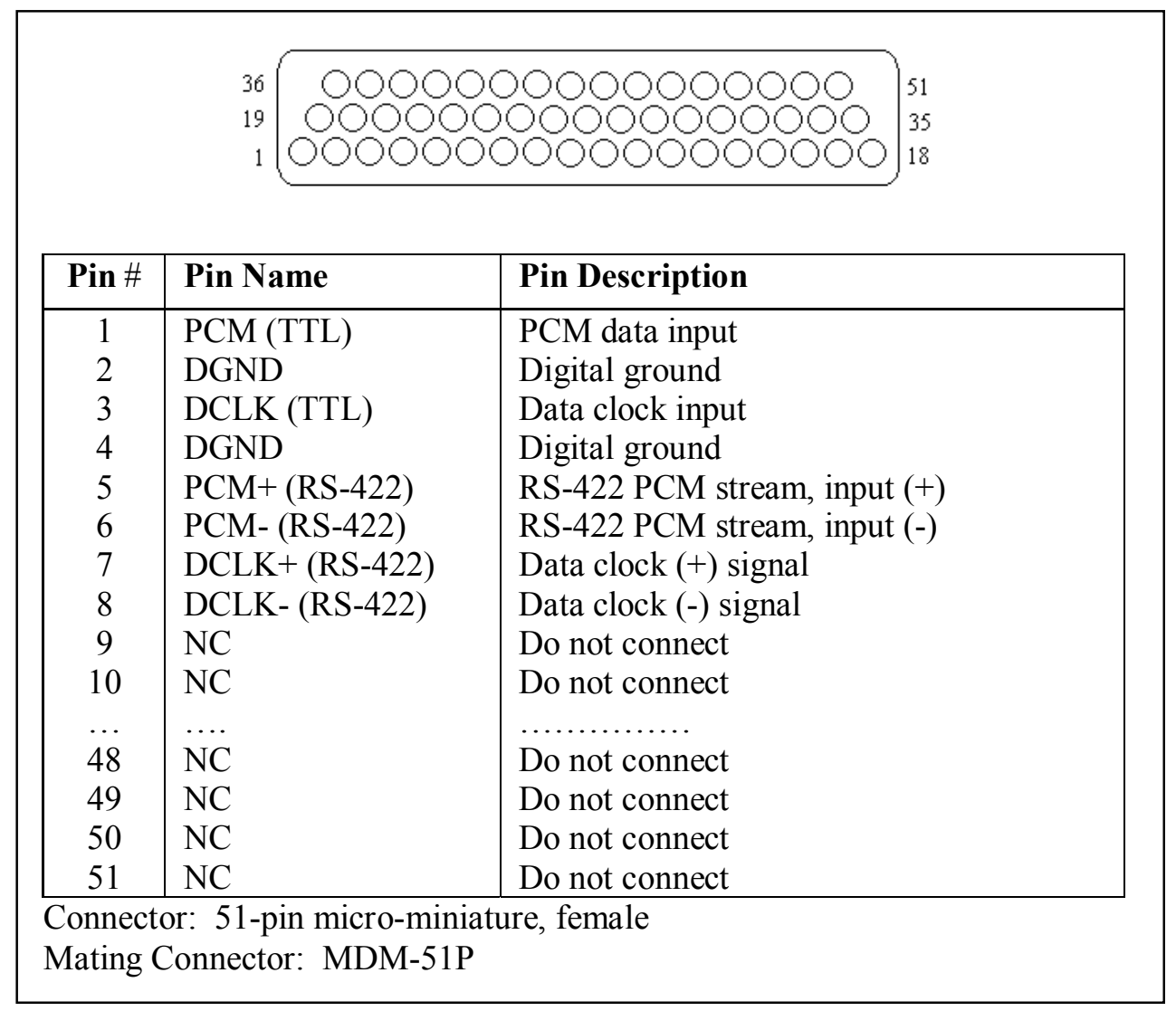

Figure 2-9. KAM-500 Merger/Decoder Pin Assignment

The DCS utilizes low-cost, frequency-hopping, spread-spectrum radio modems from Digital Wireless Corporation ${ }^{2}$ to transmit PCM data from any Slave to the Master or from the Master to the GBCU (the PCM data link) and to transmit control and programming information between the GBCU and any Slave (the RS-232 link). The RS-232 link and data link each consists of a pair of Digital wireless WIT-2400 modems. These pairs are programmed to operate as separate, independent networks and do not interfere with each other (16 separate network numbers are available). The WIT-2400 modems operate at a frequency of $2.4 \mathrm{GHz}$, incorporate a transparent error-correction feature that automatically requests retransmission of any data not received properly, and are capable of data rates as high as $115 \mathrm{kbps}$ (thousands of bits per second). The spread-spectrum technology makes the radio link much less susceptible to the interference found in a wind-turbine environment than a conventional technology, single-frequency radio link. The radio systems require no license for operation, and the maximum transmit power of $100 \mathrm{~mW}$ minimizes interference with other radio systems. Each radio modem module is $2.4 \times 2.0$ $\times 0.6$ in. in size and consumes a maximum of $1.5 \mathrm{~W}$ of power. These units are programmed to operate in the asynchronous transfer mode for the RS-232 link and in the synchronous transfer mode for the PCM data link.

\footnotetext{
${ }^{2}$ Digital Wireless Corporation, One Meca Way, Norcross, GA, 30093, (770) 564-5540
} 


\subsection{Programmable Accurate Time Synchronization Module}

Precise time sequence and phase information from all parts of the turbine and the anemometry is necessary to understand the load and response phasing, the loading sequences, and the load paths of the turbine. Therefore, data must be simultaneously acquired by all of the DASs on a turbine, whether they are located on the turbine rotor, the turbine tower, the meteorological tower, or the ground. The actual data acquisition time for each DAS unit is normally driven by an internal clock; if these clocks are independent, their inherent inaccuracies will result in the time for each clock drifting with respect to the other clocks. For a typical clock accuracy of one part in one million, the drift between two clocks could be as much as 0.17 seconds in 24 hours. This will result in data acquisition at different absolute times for each DAS unit and can make time correlation of the data from the various DAS units difficult.

To maintain very accurate clock synchronization between the DAS units over long periods of time, ATLAS utilize the GPS system. In normal operating mode, each GPS satellite continually transmits its orbital parameters, along with the precise universal time clock (UTC). GPS receivers decode that information and utilize triangulation techniques to accurately determine their position and UTC. The internal clock in each GPS receiver is continually adjusted to keep it in agreement with UTC. If the DAS clocks are slaved to GPS receiver time (UTC), they will not drift with respect to each other. The PATSyM, developed by Sandia National Laboratories (SNL) specifically for the ATLAS application, utilizes a commercial Jupiter GPS receiver ${ }^{3}$ to do exactly that. As long as the Jupiter antenna is receiving signals from three or more GPS satellites, the receiver will remain synchronized with UTC within $\pm 1 \mu$ s. Thus, the clocks in two of these receivers will vary with respect to each other by a maximum of $2 \mu \mathrm{s}$, regardless of how long they have been synchronized with each other. The Jupiter receiver also generates a one pulse per second (1PPS) signal, with the rising edge of the pulse occurring exactly on the UTC second. PATSyM, shown in Figure 2-10, utilizes this 1PPS signal to generate two clock pulse trains that are precisely synchronized to UTC. These pulse trains control the actual data acquisition times of all the DAS units, forcing them to acquire data within $2 \mu$ s of each other, indefinitely. The actual data acquisition time, accurate to $\pm 1 \mu \mathrm{s}$, is available from each PATSyM and can be included in the PCM data stream (i.e., the data from each DAS can be time-stamped). This information can then be used to associate the data acquired by one DAS at a specific time with the data acquired by other DASs at that same time. In practice, using modems to transfer data from the rotor delays the data by one sample period (for $30 \mathrm{~Hz}$ data) - the rotor data received in a data frame usually corresponds to the ground-based data received one sample data frame earlier.

${ }^{3}$ Conexant Systems, Inc., 4311 Jamboree Road, P.O. Box C, Newport Beach, CA, 92658-8902, (949) 483-4600. 


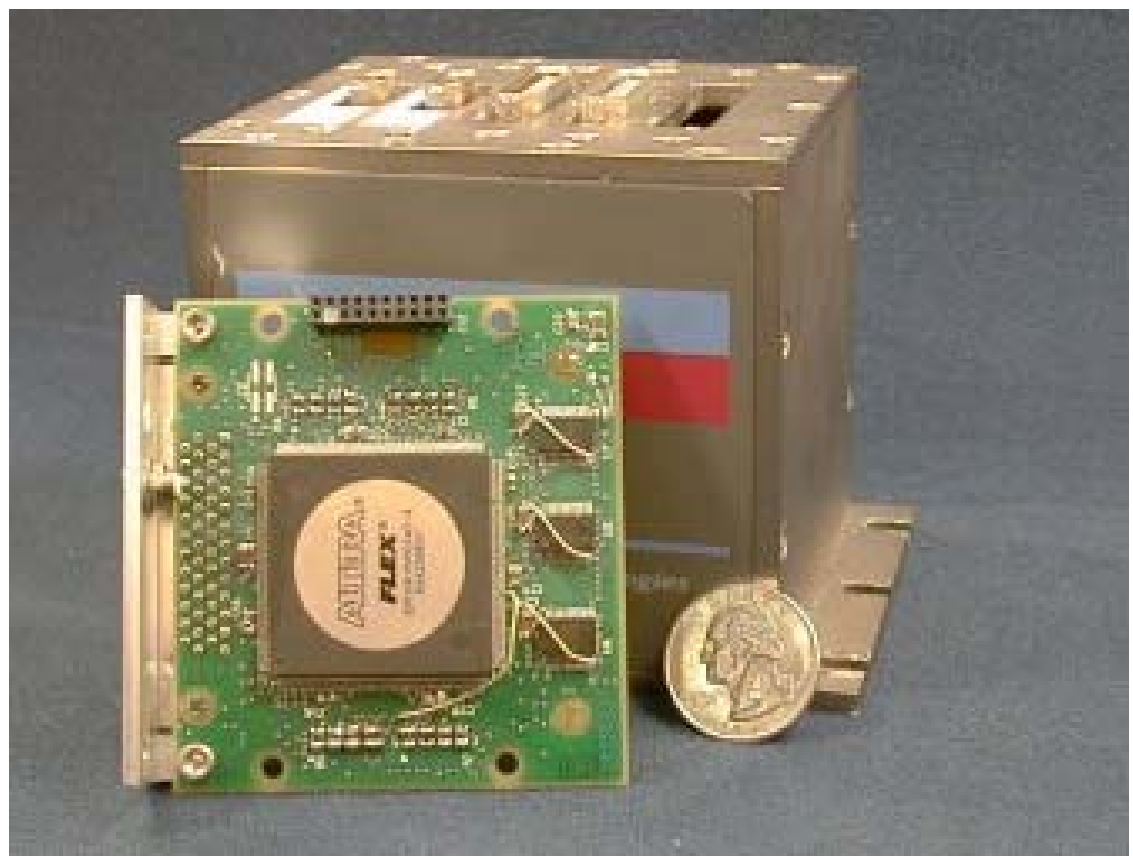

Figure 2-10. The Programmable Accurate Time Synchronization Module

PATSyM is a custom-built eight-layer card that fits in the KAM-500 mainframe. It incorporates an ALTERA $^{\circledR}$ 10K70 programmable logic device (PLD) from ALTERA $^{\circledR}$ Corporation $^{4}$ and associated hardware. An SNL-developed logic program controls the operation of the PLD and, thus, the PATSyM. In addition to providing time synchronization for the DAS, PATSyM also handles all RS-232 communications with the user, all communications and data interchange between the DAS and the DCS, and subsystem activity coordination in order to meet the system requirements. Berg et al. (1999) contains additional technical information on PATSyM. Characteristics of the module are summarized in Table 2-5.

Table 2-5. PATSyM Characteristics

\begin{tabular}{|l|l|}
\hline \multicolumn{1}{|c|}{ Parameter } & \multicolumn{1}{c|}{ Value } \\
\hline Drift with respect to GPS (UTC) time & $\begin{array}{l}\text { Maximum of one microsecond, assuming } \\
1 \times 10^{-6} \text { clock accuracy }\end{array}$ \\
\hline Frequency of resync with GPS time & Once per second \\
\hline RS-232 comm speed for GPS data & 9,600 bits per second \\
\hline $\begin{array}{l}\text { RS-232 comm speed for programming } \\
\text { KAM/500 }\end{array}$ & 38,400 bits per second \\
\hline Current consumption (5 VDC) & $200 \mathrm{~mA}$ \\
\hline
\end{tabular}

\footnotetext{
${ }^{4}$ Altera Corporation, 2610 Orchard Parkway, San Jose, CA 95134-2020.
} 
The GPS receiver in each PATSyM must be connected to an antenna with a generally unobstructed view of the sky to receive the GPS signals. These signals will pass through small amounts of common building materials, such as glass, wood, brick, and concrete block, but will usually not pass through metal objects. A general rule of thumb is that the GPS antenna must be mounted outside of any building, but some antennas may work just fine inside some buildings. The receiver requires signal reception from at least three satellites before it can synchronize, or "lock," its internal clock to UTC. Even if the antenna is placed so it has an unobstructed view of the sky, a receiver may take as long as five minutes to acquire lock after the receiver power is turned on. Keep in mind that one of these antennas must be mounted on the rotor to provide GPS signals to the DAS mounted there. The ability of the rotor-mounted GPS receiver to retain satellite communications and time lock is dependent on both the antenna rotation speed and antenna configuration. A half-wavelength antenna configuration (about 3 in. in diameter) is adequate for maintaining time lock at rotation speeds as high as $350 \mathrm{rpm}$. Experience has shown that an antenna mounted on a non-rotating wind-turbine rotor will usually lock onto six or more satellites. As the antenna rotation speed is gradually increased, the number of satellites that the receiver is locked onto gradually decreases. At $350 \mathrm{rpm}$, the receiver is usually locked onto only three or four satellites at any one time, and the actual satellites in lock change frequently (perhaps every revolution). Momentary satellite communication dropouts, which might occur during brief periods of higher rotation speed, are not a problem because the clock in the receiver will continue to run and produce the 1PPS signal, although that clock will slowly drift with respect to UTC. Once the antenna rpm drops to 350 or less, the receiver will reestablish communications with three or more satellites, and the receiver clock will be quickly relocked to UTC time. SNL has always mounted the rotor antenna so that its axis of rotation coincides with the rotor axis of rotation to minimize rotation-caused motion. Antenna wobble due to mounting the antenna so that its axis is offset several centimeters from the rotor axis is not expected to cause loss of lock at low rpm (100 rpm or below), but this has not been verified. It is important that the antenna be mounted so it always has an unobstructed view of the sky throughout its rotation, but this has not been tested.

\section{NOTE}

Be sure that each GPS receiver is receiving messages from at least three satellites, because only then is the internal clock locked to the UTC. The status of each GPS receiver can be determined by monitoring the GPS output from that receiver (see Section 3.2.4.1).

The GPS signals are very weak and signal reception from the maximum number of satellites is enhanced by mounting the GPS receiver as close to the antenna as possible. The communications between the receiver and PATSyM consist of RS-232 and high-level pulse trains, so the receiver can be mounted several meters away from the PATSyM without causing communications degradation. The receiver may be placed in a weatherproof box that then serves as a mount for the GPS antenna, as shown in Figure 2-11. 


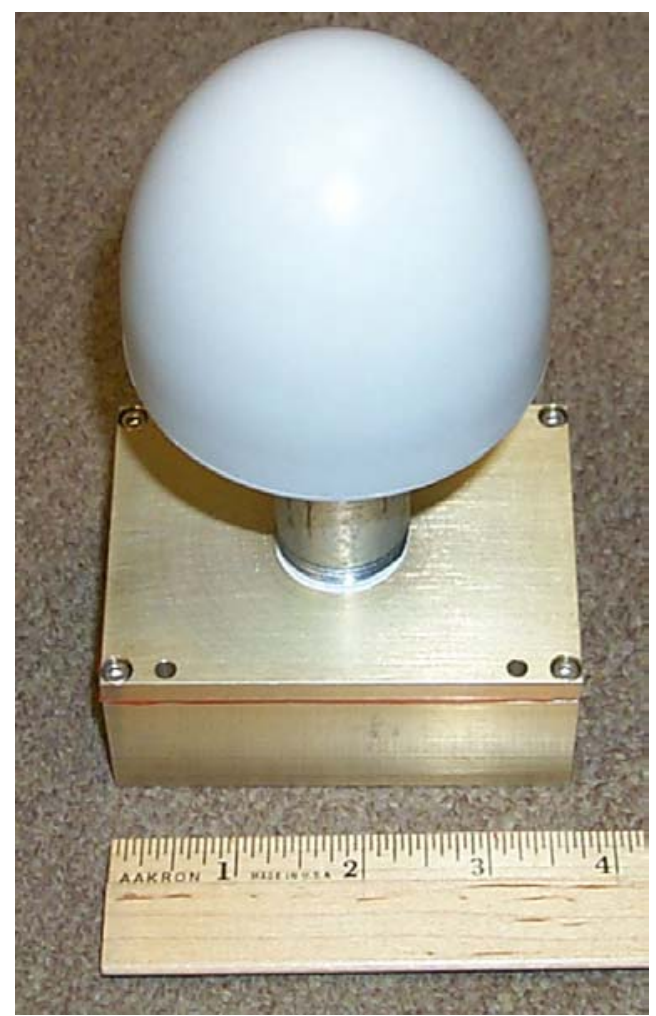

Figure 2-11. GPS Receiver/Antenna Configuration.

Figure 2-12 illustrates the pin assignment on the 51-pin connector of the PATSyM. Inputs on pins 1-3 must supply $12 \mathrm{VDC}$ and $5 \mathrm{VDC}$ power to the module. Pin 4 outputs 12 VDC that can be switched off by a user-controlled (usually closed) relay on the module. Pins 11 and 12 output the external clock pulse-trains that are input to encoder pins 4 and 5, respectively, as shown in Figure 2-6. Pins 13 and 14, shown in Figure 2-7, receive the TTL-level PCM data from encoder pins 11 and 12. Pins 15 and 16 are connected to the encoder RS-232 serial communications pins 13 and 14, respectively. Pins 19 and 3034 are connected to the GPS receiver/antenna unit, wired to the pins with the same labels on the GPS connector.

Pins $15-18$ and 48-50 are usually used only in a rotor-mounted DAS configuration when all serial communications must go through a single modem. In this case, you can utilize the "GPS Data" routine in the ATLAS software (see Section 3.2.4.1) to switch the serial communications between receiving GPS data and programming the KAM-500. Pin 50 then determines which set of communication lines is active.

Pins 17 and 18 provide TTL-level RS-232 serial communications (internally connected to pins 16 and 15, respectively) when pin 50 is grounded, and they are disconnected when pin 50 is allowed to float high. Pins 48 and 49 (internally connected to the receive and transmit pins, respectively, on the RS-232 data modem) provide CMOS-level communications signals (internally connected to pins 16 and 15, respectively) when pin 50 is allowed to float high, and they are disconnected when pin 50 is grounded. 


\begin{tabular}{|c|c|c|}
\hline \multicolumn{3}{|c|}{\begin{tabular}{r|r}
36 & 00 \\
19 & 000
\end{tabular}} \\
\hline Pin \# & Pin Name & Pin Description \\
\hline 1 & $+5 \mathrm{~V}$ & $5 \mathrm{~V}$ input \\
\hline 2 & DGND & Digital ground \\
\hline 3 & $+12 \mathrm{~V}$ & $12 \mathrm{~V}$ input \\
\hline 4 & $+12 \mathrm{~V}$ SWITCH & Switched $12 \mathrm{~V}$ output \\
\hline 5 & $\mathrm{NC}$ & Do not connect \\
\hline 6 & $\mathrm{NC}$ & Do not connect \\
\hline 7 & $\mathrm{NC}$ & Do not connect \\
\hline 8 & $\mathrm{NC}$ & Do not connect \\
\hline 9 & $\mathrm{NC}$ & Do not connect \\
\hline 10 & $\mathrm{NC}$ & Do not connect \\
\hline 11 & EXT_SYNC & External sync pulse output \\
\hline 12 & EXT CLK & External clock pulse output \\
\hline 13 & PCM_DATA & PCM data input (in user-specified code) \\
\hline 14 & DCLK & Data clock input \\
\hline 15 & S IN2 & RS-232 transmit from encoder, input \\
\hline 16 & S OUT2 & RS-232 receive to encoder, output \\
\hline 17 & S_IN1 & RS-232 input from hardwire connection \\
\hline 18 & S_OUT1 & RS-232 output to hardwire connection \\
\hline 19 & GPS_TX & RS-232 link to GPS receiver, output \\
\hline 20 & $\mathrm{NC}^{-}$ & Do not connect \\
\hline 29 & $\mathrm{NC}$ & Do not connect \\
\hline 30 & PWR_IN & $\begin{array}{l}5 \mathrm{~V} \text { switched power for GPS receiver, } \\
\text { output }\end{array}$ \\
\hline 31 & M_RST & Master reset for GPS receiver, output \\
\hline 32 & 1_PPS & $\begin{array}{l}1 \text { pulse per second from GPS receiver, } \\
\text { input }\end{array}$ \\
\hline 33 & 10_HZ_GPS & $10 \mathrm{~Hz}$ pulse train from GPS receiver, input \\
\hline 34 & $\overline{G P S} \overline{R X}$ & RS-232 line to GPS receiver, input \\
\hline 35 & $\mathrm{NC}^{-}$ & Do not connect \\
\hline$\cdots$ & $\ldots$ & …........... \\
\hline 47 & $\mathrm{NC}$ & Do not connect \\
\hline 48 & USIN2 & CMOS-level RS-232 input from modem \\
\hline 49 & USOUT2 & CMOS-level RS-232 output to modem \\
\hline 50 & TTL/RS232 & $\begin{array}{l}\text { User-select switch for CMOS/RS-232 } \\
\text { selection, input }\end{array}$ \\
\hline 51 & $\mathrm{NC}$ & Do not connect \\
\hline
\end{tabular}

Figure 2-12. PATSyM Pin Assignment.

Figure 2-13 illustrates the pin assignment for the 13-pin connector on the antenna/ receiver box. Pin 1 should be connected to a constant source of 5 VDC. This maintains the GPS satellite information when the antenna/receiver unit is placed in the sleep mode. Pin 2 must be connected to the DAS digital ground. Pins 3 and 4 provide RS-232 


\begin{tabular}{|c|l|l|}
\hline \multicolumn{2}{|l|}{} \\
\hline Pin \# & Pin Name & Pin Description \\
\hline 1 & +5V & +5 VDC power input (stay-alive power)) \\
2 & DGND & Digital ground \\
3 & GPS_TX & GPS RS-232 transmission \\
4 & GPS_RX- & GPS RS-232 receive \\
5 & M_RST & Master reset (active low) \\
6 & 1 PPS & One pulse per second time mark output \\
7 & $10 \mathrm{kHz}$ GPS & 10 KHz clock output \\
8 & PWR_IN & Primary +5 VDC power input \\
9 & NC & Do not connect \\
10 & NC & Do not connect \\
11 & NC & Do not connect \\
12 & NC & Do not connect \\
13 & NC & Do not connect \\
\hline Connector: 13-pin miniature circular shell female \\
Source: C ANNON Part number: JT07H-10-13S \\
\hline
\end{tabular}

Figure 2-13. GPS Antenna/Receiver Pin Assignment.

communication between the GPS receiver and the PATSyM. Pin 5 causes a master reset of the GPS (a cold start) when tied to ground. Pin 6 is the time mark 1PPS used by PATSyM to synchronize the generated pulse trains to UTC, and pin 7 is a $10 \mathrm{kHz}$ pulse train output by the GPS receiver. Pin 8 is the primary power supply to the GPS. When this is pulled to ground, the GPS receiver and antenna shut down. If power is supplied on pin 1 during this time, the system will come up much quicker than would be the case if pin 1 were not kept high because the satellite location table is kept current.

\subsection{Lightning Protection Equipment}

DAS units and other ATLAS components are susceptible to damage from high voltages due to lightning or other types of electrostatic discharge (ESD). It is important to include overvoltage protection for these components. The Citel E280-6V and-12V lightning protection modules from Citel Corporation ${ }^{5}$ have worked well for the ATLAS. Specification sheets on this product may be found in Appendix A. Each module supplies protection for two pairs of signal lines at a cost of $\$ 40-50$ per module.

The Citel units contain both a quick-switching silicon avalanche diode and a gas tube between the line to be protected and the ground, along with a small resistor that causes currents to flow through the gas tube when it is switched. The avalanche diode provides quick response to an electrostatic discharge such as lightning, but it cannot discharge much power. The gas tube, on the other hand, does not switch quickly and needs a volt

${ }^{5}$ Citel Corporation, 1111 Park Centre Boulevard, Suite 340, Miami, FL 33169, (305) 621-0022, www.citelprotection.com 
age potential of about $100 \mathrm{~V}$ to fire, but it can discharge large amounts of power. The Citel specification sheet claims a response time of less than $1 \mathrm{~ns}$, with a peak current capacity of $10 \mathrm{kA}$ for these units. If one of these devices is placed in series in the bridge excitation line for a strain-gauge instrumentation module, the current drawn by the bridge (a few milliamps) will create a small voltage drop across that resistor. That voltage drop will result in an excitation voltage at the strain-gauge bridge that is lower than that specified by the user during system configuration; a significant problem in some applications. The bridge signal lines, however, carry very little current, so the voltage drop due to the resistor in a Citel device placed in the line is very small. Thus the Citels can easily be used to protect these lines. The Citels are used to protect all of the bridge lines, but they are connected as a shunt to ground (the line from the instrumentation module to the bridge is connected to the line terminal on the Citel unit) on the excitation lines and in series (the lead from the instrumentation module is connected to the equipment side of the Citel unit and the lead to the bridge is connected to the line side of the Citel) on the signal lines. These connections are illustrated in the wiring schematic for the LIST units in Appendices B and C. In these configurations, the Citel devices can protect the bridge excitation lines from overvoltage events with up to $85 \mathrm{~A}$ currents, and the signal lines are protected for up to $10,000 \mathrm{~A}$ currents. While the 10,000 A protection should be sufficient for protection against most direct lightning strikes, the $85 \mathrm{~A}$ protection certainly is not - it does offer protection from handling-induced ESD, however.

If the Citels do trigger, they will automatically reset as soon as the voltage level drops to normal operating voltage, and they will provide protection against future overvoltage effects. However, the gas tubes tend to lose their charge over a period of time and eventually they cease to provide protection, so each module should be tested to ensure that it still functions every two to three years.

Another device appears to be well suited for providing general overvoltage protection: SIDACtor, made by Teccor Electronics, Inc. ${ }^{6}$ These small devices have a very high offstate impedance, but turn on quickly (within $5 \mathrm{~ns}$ ) when their break-over voltage is exceeded. They do not require the insertion of a resistor in a line in order to protect that line. In the "on" state, they create a short to ground, preventing high voltage from reaching the protected device, and they remain in this state until the current drops below a holding value. Their protection capability does not deteriorate with time. These devices can shunt approximately $200-500$ A to ground for short periods of time. This is much more protection than is provided by the Citel devices on the bridge excitation lines, but much lower than the protection provided by the Citel devices on the bridge signal lines. It should be sufficient to protect against most overvoltage events, such as ESD or nearby lightning, but probably will not protect against a direct lighting hit. However, the Citel modules may also prove to be inadequate in case of a direct lightning hit. In the two years that ATLAS has been deployed at the Bushland site, numerous thunderstorms have occurred in the immediate vicinity, but no direct lightning hits on ATLAS have occurred. These devices should be considered for lightning protection, as they are much smaller

\footnotetext{
${ }^{6}$ Teccor Electronis, Inc, 1800 Hurd Drive, Irving, TX 75038, (972) 580-7777, www.teccor.com
} 
than the Citels, do not degrade over time, and do not cause a voltage drop in the line being protected, regardless of the amount of current flowing through that line.

\subsection{Power Supplies}

A DAS power supply must not only supply power for the DAS and the instrumentation modules contained within it, but it must also supply excitation to the strain gauges attached to those modules, power the PATSyM module, and perhaps supply excitation to the analog instrumentation being monitored, depending on the particular application. If telemetry is used, the power supply must also power two modems. The strain-gauge and analog excitation can be supplied through the KAM-500 (within the limits listed on the specification sheet), or directly from the power supply. As noted above, the strain-gauge instrumentation module has two pins for bridge excitation input. The voltage at these inputs must be at least $20 \%$ above the highest user-specified level for bridge excitation. This voltage is converted down to the user-specified bridge-excitation voltage level and then output to the actual bridge through the 51-pin module connector (see the connector pin assignment in Figure 2-7). Information on estimating the power supply requirements for the DAS may be found in Appendix D. Pick a power supply that can supply more current than the amount needed, to allow for the possible addition of more instrumentation. Power supply size and weight are of much more importance for an RBU than for a GBU.

\section{NOTE}

If a switching power supply is used, do not connect multiple units in parallel to achieve the necessary current - the feedback circuits in the power supplies will "buck" each other and the resultant voltage and current output levels will be unstable.

The power supply voltage for the DAS can be anywhere in range of 9 to 36 VDC. Noise regulation of the power supply is not particularly important if all of the power is to be passed through the KAM-500, as the KAM-500 filters the incoming power. However, if the power supply is to provide instrument excitation voltage directly (rather than through the KAM-500 voltage output lines), the power supply should be regulated to $\pm 50 \mathrm{mVDC}$ or better. The COSEL MMB50U-5 $12 \mathrm{VDC}$ power supply has worked well for this application. This unit operates off $110 \mathrm{VAC}$, single phase, and supplies two $12 \mathrm{VDC}$ outputs; one with $3 \mathrm{~A}$ of output, the other with $1.5 \mathrm{~A}$ of output. By connecting the negative side of the 3-A output to the positive side of the 1.5-A output, the output votages can be changed to +12 VDC ( $3 \mathrm{~A})$ and -12 VDC (1.5 A). This provides enough current to power most DAS configurations.

\subsection{Connectors}

Connectors are needed to connect the DAS units with data, communication, and power lines. Using the same connectors for both indoor- and outdoor-mounted units makes it 
easy to interchange units, minimizes the number of connector configurations required, and minimizes the number of test cables needed. The cylindrical military/aerospace weatherproof connectors supplied by ITT Cannon, AMP, and other connector manufacturers offer good quality at reasonable prices. Using JT07-14-18S (bulkhead connector)/JT06-14-18P (cable connector) 18 pin connectors and JT07-12-98S (bulkhead connector)/JT06-12-98P (cable connector) 10 pin connectors to connect strain gauge signals to the DAS units works quite well. The same connectors in reverse polarity (JT07-1418P for bulkhead/JT06-14-18S for cable, etc.) can then be used to connect analog signals. Although these connector pairs contain the same number of pins, the connector polarity is reversed between the strain-gauge connectors and the analog connectors. For the strain gauge connections, the cable connector contains pins. For the analog connections, the cable connector contains sockets. The difference in polarity prevents possible damage to instrumentation and DAMs due to accidental connection of strain gauge DAMs to analog instrumentation and vice versa. JT07-16-26S/JT06-16-26P 16-pin connector pairs work well for digital input. A JT07-8-3P/JT06-8-3S (3-pin) connector works well for the AC power connection, JT07-10-13P/JT06-10-13S (13 pin) connectors for the GPS antenna connection, and LJT07-11-13S/LJT06-11-13P (13-pin) connectors for the communications cable connection. These connectors are readily available from Spacecraft Components Corporation. ${ }^{7}$ Connections to the KAM-500 power and signal lines require the use of female subminiature D connectors in 9, 15, and 51-pin configurations. Prewired cables with these connectors are marketed by Cinch and Cannon and are commercially available.

\subsection{ATLAS Application-Specific Configuration}

\subsubsection{Application Planning}

The hardware components of ATLAS can be configured in many different ways to tailor the system to specific applications. The first step in assembling an ATLAS for a new application is to determine the hardware needed for the particular application and separate that hardware into the distinct data acquisition units. The RBU contains the acquisition hardware that will be mounted on and rotate with the turbine rotor. The GBUs contain the rest of the acquisition hardware; that hardware which will be mounted on the meteorological tower, the nacelle, the turbine tower, the turbine base, and perhaps other turbine components.

The RBU typically contains a DAS with associated DAMs and a PATSyM, the telemetry modems that make up the DCS (if telemetry data and communications links will be used), a power supply, lightning-protection equipment, and a GPS receiver/antenna unit. All of these components must be mounted in or on a small, weatherproof container as shown in Figure 2-14. The RBU components are shown in Figure 2-15.

\footnotetext{
${ }^{7}$ Spacecraft Components Corporation, 14137 Chadron Avenue, Box Number 5027, Hawthorne, CA 90251, (310) 973-6400.
} 


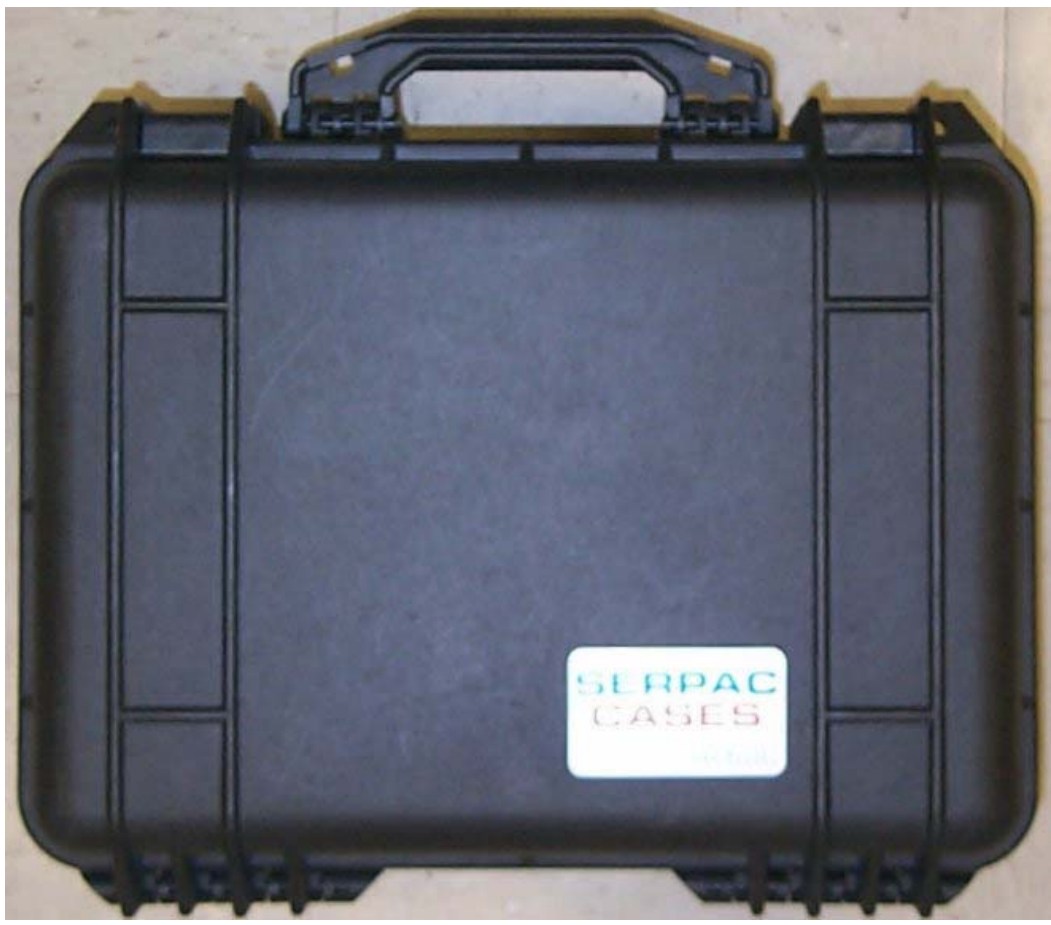

Figure 2-14. Typical RBU Weatherproof Case.

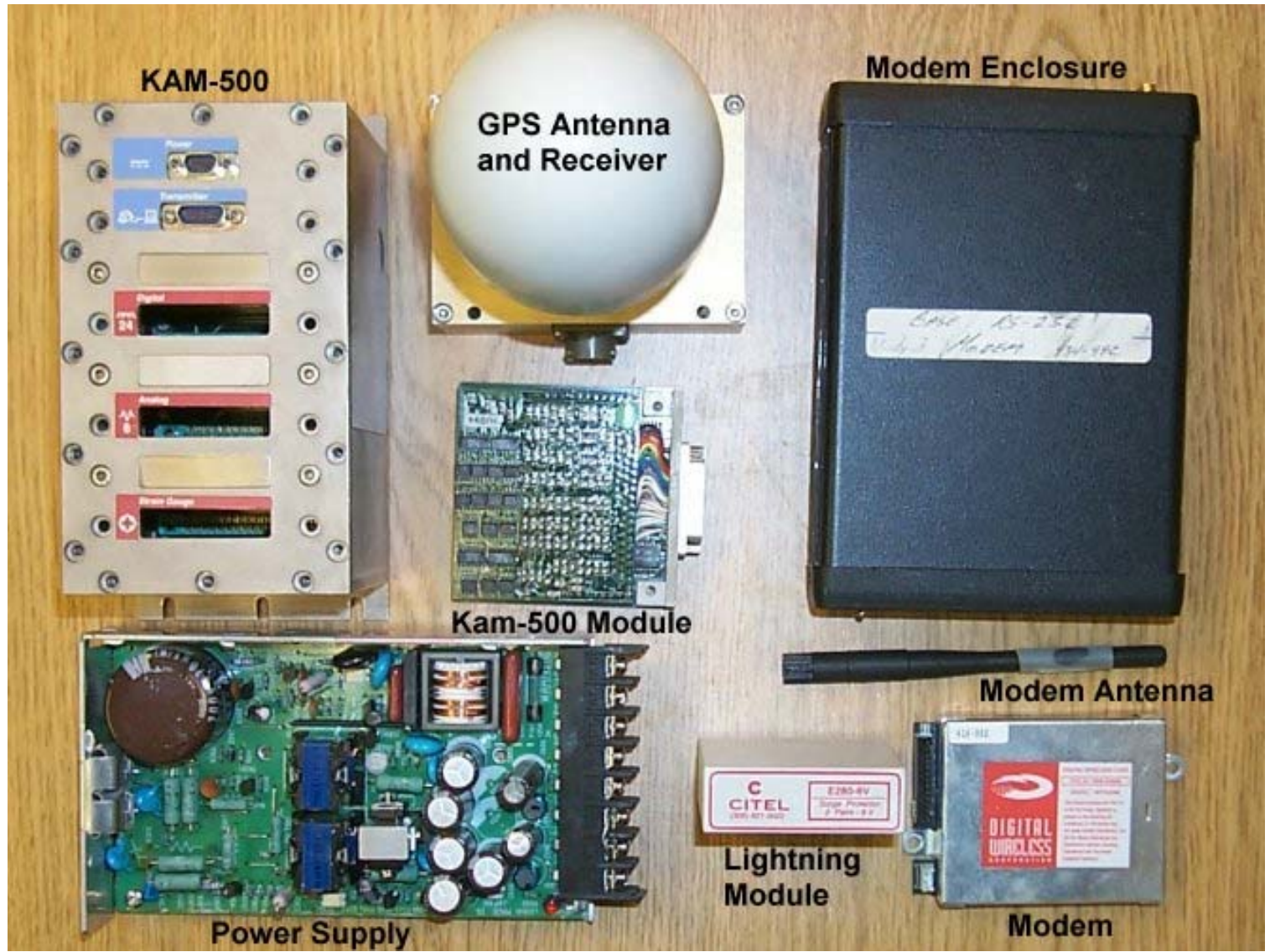

Figure 2-15. RBU components. 
A GBU typically contains a DAS with associated DAMs and a PATSyM, along with a power supply and lightning-protection equipment. If the mounting location for a GBU will be exposed to the elements, the GBU must be mounted in a weatherproof container. Otherwise, it can be mounted in an instrumentation rack.

\section{NOTE}

The DAS generates heat that must be dissipated, so it is a good idea to mount it on a metal plate and to mount that plate so it can effectively dissipate heat.

The Master GBU receives data from the RBU and other GBUs, merges all the data into one data stream, and sends that data stream to the GBCU. All other GBUs and the RBU are Slaves. Data links between the Slaves and the Master may be hardwire, fiber-optic, or telemetry. The Master GBU must contain the receiving modem for any telemetry link that is used. It must also contain one merger/decoder module to merge RBU data into the Master data stream, one additional merger/decoder module for each Slave GBU (to merge their data streams), and one or more DAMs to acquire data.

The GBCU is usually located in a building and includes the PCM decoder and the ATLAS and ADAS II software. The full data stream is typically transmitted from the Master GBU to the decoder via either hardwire or fiber-optic cable. The GBCU must also contain hardwire, fiber optic, or telemetry RS-232 communication links with the RBU and each GBU.

The actual hardware configuration of the system must now be planned to determine the number and type of DAMs to be placed in each DAS, and thus the minimum allowable size (i.e., the number of slots) of each DAS.

\section{NOTE}

All DAS units should be located close to the sensors and indicators from which they are acquiring data in order to minimize contamination of the data by electrical noise picked up by analog signal wires.

The following steps will aid in identifying the components to be included in the RBU and the GBUs for a specific application.

1. Determine the number of data sensors to be monitored and the type of data to be acquired from each sensor.

a) Digital sensors will require the use of a digital input module (see Table 2-1 and Figure 2-5) with one line per bit connecting the sensor to the module and 
additional lines to provide sensor excitation, as needed. A digital input module will sample up to 48 bits of digital input.

b) Analog sensors $(0 \pm 10 \mathrm{~V}$ output $)$ will require the use of a high-level analog input module (see Table 2-2 and Figure 2-6), with two lines connecting each gauge to the module and additional lines to provide sensor excitation, as needed. A high-level analog module will sample up to eight differential analog inputs.

c) Strain-gauge sensors will require the use of a strain-gauge input module (see Table 2-2 and Figure 2-7). Strain-gauges are normally connected to the instrumentation module with four wires per gauge $(+$ and - excitation and + and - signal). If the excitation wires between the module and the gauge are long enough that the voltage drop that will occur is of concern, run a 5th line (the B lead) between the two to permit sensing (and control) of the excitation voltage at the gauge itself. A strain-gauge module will handle as many as eight gauges. The normal strain-gauge modules will work with 120,350 , or $1000 \Omega$ full-bridge configurations. Strain-gauge modules can also be factory configured to work with half-bridge or quarter-bridge strain gauge arrangements.

2. Determine the number of DAS units that will be used to acquire the data of interest. It is preferable to put a DAS close to each major group of sensors to minimize noise caused by long wires between the sensor and the associated DAS.

3. Determine the number of DAMs required in each DAS. As noted above, a single DAM will acquire up to eight channels of strain-gauge data, eight channels of highlevel analog data, or 48 bits of digital data. Use this information to determine the minimum number of slots needed in each DAS. DAS units are available with 3, 6, 9, or 13 module slots.

4. The DAS that will be mounted on the rotor and used to acquire the rotor data becomes the RBU. All of the other DASs are GBUs.

5. The RBU and each GBU will require a PATSyM to sychronize the acquisition timing (see Table 2-5 and Figure 2-12). It is possible to use a single PATSyM to synchronize two GBUs. However, the GBUs should be quite close to each other or the PATSyM clock pulse trains may degrade to the point where they will not properly trigger the DAS. It may be possible to drive three or more GBUs with a single PATSyM, but this has not yet been demonstrated.

6. Designate one GBU as the Master. All GBUs other than the Master will be considered Slaves. As indicated above, the Master unit receives the data streams from the RBU and the Slave GBUs and merges all of them into a single data stream for transmission to the GBCU and storage to disk. One merger/decoder DAM will be 
required in the Master to receive the data from the RBU and another will be required for each Slave GBU (see Table 2-4 and Figure 2-9).

7. Determine the number of lightning protection modules required for the RBU and each GBU.

8. Determine the number of power supplies required and the current requirements of each.

9. Determine the number and types of connectors needed.

10. Gather the necessary DAS units, DAMs, PATSyMs, the GBCU, the power supplies, the lightning protection equipment, and the connectors. Although the usual procedure is to purchase everything required for an ATLAS application, an agreement with SNL or National Renewable Energy Laboratory (NREL) may provide for the loan of DAS units and DAMs. In any case, the power supplies, lightning protection equipment, and connectors will probably have to be purchased. Be sure to purchase a few extra connectors to accommodate mistakes in assembly, miscalculations, etc.

Assembly of the ATLAS for the specific application can now begin.

\subsubsection{General Fabrication Notes}

All lines into and out of the GBU or RBU should be shielded to minimize the possibility of introducing noise or induced voltages into those lines. The shield should be grounded either at the GBU/RBU or at the instrumentation end of the line, but not at both, because grounding at both ends creates a potential for a ground loop and could lead to inaccurate data. The power supply should also be shielded to keep the electrical noise generated by it from feeding noise into the data lines.

All DAS units, including the RBU and the Master GBU, should have encoder pin 6 wired to a +5 VDC or higher source whenever power is supplied to the DAS. This is necessary for the DAS to accept the clock information furnished to it by the PATSyM.

\section{NOTE}

The necessary cables must be built to connect the components within each GBU and RBU and to connect those units to the instrumentation. See Appendices B and C for typical cable schematics.

For both GBUs and RBUs, the systems are wired so all serial data goes through the PATSyM. The user must switch the operating mode of the PATSyM to "DAS" in the ATLAS "GPS Data" routine (see Section 3.2.4) before programming the RBU DAS. After the DAS is programmed, return to the ATLAS 'GPS Data' routine to switch the PATSyM mode back to "GPS" for normal operation. This is necessary to permit the user to both 
receive GPS serial data and program the DAS with only one RS-232 cable or modem pair.

\subsubsection{Ground-Based Unit Assembly}

As mentioned earlier, the GBUs are custom-built for each data acquisition installation, using the standard components described above. Examples of GBUs SNL has built may be found in Appendices B and E. The basic procedure to be followed is contained in the following paragraphs.

The components for each GBU must be mounted in an enclosure suitable for the environment in which that GBU will be located. Keep in mind that the DAS units generate heat when operating, and that heat must be dissipated. Since the size and weight of the GBU are not usually serious issues, consider utilizing metal weatherproof boxes for all external GBUs, and mount the DAS units directly to the metal floor of the boxes. For indoor applications, mount the DAS units on metal shelves in instrumentation racks.

Additional information on KAM-500 instrumentation module operation and wiring may be found in the manuals supplied by ACRA Control with those units.

A wiring schematic for a GBU that SNL personnel assembled can be found in Appendix B. Photos of GBU units are included in Appendix E.

\subsubsection{Rotor-Based Unit Assembly}

The RBUs are also custom-built for each particular application. In general, they are built very much like the GBUs, but with the added requirements of small size and light weight. The requirement to reduce weight has led SNL to use a waterproof SerPac R-Series case. ${ }^{8}$ for the container. These cases are made of lightweight structural resin, are stout enough to provide a solid base for the RBU components, and withstand the weather and sunlight well. They include an integral handle, which makes them easy to transport and maneuver. However, the cases must be modified by cutting out the bottom of the case and inserting a metal mounting plate. The joint between the plate and the case must be carefully sealed to make the modified case weatherproof. The plate serves as a solid mounting for the DAS and other components of the RBU, provides a means of mounting the RBU to the rotor hub, and provides a good heat conduction path from the DAS into the rotor hub.

As mentioned earlier, two Digital Wireless WIT-2400 modems are used for RBU radio communications, one to handle the user-interface communications with the GPS and the DAS, and the other to transfer the PCM data stream from the DAS to the ground receiving station. The RBU assembly uses only the actual modem module shown in the lower right-hand section of Figure 2-15, without the RS-232 interface, indicator lights, and power supply that are found in a modem enclosure, as shown in the upper right-hand section of Figure 2-15. The radio modems in the RBU are the only ones not inside the mo

${ }^{8}$ Serpac Cases, 619 Commercial Ave., Covina, CA 91723 
dem enclosure. Interface the CMOS-level signals of the PATSyM (pins 48 and 49) directly to the radio module (receive and transmit, respectively) to minimize space requirements, and to keep complexity and power consumption to a minimum. Mount the radio modems either on the DAS unit or very close to it.

Schematics of RBUs SNL has built are included in Appendix C and photos of those units are included in Appendix F.

The receiving data modem, normally located near the Master GBU, must be modified to bring the RX_CLK, the RX_DATA, and GND lines out directly from the radio module into the appropriate merger/decoder module. The ground-based RS-232 modem, on the other hand, requires no modification - it is simply attached to the GBCU serial port via a standard 9-pin serial cable. The two RBU modems and the two receiving modems must be programmed before the RBU is assembled. Details of the programming may be found in Appendix G.

\section{NOTE}

Failure to switch the PATSyM operating mode to "DAS" prior to attempting to program the RBU will cause the program routine to fail - it will "hang up" attempting to program the RBU. If programming takes over 10 minutes, press the "Cancel" button and wait for the routine to terminate. 
This page intentionally left blank. 


\section{Chapter 3. ATLAS System Software}

\subsection{What ATLAS Does}

The ATLAS system software consists of three independent user interactive software programs written in the National Instrument LabVIEW environment. The ATLAS software programs the hardware, ADAS II acquires the data, and SDAS post-processes the data. This chapter explains the ATLAS software in detail, the ADAS II and the SDAS software are introduced. For more information on those software packages, refer to their individual manuals.

ATLAS is a computer program that allows users to program the ATLAS hardware system. The software consists of several windows that allow a user to set specifics on the hardware.

\subsection{Programming the ATLAS Hardware}

\subsubsection{Launching the ATLAS Software}

Launch the ATLAS software (see Section 1.4). The ATLAS Main Window, shown in Figure 3-1 will appear.

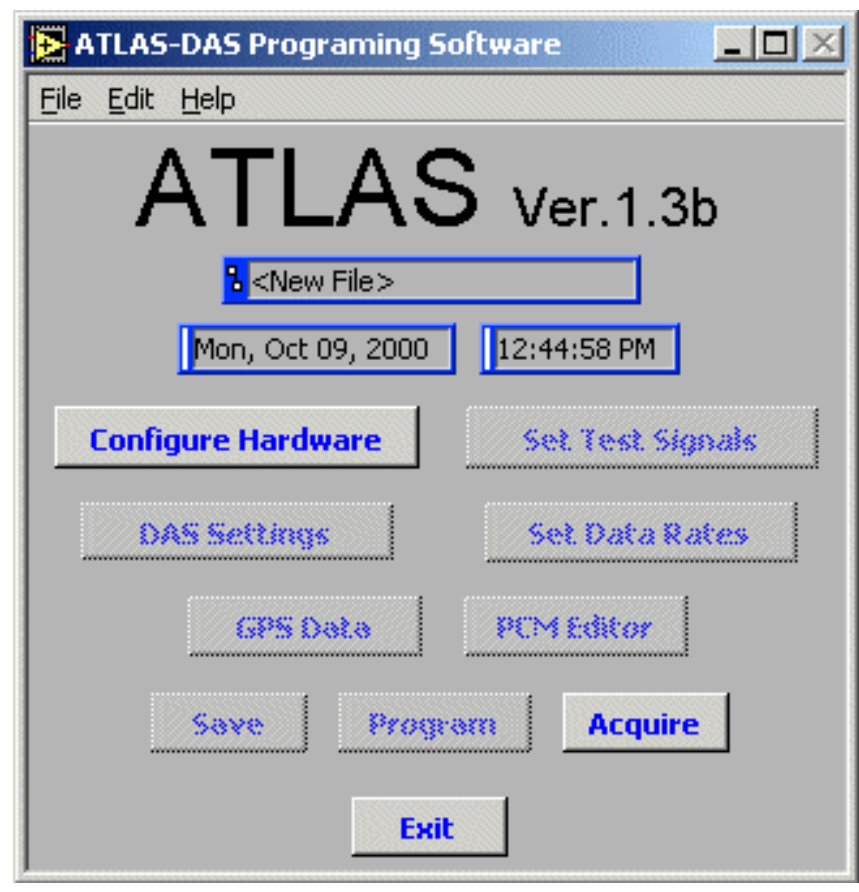

Figure 3-1. ATLAS Main Window.

At this point, the program can be used to generate a new *.pcm file or open an existing file. The PCM file is an ASCII-based file that contains all of the configuration information to program the hardware. 


\subsubsection{Opening a *.PCM File}

To open an existing file, select Open from the File menu, displayed in Figure 3-2. After the selection is made, a browse window will appear, and the desired file can be selected.

\section{NOTE}

Files with a *.pcm extension are the only supported files.

After the file has been opened, ATLAS can be used to either modify the file, acquire data, or program a system. Refer to the appropriate section throughout this chapter for further information.

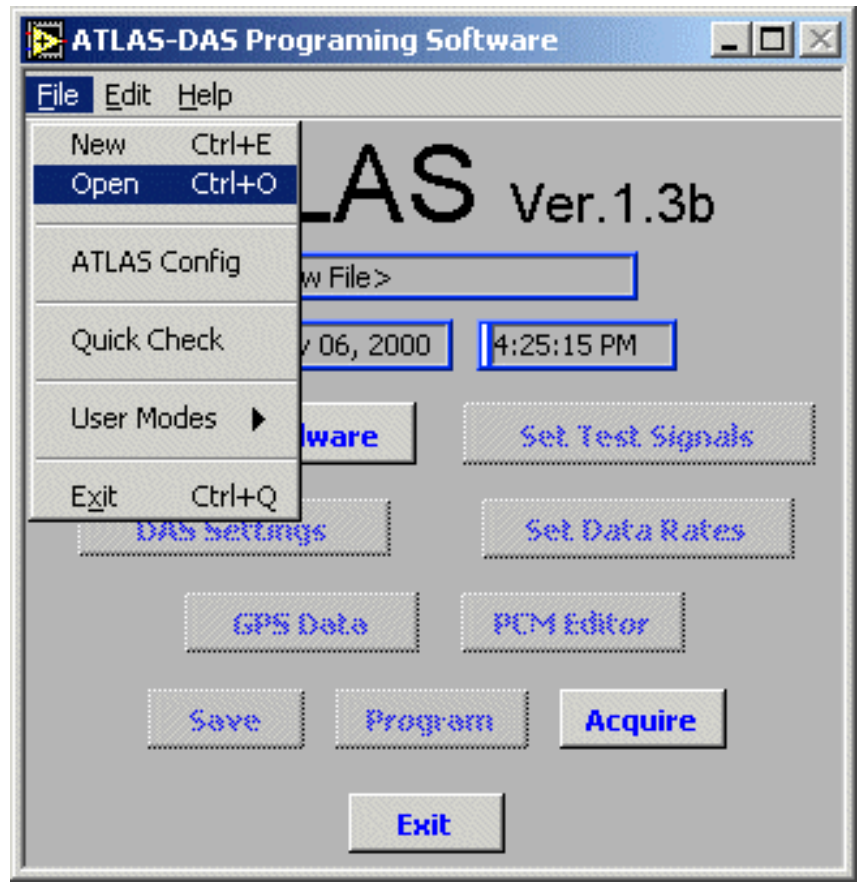

Figure 3-2. ATLAS Main Pull Down Menu.

\subsubsection{Creating a New *.PCM File}

The ATLAS software has been designed to generate the file in a systematic and easy way. The program will take you through a series of steps in order to accumulate all of the necessary information to generate the file. The first step in creating a new file is to configure the hardware. This can be done by clicking on the Configure Hardware button, shown in Figure 3-1.

\subsubsection{Configuring the Hardware}

Click on the Configure Hardware button to open the Configure DAS Channels window. In this window, you can select the mainframe size and the modules being used; see Fig 
ures 3-3 and 3-4 for examples. ATLAS can be configured for a 3-, 6-, or 9-slot unit. Any supported modules can be placed within the mainframe. Refer to Tables 2-1 through 2-5 for a list of supported modules.

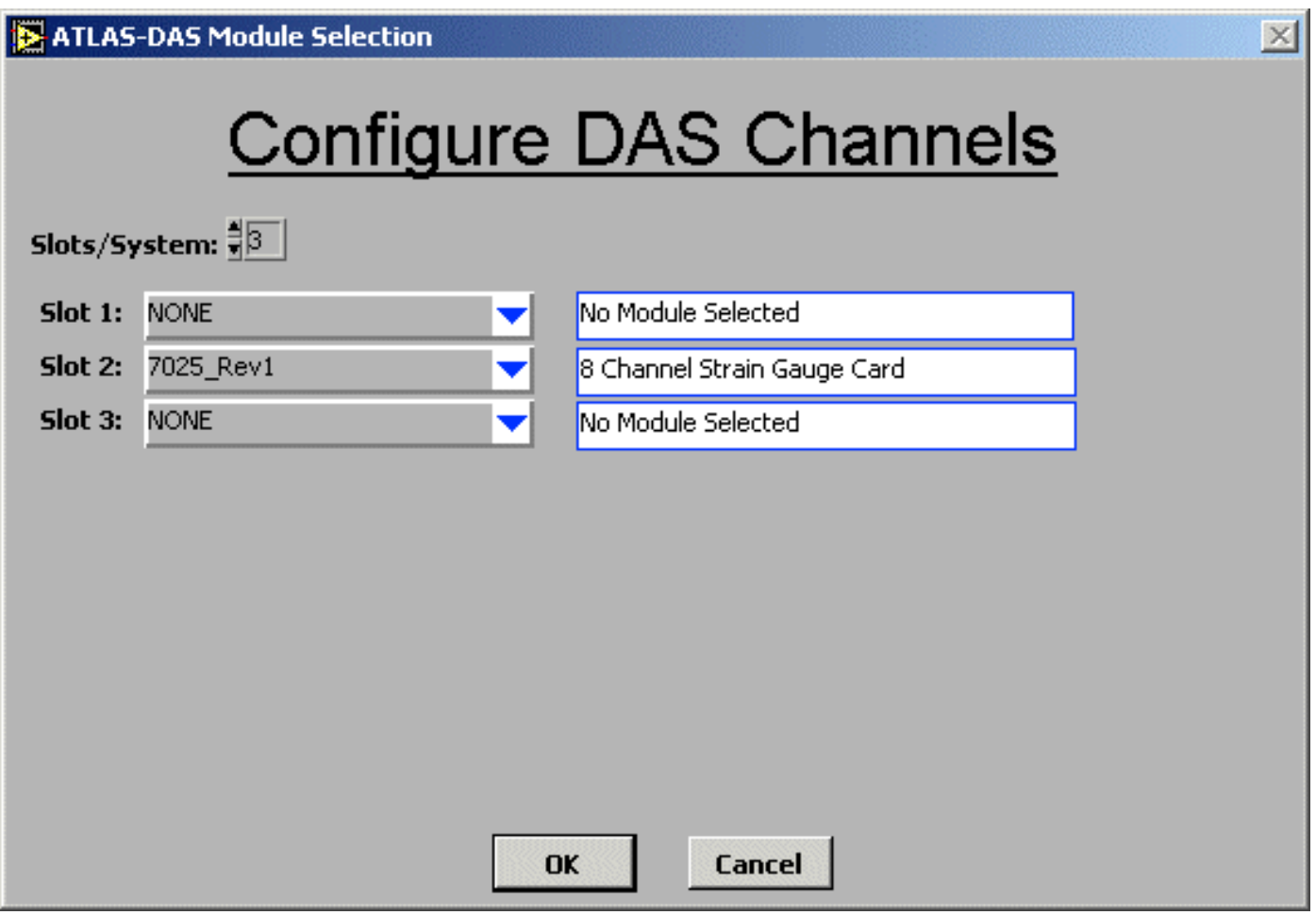

Figure 3-3. Configure DAS Channels Window.

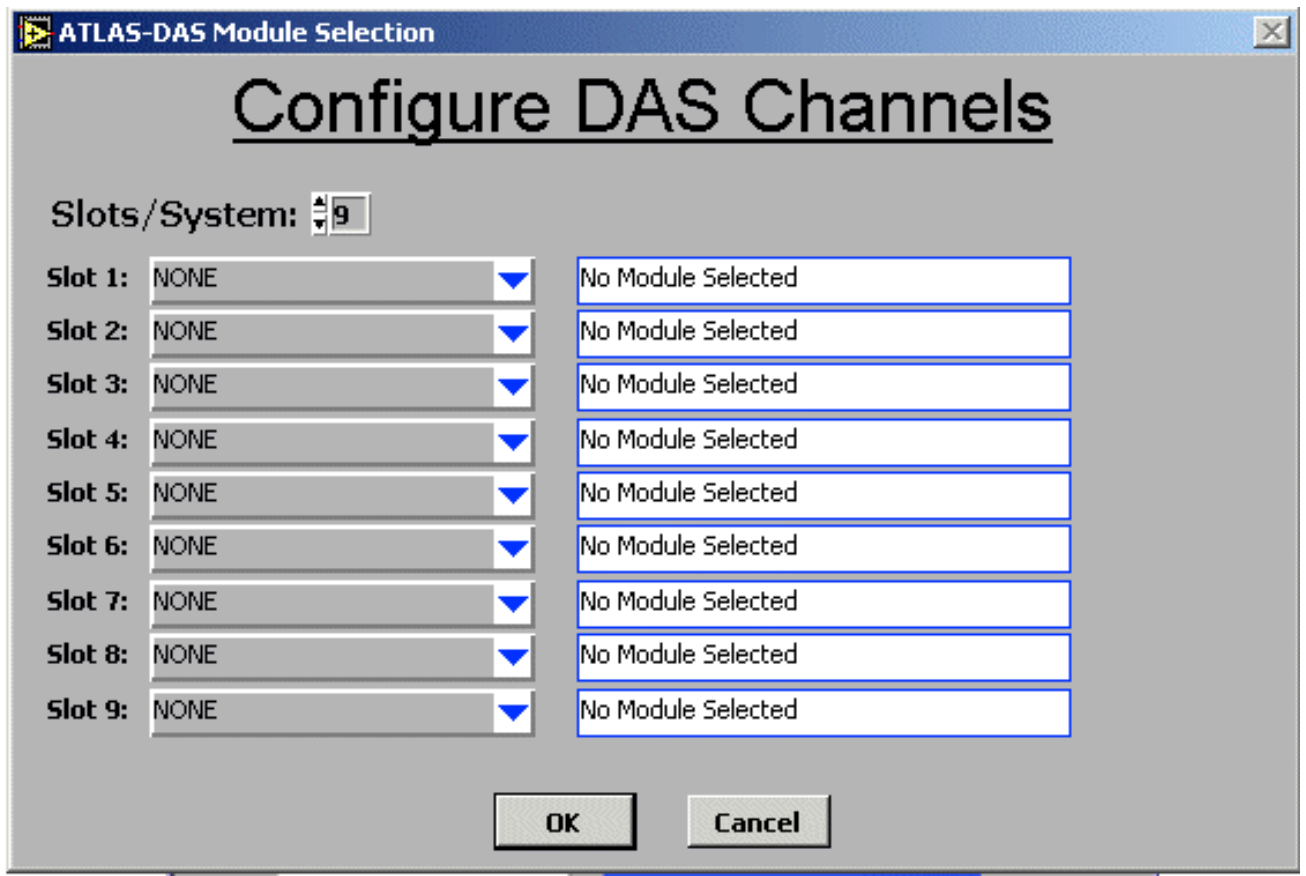

Figure 3-4. ATLAS 9-Slot Systems Configuration. 
Select the size of the DAS, and then select the module placed in each slot of the unit. Figure 3-5 displays a list of supported modules. See Tables 2-1 through 2-5 for more information on the available modules.

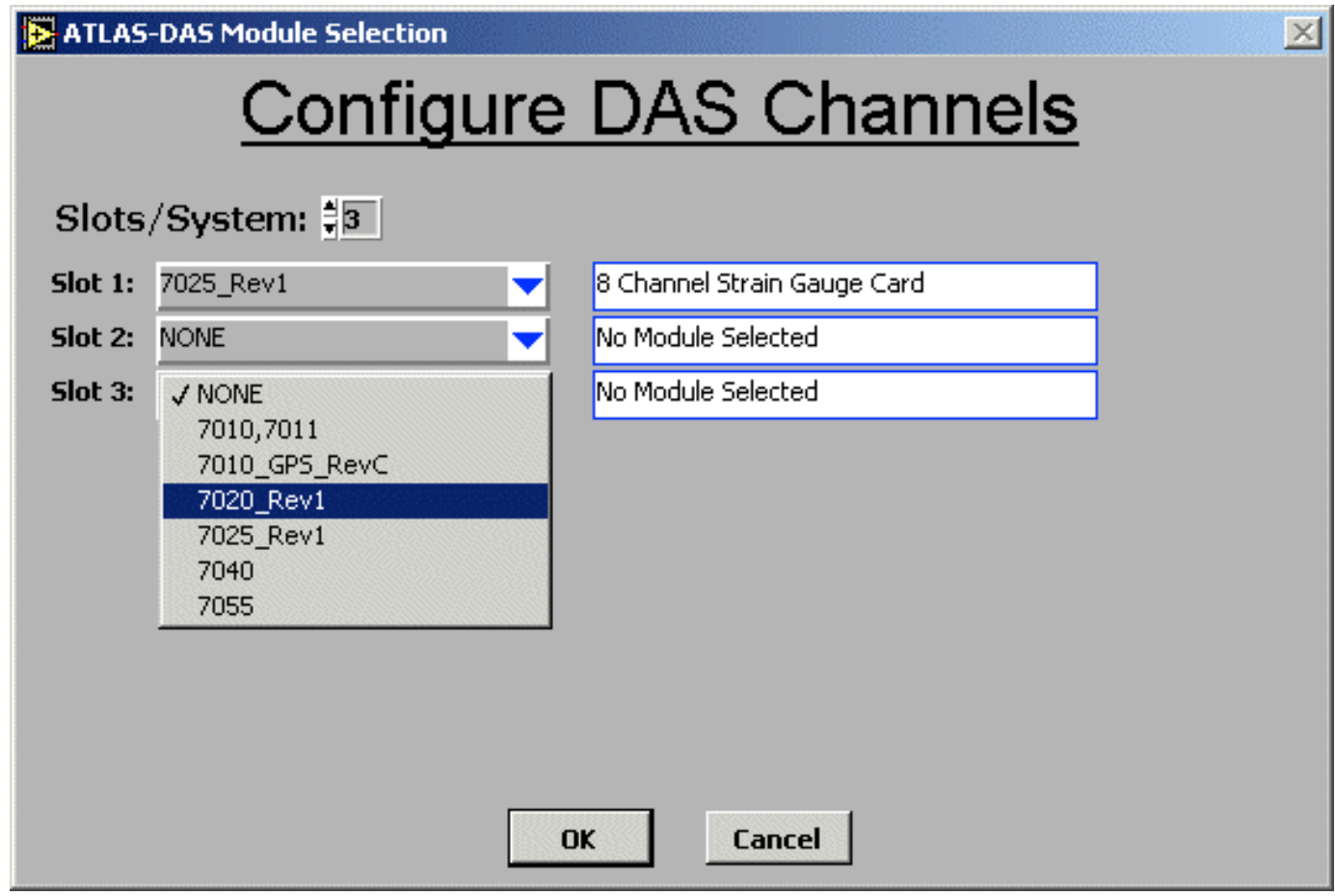

Figure 3-5. List of Supported Modules.

\section{Slave Units}

The ATLAS software also supports a system consisting of several units. In this configuration, the Master must be specified. The other units in the systems are referred to as Slave units. Note that in Figure 3-6, module 7055 (Slave/Merger Card) has been selected for slot 6; see Table 2-4 for further information. If the 7055 is selected, as shown in Figure 3-6, a Setup Slave button appears with an LED to its left. Until the Setup Slave button is selected and the configuration information for the slave is complete, the indicator next to "Slave Merger Card" will appear red. This indicates that the slave DAS unit for that slot has not been set up.

From here you can click on the Setup Slave button to configure that unit. This will bring up the Configure DAS Slave window, shown in Figure 3-7. The slave can also be configured for up to a 9-slot system. Only in this window can a slave be selected. After the slave system has been set up, click the $\mathbf{O K}$ button to go back to the main Configure DAS Channels window. If the slave unit was set up properly, the LED will be green and the word Done will appear. Figure 3-8 gives an example of a successful configuration. 


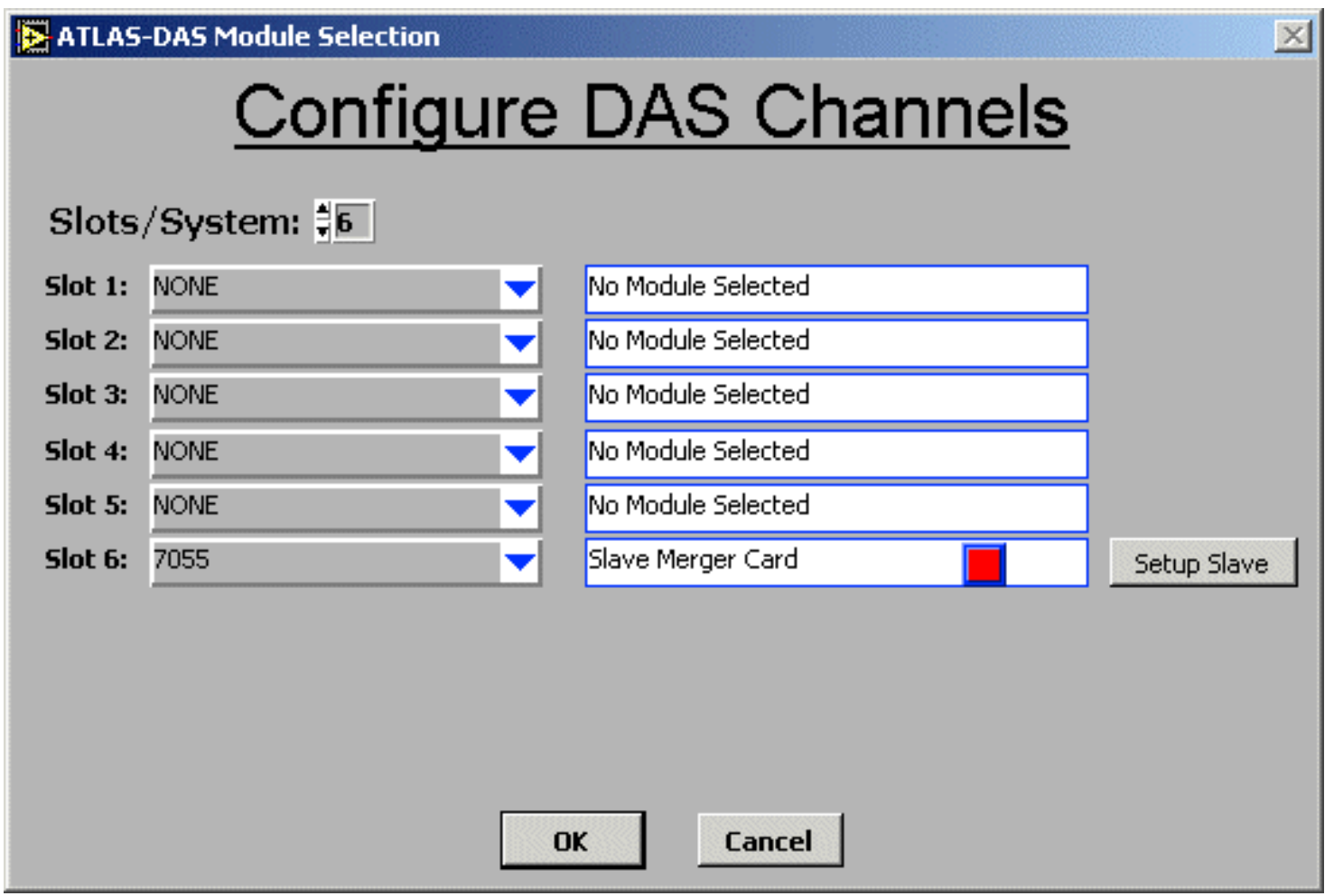

Figure 3-6. Setting up a Slave Unit.

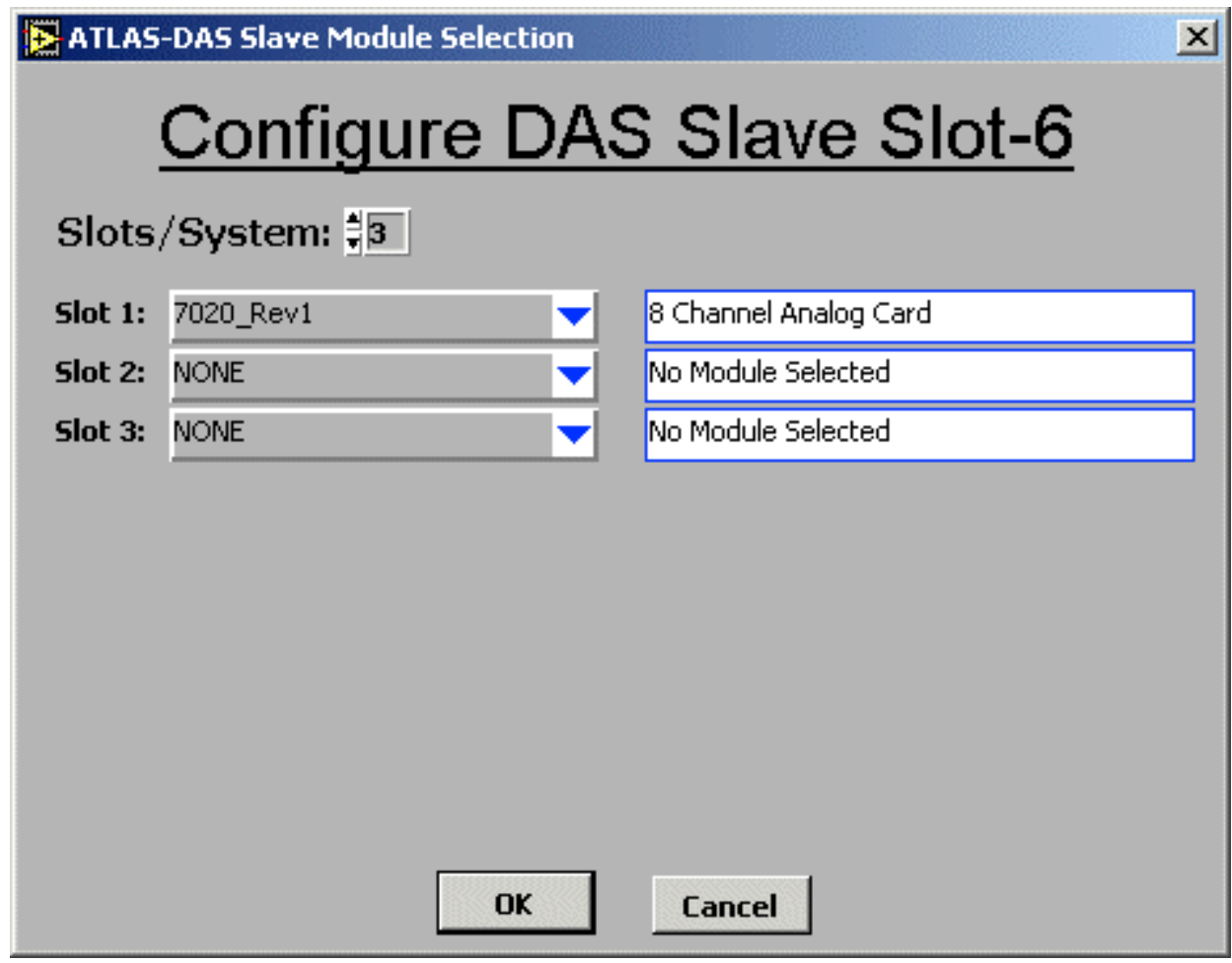

Figure 3-7. Configure the Slave System. 


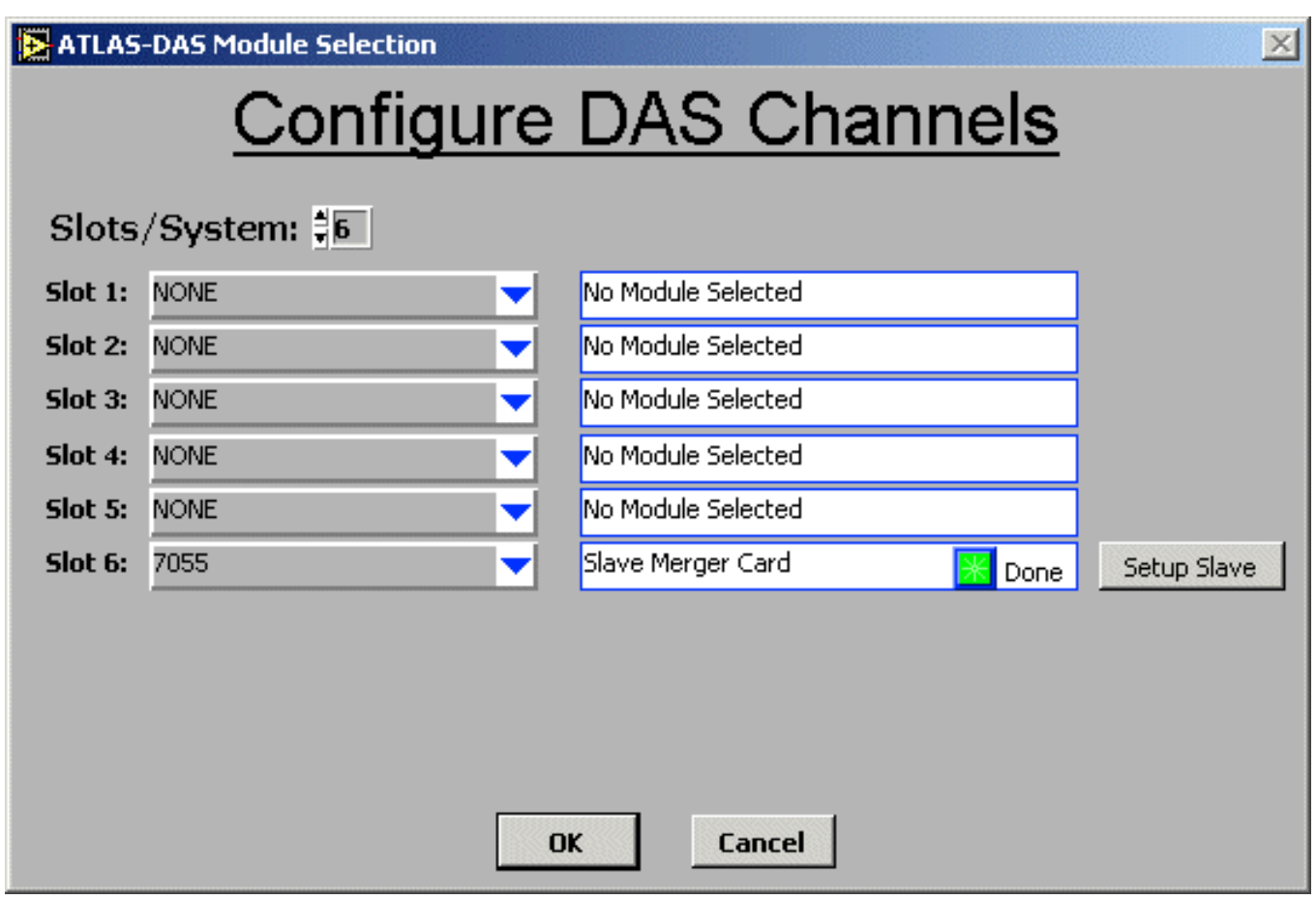

Figure 3-8. Slave Unit in Slot 6 has been Properly Configured.

When all of the necessary modules have been selected and the slave units have been configured (if applicable), click on the OK button. The program will then return to the ATLAS main window, as Figure 3-9 shows. Now that the hardware has been configured, the DAS Settings button is highlighted. Click on the DAS Settings button to set some of the hardware specifics.

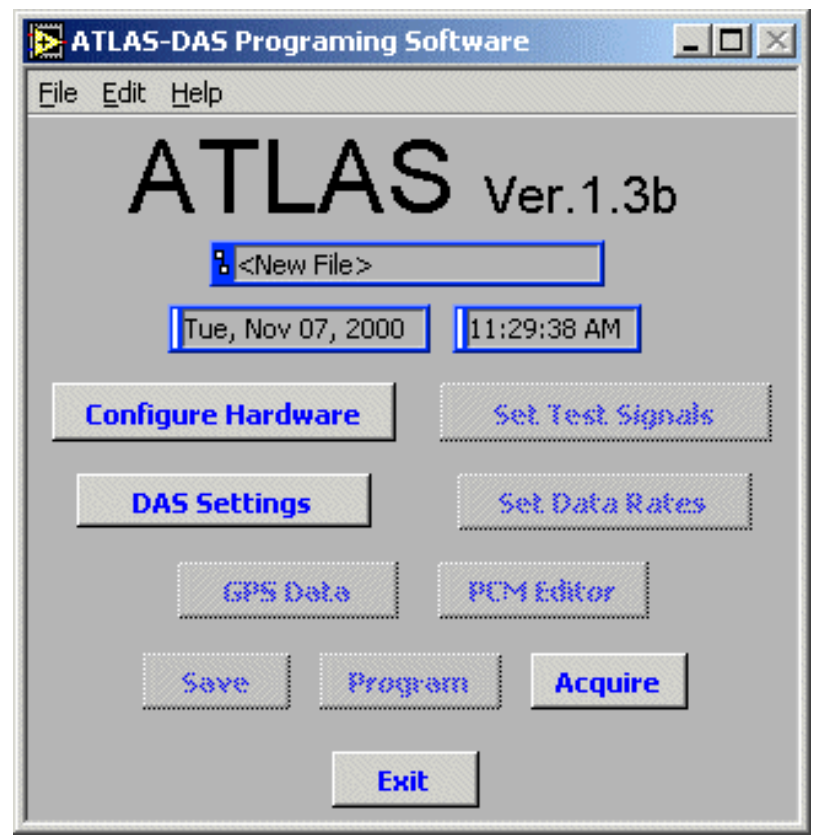

Figure 3-9. DAS Settings button is now highlighted. 


\subsubsection{Specifying DAS Settings}

After clicking the DAS Setting button, the DAS Settings window will appear, illustrated in Figure 3-10. In this window, the data word size, the sync word, and the type of data encoding (NRZ-L or Bi-phase) can be set. In general, the default settings are adequate for most configurations. All of these settings, except for the communication, apply to all DAS units. If a Slave unit was selected during the configuration of the hardware and if the communication for that unit differs from the Master, a different communication protocol can be specified for that unit, as shown in Figure 3-11. In general, RS-422 can be utilized to transfer data over distances of up to $1 \mathrm{~km}$, while TTL should be utilized only if the data transfer distance does not exceed $20 \mathrm{ft}$ or if data is being transferred via telemetry (see Table 3-1 for setting details).

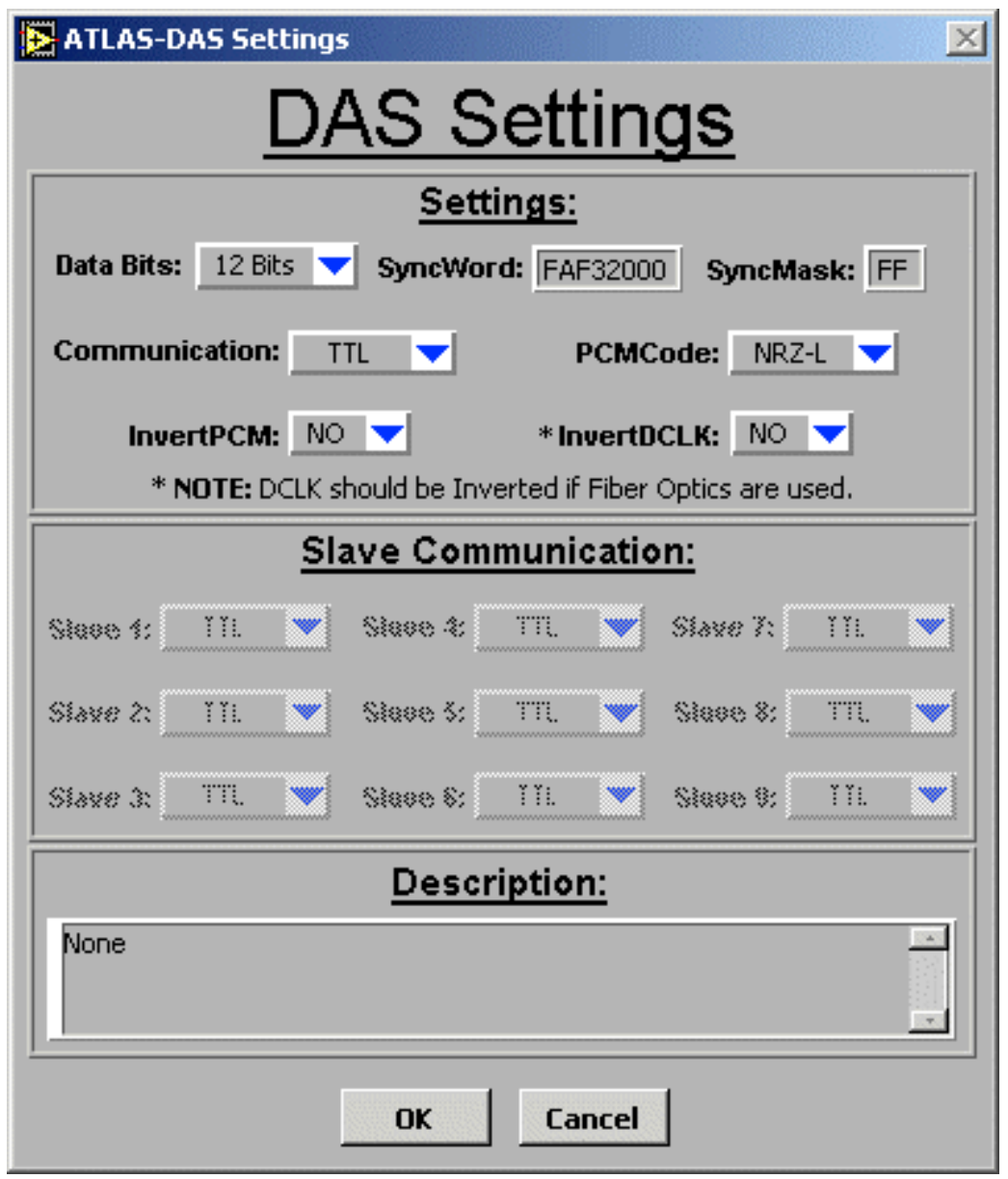

Figure 3-10. DAS Settings Window.

After all of the settings have been chosen, click the OK button. The program will then return you to the ATLAS main window. Now that the hardware settings have been specified, the Set Test Signals button, seen in Figure 3-12, is highlighted. Click on the Set Test Signals button. 


\section{Table 3-1. DAS Settings Description}

1. Data Bits (x) - Pertains to the default word size in each frame (12 or 16 bits)

2. Communication (x) - Data transfer protocol (RS-422 or TTL)

3. InvertPCM - Invert the PCM stream signal (Yes or No)

4. PCMCode - PCM code protocol (NRZ-L or BIO-L)

5. InvertDCLK - Invert clock (Yes or No)

6. Syncword - Dependant on Data Bits (Fixed Value)

7. SyncMask - Dependant on Data Bits (Non-user Input)

8. Slave Communication (x)- RS-422 or TTL (can differ from master communication)

9. Description (x) - PCM file description, up to 255 characters

$\mathrm{X}$ - only items normally changed by the user

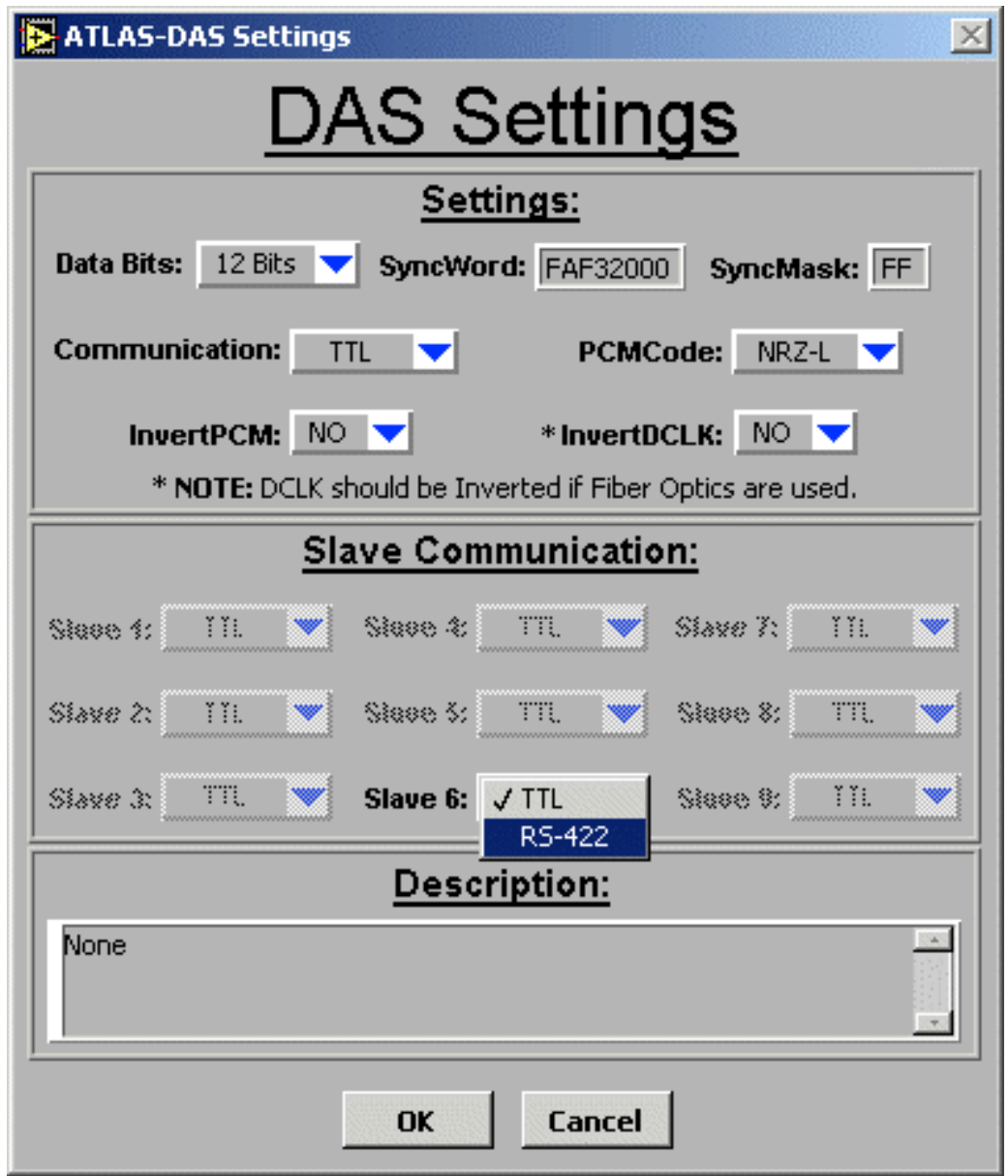

Figure 3-11. Slave Unit Communication Setup. 


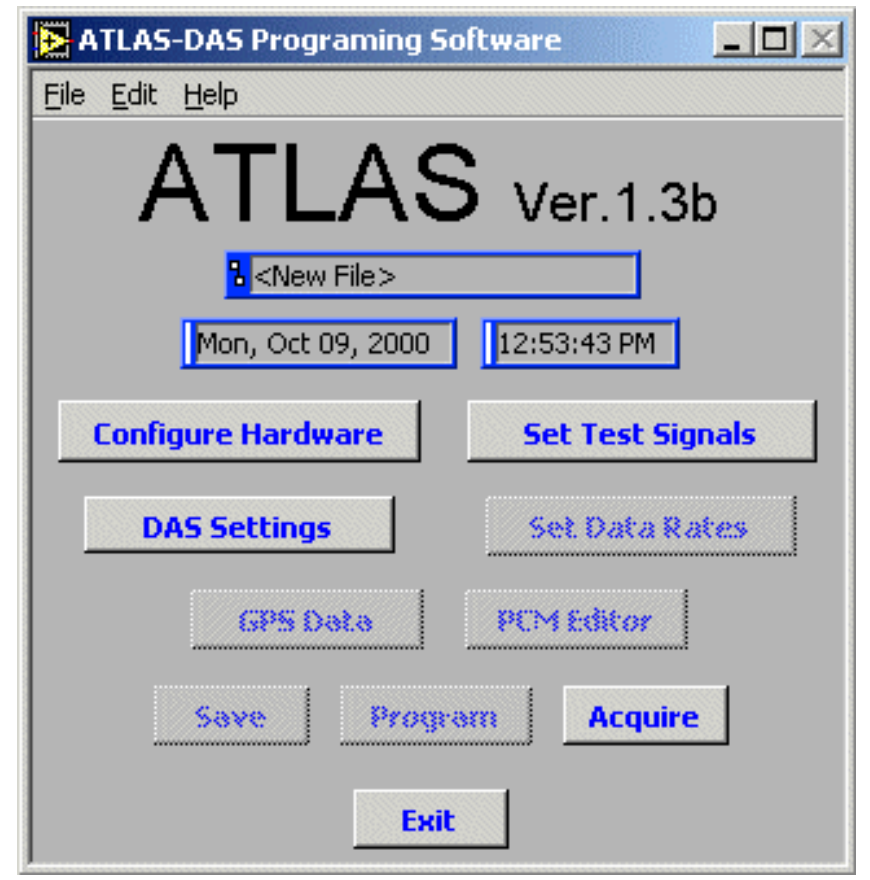

Figure 3-12. Set Test Signal Button is now Highlighted.

\subsubsection{Setting the Test Signals}

After clicking on the Set Test Signals button, the Set Test Signals window will appear, as shown in Figure 3-13. In this window, the user specifies the specific channels and channel settings that are needed for the particular data acquisition application. Signals may be created, edited, or deleted.

\section{Creating a Signal}

1. Name the signal.

2. Select the appropriate module (see Figure 3-14).

3. Specify the appropriate settings for the module selected.

4. Specify the calibration factors (optional).

5. Click on the Save button.

\section{NOTE}

After a signal is saved, click the New button in order to add another signal to the database. Repeat steps $1-5$ to save the next signal. 


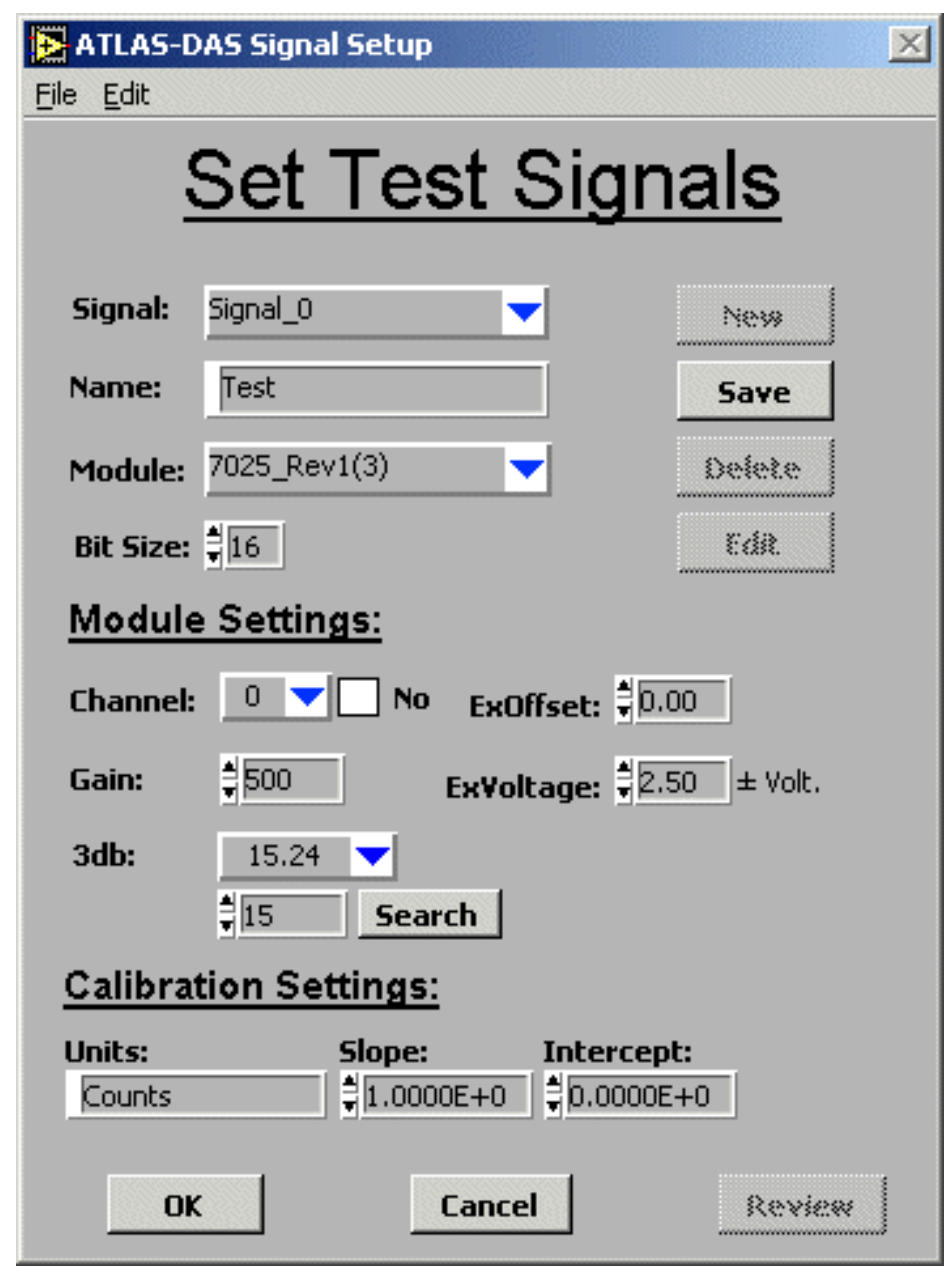

Figure 3-13. Set Test Signals Window.

\section{NOTE}

A signal can be added in between two existing signals. This can be done by selecting the signal before the location of the new one. For example: If a signal is going to be added between signal 4 and 5, select signal 4 and click on the New button. Repeat steps 1-5 to save the next signal.

\section{Editing a Signal}

1. Select the appropriate signal to be edited.

2. Click the Edit button.

3. Modify parameters as needed.

4. Click the Save button. 


\section{Deleting a Signal}

1. Select the signal to be deleted.

2. Click the Delete button.

The Set Test Signals window performs many functions. These functions are explained in Table 3-2.

At any given point, the signals that have been specified and saved, as shown in Figure $3-15$, can be viewed by clicking on the Review button. This window saves a summary of the signals that have been saved and the specific settings pertaining to that signal. If a mistake is spotted, changes can be made by returning to the Set Test Signals window and editing that specific signal.

After all of the signals have been set and saved, click the OK button. The ATLAS main window will appear, as shown on Figure 3-16.

Table 3-2. Set Test Signals Function Table

\begin{tabular}{|c|c|}
\hline Function & Description \\
\hline Signal & The current signal (signal 0 cannot be deleted). \\
\hline Name & $\begin{array}{l}\text { Name of the signal. } 25 \text { characters maximum (no spaces or special } \\
\text { characters). }\end{array}$ \\
\hline Module & $\begin{array}{l}\text { This is a list of the modules selected in the Configure DAS Chan- } \\
\text { nels window set previously. Slave modules are indented and } \\
\text { clearly marked so you can discern the difference (see Figure 3-14). }\end{array}$ \\
\hline New & Creates a new signal. \\
\hline Save & $\begin{array}{l}\text { Saves current signal. NOTE: All signals must be saved. If a signal } \\
\text { is not saved and the user exits this window, the data for that signal } \\
\text { will be lost. }\end{array}$ \\
\hline Delete & Deletes an existing signal. \\
\hline Edit & $\begin{array}{l}\text { Edits an existing signal. The signal must be saved before it can be } \\
\text { edited. }\end{array}$ \\
\hline Module Settings & $\begin{array}{l}\text { Changes dynamically, based on module selected. Depending on the } \\
\text { module selected, different input options will appear. }\end{array}$ \\
\hline $\begin{array}{l}\text { Calibration } \\
\text { Settings }\end{array}$ & $\begin{array}{l}\text { This feature only appears for the } 7025 \text { and the } 7020 \text { module (see } \\
\text { Tables } 2-2 \text { and 2-3). You can specify calibration factors for a spe- } \\
\text { cific channel. These are saved in the *.pcm file so other programs, } \\
\text { such as ADAS II or ATLAS DAQ, can retrieve them to convert the } \\
\text { data from counts to Engineering units. NOTE: If the default values } \\
\text { are used, the data will appear in counts. }\end{array}$ \\
\hline
\end{tabular}




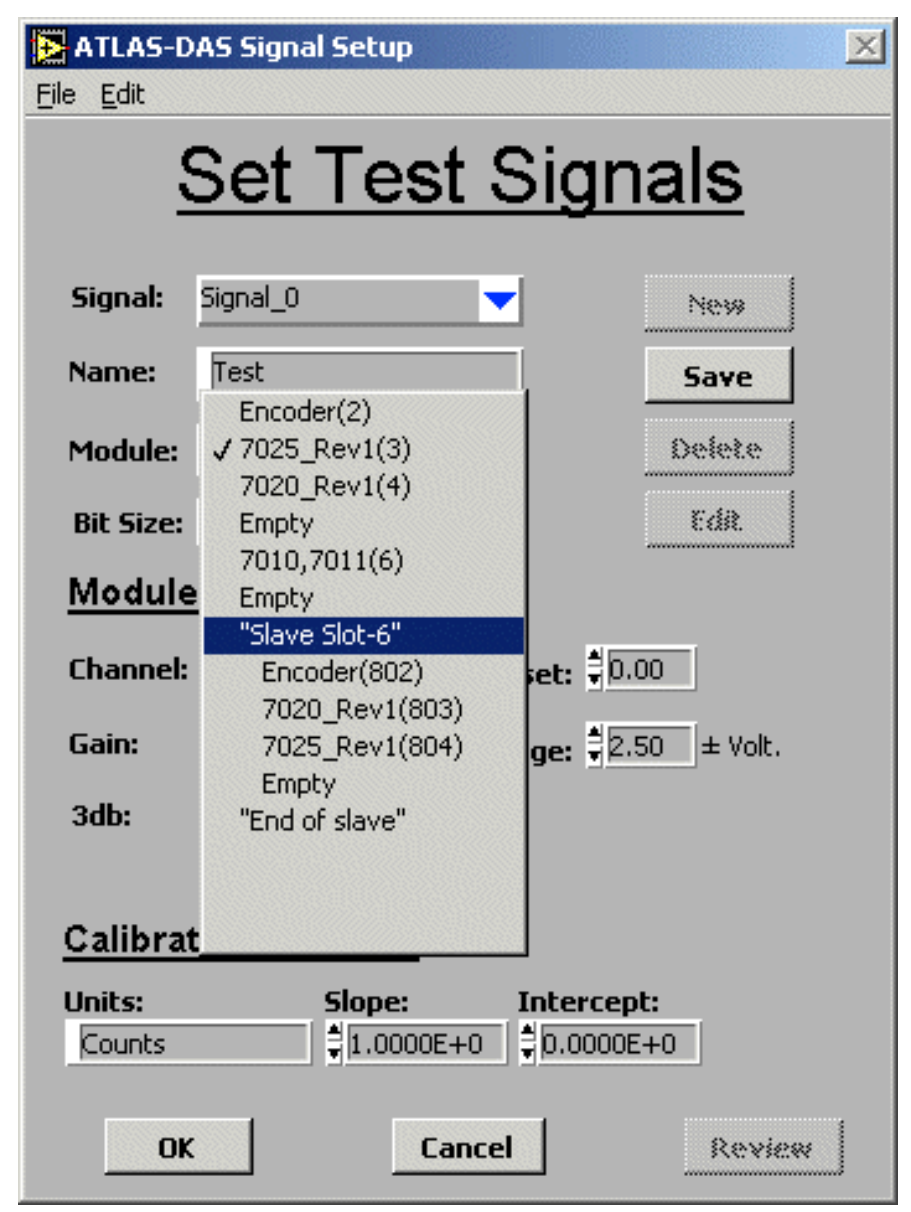

Figure 3-14. Preselected Module List.

After all signals have been specified, the last key component of the configuration definition is the specification of the data rate. Click on the DAS Data Rates button and the window shown in Figure 3-17 will appear.

\subsubsection{Setting the Data Rate}

In the DAS Data Rates window, specify the data rate at which the channels will be sampled.

\section{NOTE}

All channels are sampled at the same rate.

After the desired data rate is entered, the software computes the closest data rate that can actually be realized, given the number of bits being acquired for each sample and the internal $8 \mathrm{MHz}$ clock. In general, this rate is slightly higher than the user-specified rate. In the example in Figure 3-17, the user has requested a $30 \mathrm{~Hz}$ sample rate. The actual rate, based on the $8 \mathrm{MHz}$ clock and 74 channels of 16-bit data, is $30.03 \mathrm{~Hz}$. 


\begin{tabular}{|c|c|c|c|c|c|c|}
\hline Signal & Name & Module & Setting 1 & Setting 2 & Setting 3 & Setting 4 \\
\hline Signal_0 & Master_1234 & Encoder(2) & Value $=1234$ & Counts & $1.000000 \mathrm{e}+00$ & $0.000000 \mathrm{e}+00$ \\
\hline Signal_1 & BTBFA & 7025_Rev1(6) & Channel $=0$ & Gain $=500$ & $3 \mathrm{db}=1.524000 \mathrm{E}+1$ & ExVoltage $=5.000 \mathrm{C}$ \\
\hline Signal_2 & BTBSS & 7025_Rev1(6) & Channel=1 & Gain $=500$ & $3 \mathrm{db}=1.524000 \mathrm{E}+1$ & ExVoltage $=5.000 \mathrm{C}$ \\
\hline Signal_3 & BTAFA & 7025_Rev1(6) & Channel=2 & Gain $=500$ & $3 \mathrm{db}=1.524000 \mathrm{E}+1$ & Ex Woltage $=5.000 \mathrm{C}$ \\
\hline Signal_4 & BTASS & 7025_Rev1(6) & Channel=3 & Gain $=500$ & $3 \mathrm{db}=1.524000 \mathrm{E}+1$ & Ex Woltage $=5.000 \mathrm{C}$ \\
\hline Signal_5 & M_GPS-hrmin & 7010_GPS_RevC(8) & Status_Word & Group $=0$ & Counts & $1.000000 \mathrm{e}+00$ \\
\hline Signal_6 & M_GPS-sec & 7010_GPS_RevC(8) & Status_Word & Group $=1$ & Counts & $1.000000 \mathrm{e}+00$ \\
\hline Signal_7 & M_GPS-msec & 7010_GPS_RevC(8) & Status_Word & Group $=2$ & Counts & $1.000000 \mathrm{e}+00$ \\
\hline Signal_8 & M_GPS-year & 7010_GPS_RevC(8) & Status_Word & Group $=3$ & Counts & $1.000000 \mathrm{e}+00$ \\
\hline Signal_9 & Slave_2345 & Encoder(302) & Value $=2345$ & Counts & $1.000000 \mathrm{e}+00$ & $0.000000 \mathrm{e}+00$ \\
\hline Signal_10 & BACTATIU & 7020_Rev1(303) & Channel $=0$ & Gain $=1$ & $3 \mathrm{db}=1.524000 \mathrm{E}+1$ & Exoffset $=0.00000$ \\
\hline Signal_11 & BACTATIV & 7020_Rev1(303) & Channel=1 & Gain $=1$ & $3 \mathrm{db}=1.524000 \mathrm{E}+1$ & ExOffset $=0.0000$ \\
\hline Signal_12 & BACTATIW & 7020_Rev1(303) & Channel=2 & Gain=1 & $3 \mathrm{db}=1.524000 \mathrm{E}+1$ & ExOffset $=0.00000$ \\
\hline Signal_13 & BACTATIT & 7020_Rev1(303) & Channel=3 & Gain $=1$ & $3 \mathrm{db}=1.524000 \mathrm{E}+1$ & ExOffset $=0.00000$ \\
\hline Signal_14 & BACCATIU & 7020_Rev1(303) & Channel=4 & Gain=1 & $3 \mathrm{db}=1.524000 \mathrm{E}+1$ & ExOffset $=0.00000$ \\
\hline Signal_15 & BACCATIV & 7020_Rev1(303) & Channel=5 & Gain $=1$ & $3 \mathrm{db}=1.524000 \mathrm{E}+1$ & ExOffset $=0.0000$ \\
\hline Signal_16 & BACCATIW & 7020_Rev1(303) & Channel $=6$ & Gain $=1$ & $3 \mathrm{db}=1.524000 \mathrm{E}+1$ & ExOffset $=0.0000$ \\
\hline Signal_17 & BACCATIT & 7020_Rev1(303) & Channel=7 & Gain $=1$ & $3 \mathrm{db}=1.524000 \mathrm{E}+1$ & ExOffset $=0.0000$ \\
\hline Signal_18 & BACBATIU & 7020_Rev1(304) & Channel $=0$ & Gain $=1$ & $3 \mathrm{db}=1.524000 \mathrm{E}+1$ & ExOffset $=0.00000$ \\
\hline Signal_19 & BACBATIV & 7020_Rev1(304) & Channel=1 & Gain $=1$ & $3 \mathrm{db}=1.524000 \mathrm{E}+1$ & ExOffset $=0.00000$ \\
\hline Signal_20 & BACBATIW & 7020_Rev1(304) & Channel=2 & Gain $=1$ & $3 \mathrm{db}=1.524000 \mathrm{E}+1$ & ExOffset $=0.00000$ \\
\hline Signal_21 & BACBATIT & 7020_Rev1(304) & Channel=3 & Gain=1 & $3 \mathrm{db}=1.524000 \mathrm{E}+1$ & ExOffset $=0.00000$ \\
\hline \multicolumn{7}{|l|}{4} \\
\hline
\end{tabular}

Figure 3-15. Complete Listing of Signals.

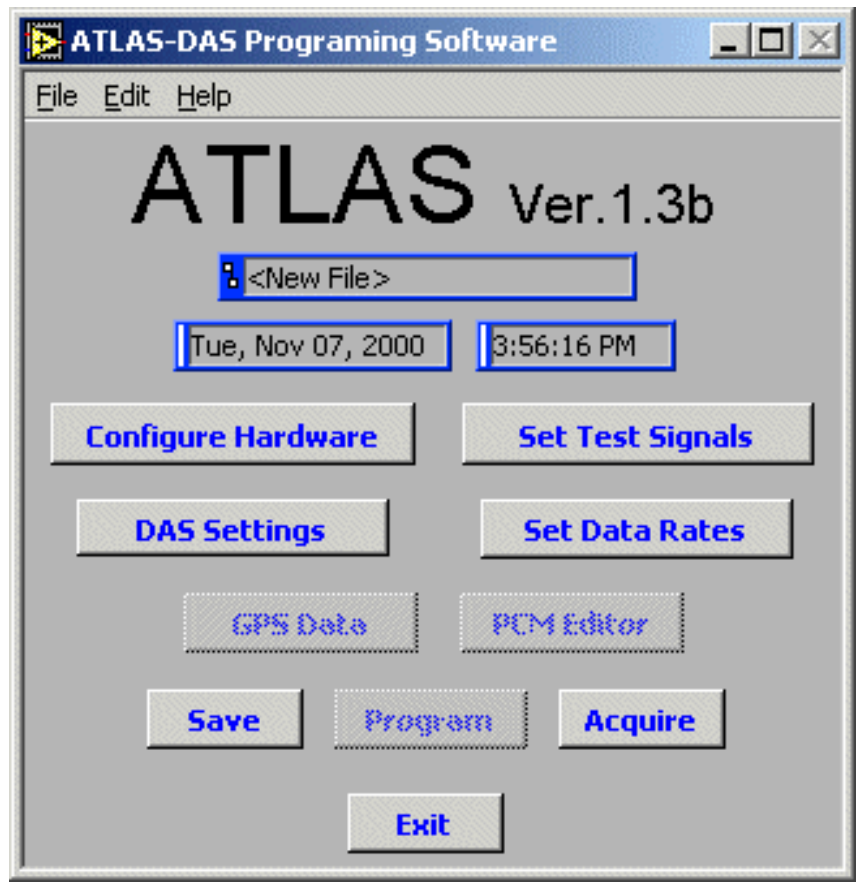

Figure 3-16. Set Data Rates Button is now Highlighted. 


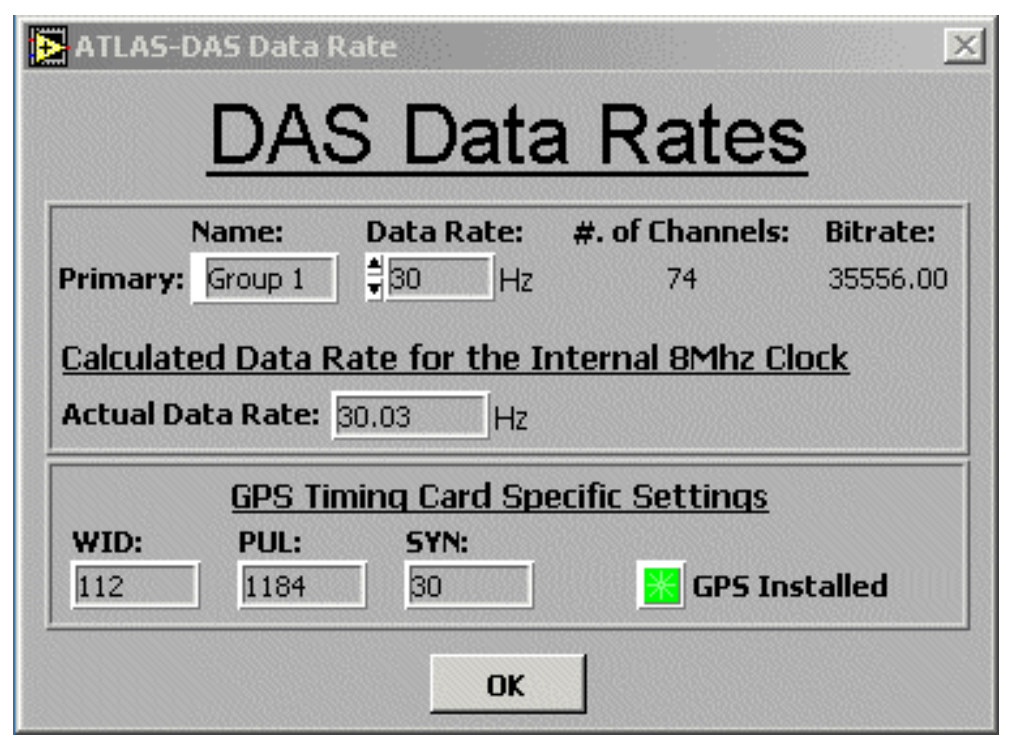

Figure 3-17. DAS Data Rates Window.

GPS Specific Settings

If a GPS Module was selected in the Configure DAS Channels window, indicated in Figure 3-5, the program automatically detects it and calculates the settings for the module to produce the data rate selected. The data rate is used to specify the pulse train characteristics. The WID, PUL, and SYN settings cannot be modified manually; they are for user information only. After the data rate has been specified, click the OK button to go back to the main window, shown in Figure 3-18.

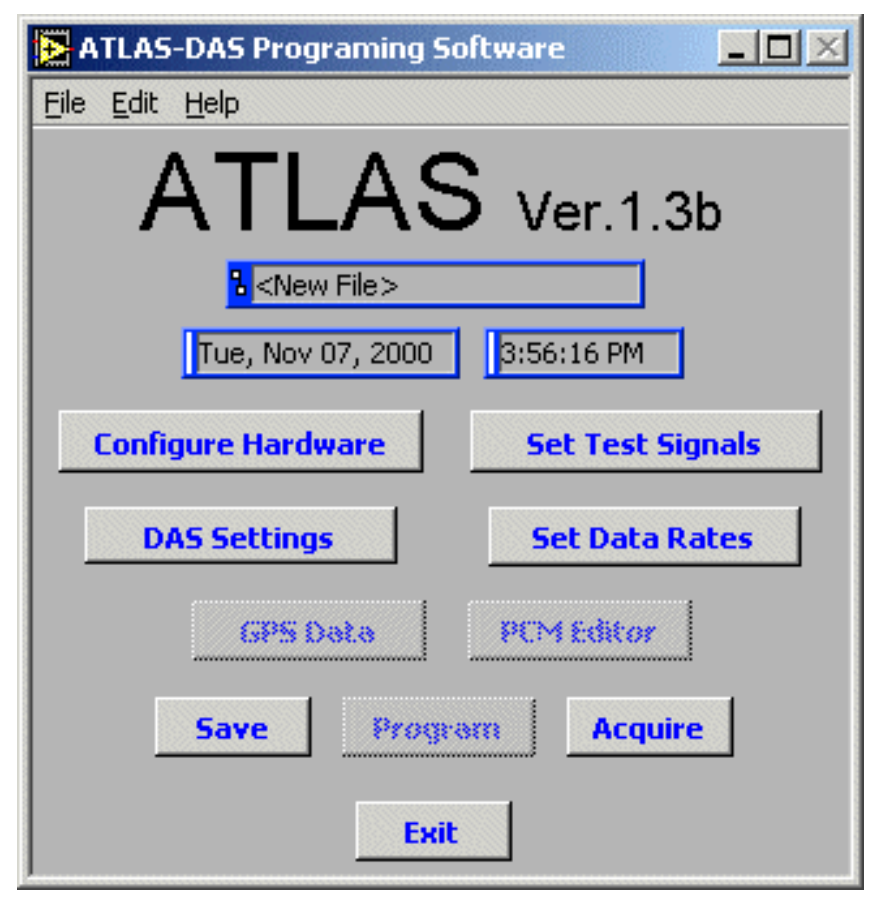

Figure 3-18. Save Button is now Highlighted. 
At this point all of the settings, signals, and data rate information have been set. The next step is to save the *.pcm file; this can be done by clicking on the Save button from the ATLAS main window. Clicking on the button will cause a browse window to appear. From here, you can select the name of the file and the location where the file is to be stored. After the file has been saved, the system is ready for programming.

\section{NOTE}

If an existing file is being modified, the file must be saved before the hardware is programmed.

\section{NOTE}

Advanced users can view the *.pcm file directly by clicking on the PCM Editor button, shown in Figure 3-19. This feature can be particularly useful if minor modifications need to be done to the file. It can also be used for debugging purposes. Keep in mind that if the manual modifications corrupt the file, the file is lost and cannot be read back into the ATLAS software.

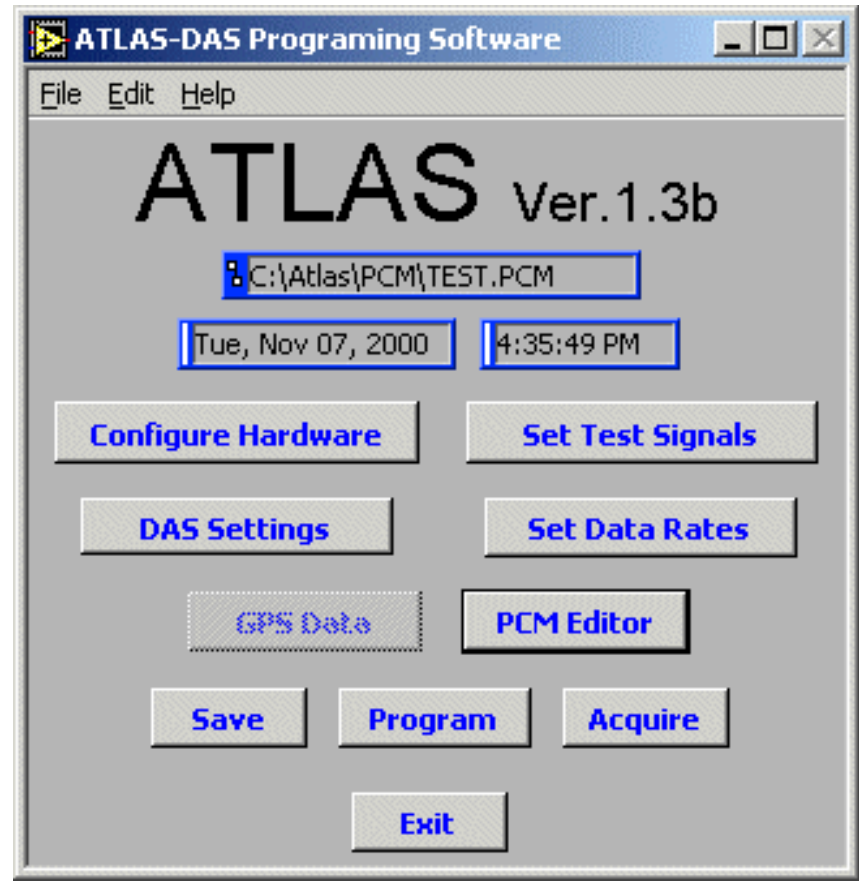

Figure 3-19. PCM Editor and Program Button are Highlighted.

\subsubsection{Programming the Hardware}

After the file has been saved, clicking on the Program button will program the hardware. 


\section{NOTE}

Be sure that the hardware is connected to the serial port before you program.

If the ATLAS system contains slave units (specified in the Configure DAS Channels window in Figure 3-6), a programming window will appear asking if you wish to program the entire system or a particular unit. Figures 3-20 and 3-21 display the programming options. This can be particularly useful if modifications were only done to one unit. In this case, connect the proper unit to the serial port, select the unit, and program.

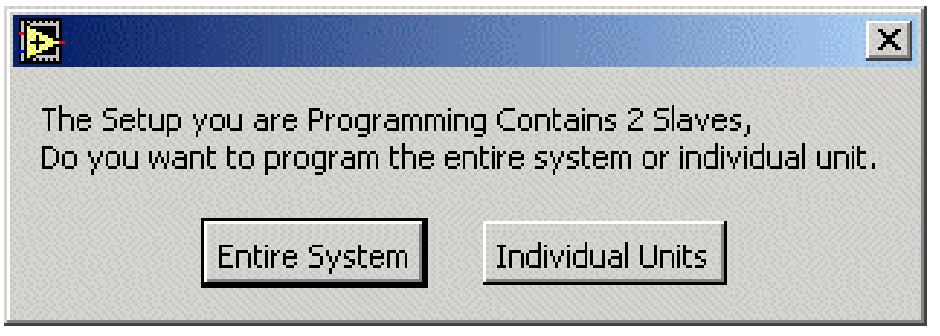

Figure 3-20. Programming Multiple Units.

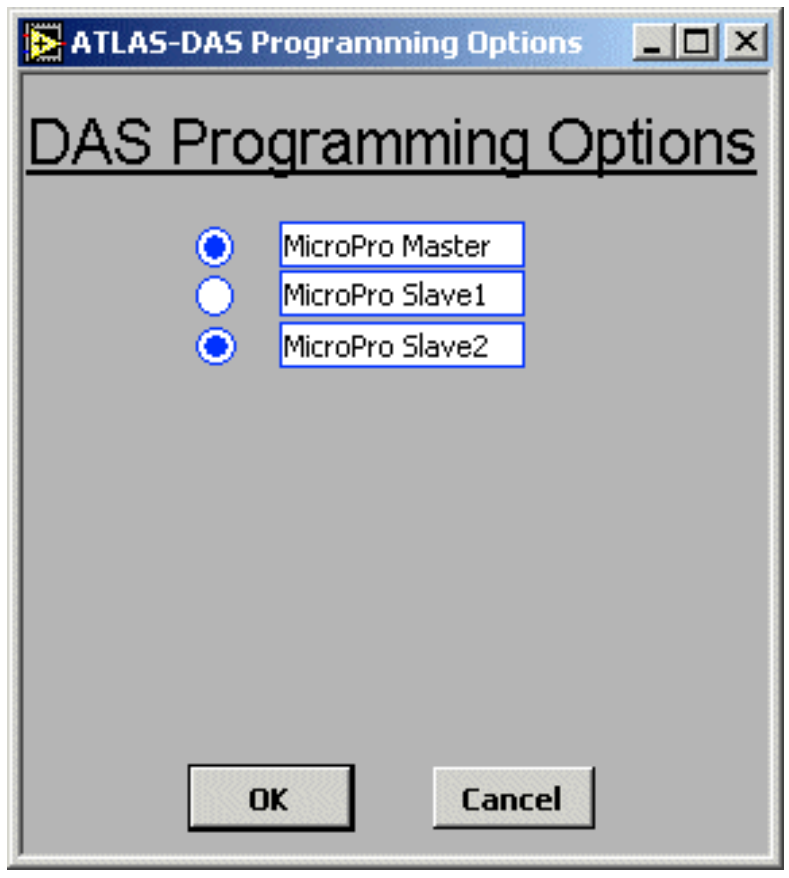

Figure 3-21. Programming Options.

If Entire System is selected, the software will sequentially program the system. The Master unit is always first. After it is done, the software will pause and ask the user to connect the next unit. The order of the programming is the same as the order in which the slave units were set up in the Configure DAS Channels window. 


\section{NOTE}

If the setup only contains one unit, the software will program that unit after the Program button is selected. In this case, the Option window will not appear.

\subsubsection{Other Software Features}

\subsubsection{GPS Data}

If the ATLAS system contains a PATSyM module, the software can be used to monitor the GPS data. In order to activate the GPS Data button in the main window, the *.pcm file in use must contain a GPS module or a GPS module must be selected from the Configure DAS Channels window, shown in Figure 3-5. If either of these conditions is met, the GPS Data button activates; see Figure 3-22 for an example. Clicking on this button brings up the GPS Communication window in Figure 3-23.

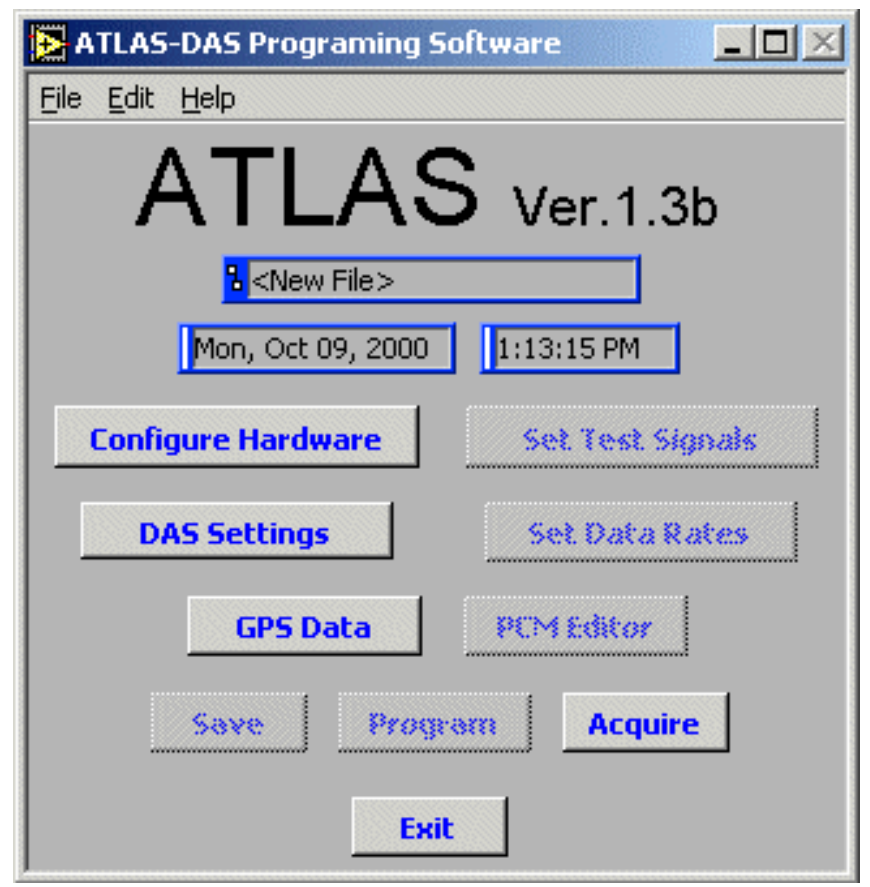

Figure 3-22. GPS Data Button is Highlighted.

\section{NOTE}

The GPS window contains no specific hardware settings; the hardware system can be properly configured without entering this window. If the ATLAS system contains a GPS module and is wired as recommended in Sections 2.7.3 and 2.7.4, this window must be accessed to turn off the GPS before the system can be programmed. See Appendix $\mathrm{B}$ and $\mathrm{C}$ for typical wiring schematics. 


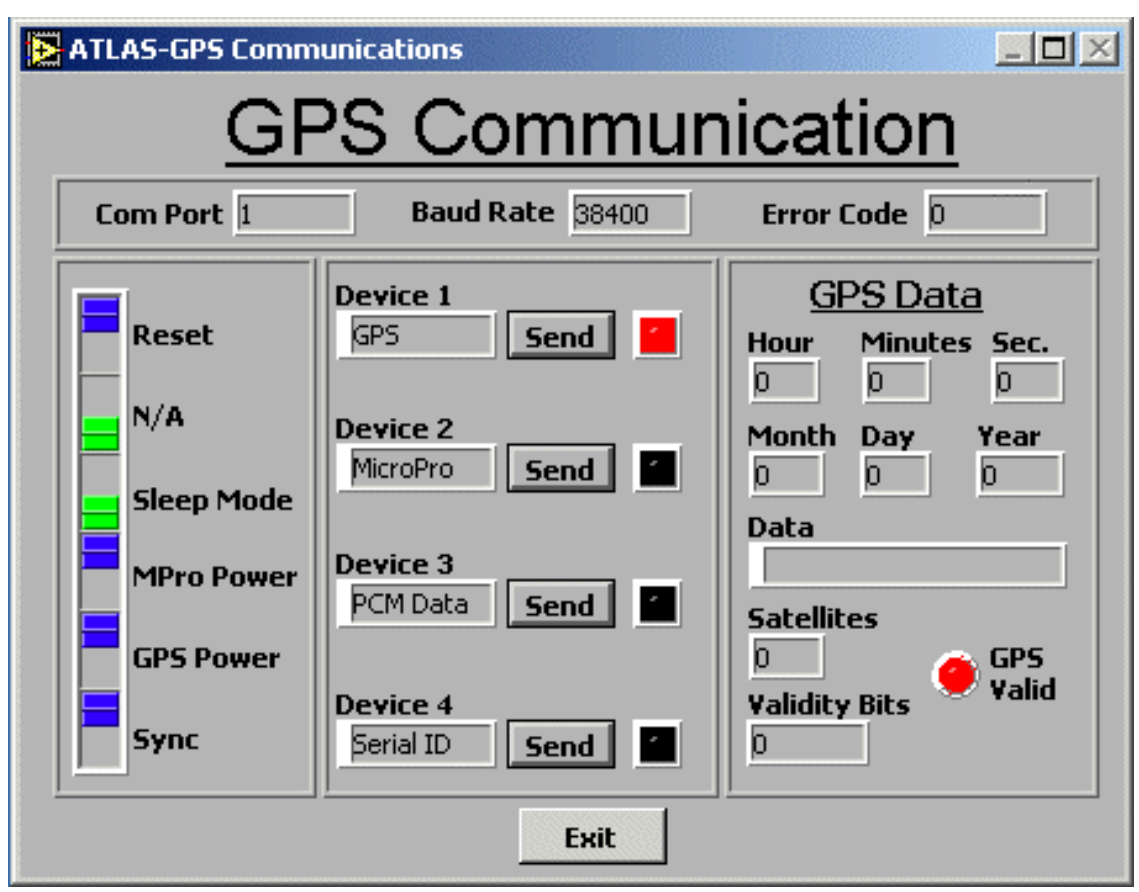

Figure 3-23. GPS Communication Window.

In the GPS window, you can monitor the timing information, the number of satellites in view, control the GPS module, and, most importantly, determine whether the GPS receiver has a valid solution and thus is locked to UTC. The "GPS Valid" LED will be green when the system is locked to UTC.

The GPS Communication window seen in Figure 3-23 can be broken down into four distinct parts. The top part contains the specific RS-232 settings and protocol. The software configures the computer serial port automatically; if any errors are detected sending or receiving serial commands, the error is flagged. In the left part of the window, a series of inline switches can be used to control the GPS device. The default setting should be used for most applications. In the center of the window, several commands can be sent to the PATSyM to select the operating mode. Device 1 turns on the GPS module; this is the default state of the module every time it is powered on. Device 2 sends a command that instructs the PATSyM to shut off the GPS communication and enable two-way user communication with the DAS. Devices 3 and 4 are features that are not supported at the moment, but will be supported at a later time.

\section{NOTE}

Device 2 should be selected prior to programming if the RS-232 communication goes though the GPS module (see Appendix C). 


\subsubsection{Data Acquisition Window}

The ATLAS software also contains a simple, yet powerful, data acquisition routine seen in Figure 3-24. It can be accessed with the Acquire button from the main window. See Figure 3-22 for an example.

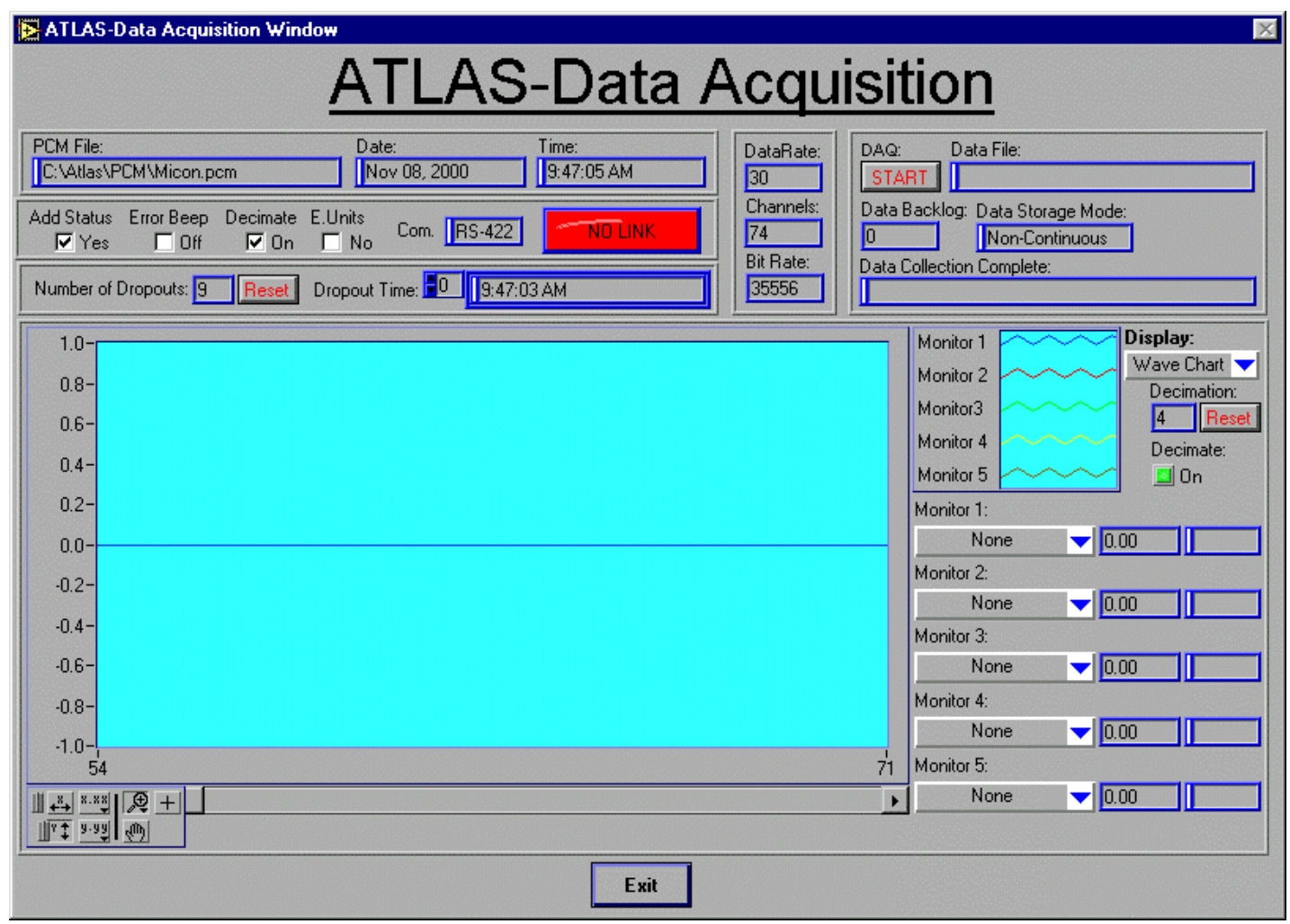

Figure 3-24. ATLAS Data Acquisition Window.

From the Data Acquisition window, you can monitor the hardware system. This program can be used to monitor data (up to five channels), acquire data (non-continuously), monitor the number of dropouts, and, most importantly, determine if the system is in lock or linked. The ATLAS data acquisition software can be divided into three sections, as Figure 3-25 indicates.

Section 1 consists of several minor sections. In Section 1, you can view the name of the current *.pcm file, the date, the current time, the communication protocol, the number of dropouts, and the status of the hardware (either "Link" or "No Link"). In this section several parameters can be set, such as Error Beep and Engineering units. By selecting the Add-Status option, the status of the hardware channel will be added to the data stream. This can be particularly useful in post-processing to determine if the data being processed is valid. The Error Beep option allows the user to hear if a dropout happened; this is useful in field testing. The Decimate function is used to decimate the data to avoid losing frames. If the computer processor speed is relatively slow, this is necessary to avoid losing data frames. The last option, E. Units, is used to convert the raw counts to engineering units. 


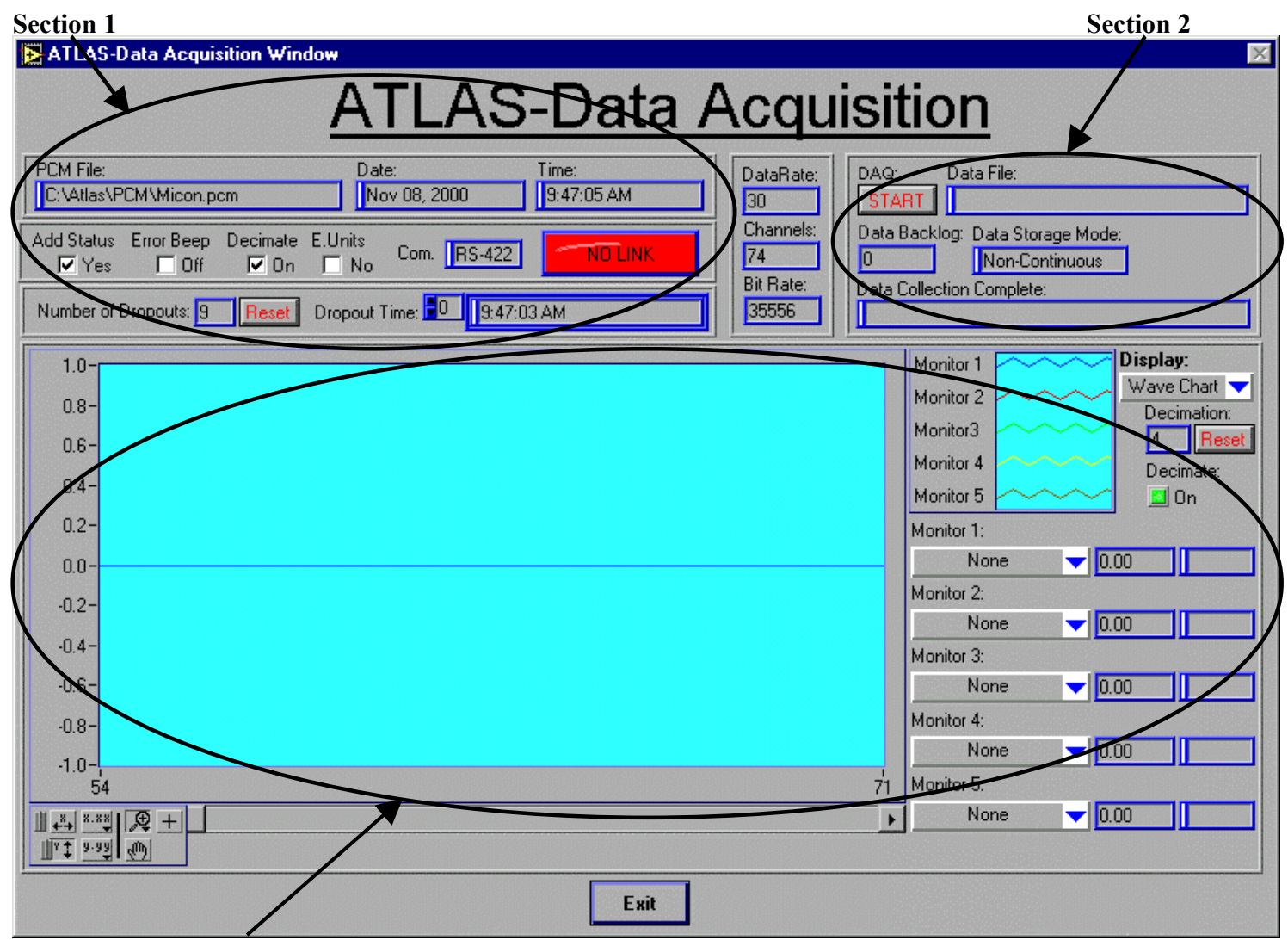

Section 3

Figure 3-25. ATLAS Data Acquisition Window Sections.

\section{NOTE}

E. Units only works if the engineering units were set during the channel selection process, given in Figure 3-13.

Section 2 consists of data acquisition routines. Clicking on the Start button will take you through a series of steps to set up acquisition.

\section{NOTE}

In the current version of the program, only single data files can be taken.

The data channels are displayed in Section 3. Selecting a particular channel from the pulldown menu will cause the data for that channel to appear in the main screen, shown in Figure 3-26. Different styles of displays can be selected from the Display menu button located in the top-right corner of Section 3. Figure 3-27 shows the various display options on the right-hand section of the screen. 


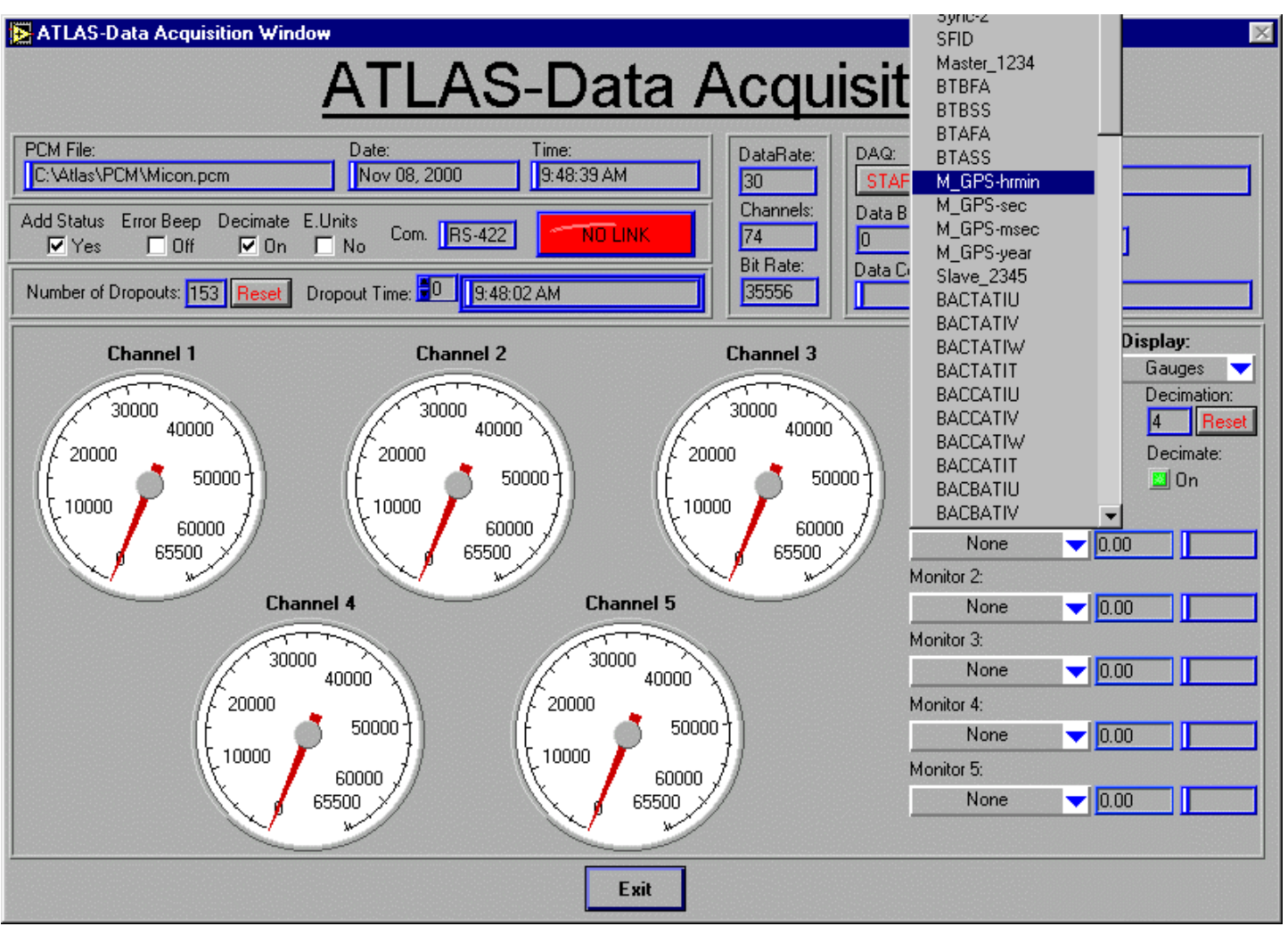

Figure 3-26. Channel Selection on Channel 1.

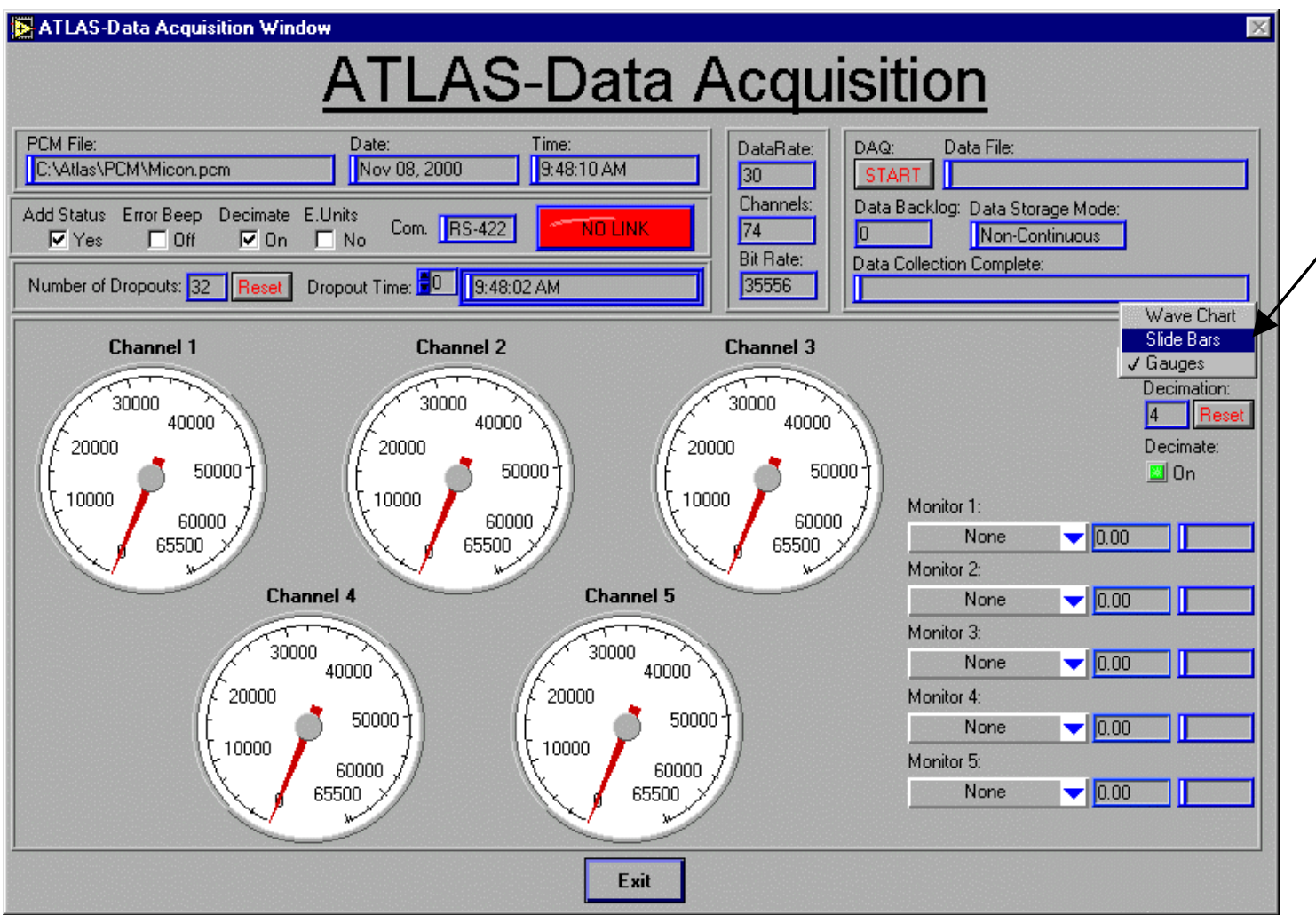

Figure 3-27. Display Options. 
The ATLAS Data Acquisition window can display up to five channels and has three different display options. Depending on the computer Central Processing Unit (CPU) speed, the program will decimate the data displayed accordingly. Unless the decimation indicator, located in the upper right portion of Section 3 is "1," the data displayed is decimated and may not appear $100 \%$ correct. For example: if the decimation indicates a value of "4," every fourth point will be displayed. Even though the display may not show every point, every data point is being saved to disk during data acquisition.

\subsection{Advanced Data Acquisition Software (ADAS II)}

The ADAS II software is a modified version of the ADAS software developed by NREL for acquiring data from the ADAS hardware. The software has been modified to acquire and store continuous time-series data from the ATLAS hardware.

\subsubsection{Computer Requirements}

- Pentium $200 \mathrm{MHz}$ or faster

- $64 \mathrm{Mb}$ of RAM (128 Mb recommended)

- $25 \mathrm{Mb}$ disk space (plus necessary disk space for data storage)

- $1024 \times 768$ minimal resolution

- Windows ${ }^{\circledR} 95$ or 98 (Windows ${ }^{\circledR}$ NT and 2000 support released May '01)

\subsubsection{Launching ADAS II}

When the ADAS II software is launched, the main menu window will appear, as shown in Figure 3-28. If the hardware system has been programmed, the ADAS II software can now acquire data.

\section{NOTE}

All changes in the hardware configuration must be specified from the ATLAS software.

From the main ADAS II menu, the initial step is to configure the software. This can be done by clicking on the Make Master Config. File button in Figure 3-28.

\subsubsection{Configuring the Software}

After opening the configuration window (see Figure 3-29), several parameters need to be specified in order for ADAS II to configure itself. The first time the program is opened, all directories and configuration files will be default values and may not be the correct files for your application. If the directory is not correct, modify the directory to the appropriate one. This can be done by clicking on the path. A browse window will appear, and the correct directory can be selected. After all directories have been set, the data archiving parameters can be set. First, select the directory where all data files are to be stored. 


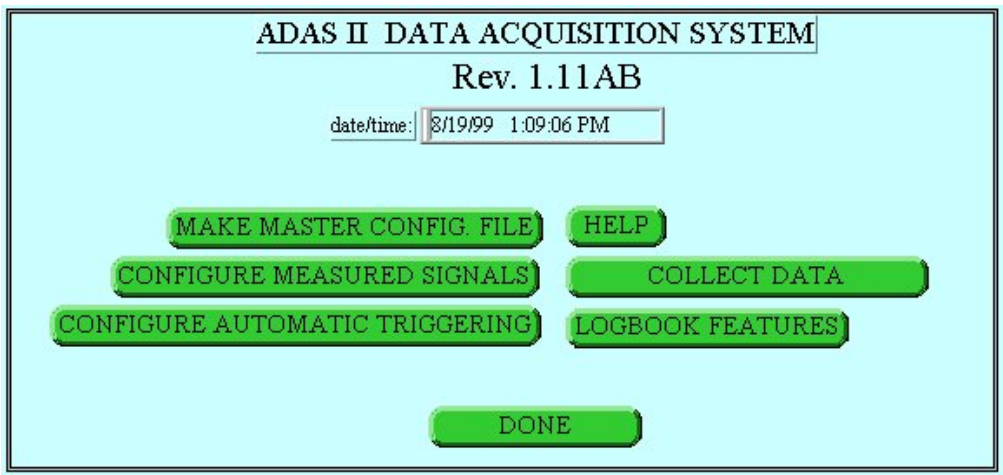

Figure 3-28. ADAS II Software Main Menu.

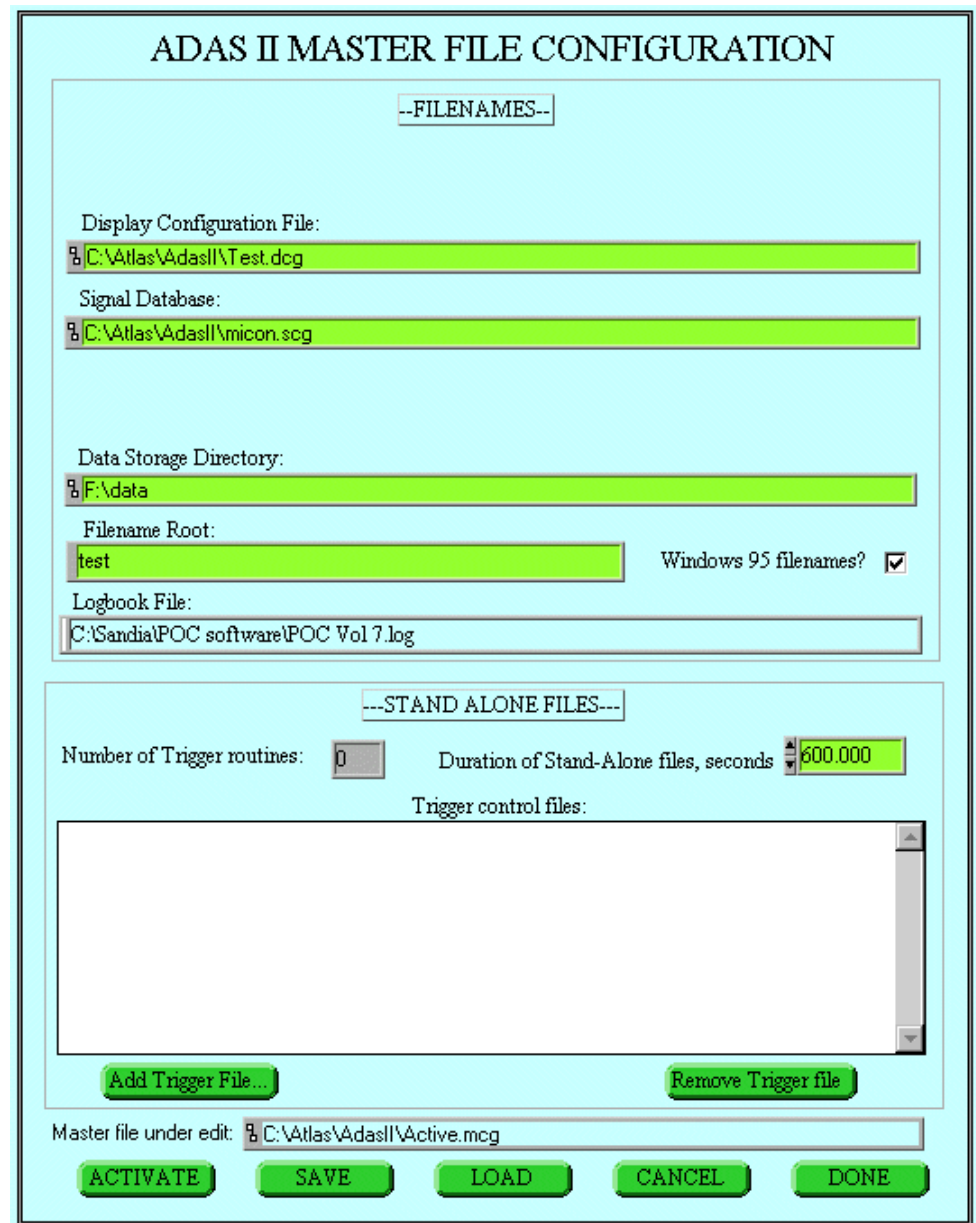

Figure 3-29. ADAS II Configuration Window.

\section{NOTE}

The program generates ASCII data files that can be quite large, depending on the number of channels and the acquisition rate, and can fill up the computer hard drive quite rapidly. The program contains NO hard drive overflow 
protection. If the hard drive reaches it full capacity, the PC will crash and possibly corrupt the data. The data file size can be approximated by the following equation.

$$
\text { FileSize }=C * D * S * 12
$$

$\mathbf{C}=$ Number of channels being acquired (see Figure 3-17)

$\mathbf{D}=$ Data Rate (see Figure 3-17)

$\mathbf{S}=$ Duration of stand-alone files, seconds (see Figure 3-29)

Next, set the filename root. This applies to the naming of the data files. For example, if the root name is 'test,' the data file name would be 'test(date and time).dat' (i.e., test2000/07/12/1725). It is important to fill in the duration of the file.

\section{NOTE}

The time is in seconds. If ADAS II is being used to monitor data and not to store it to disk, "0" must be typed in the field.

ADAS II accesses the *.pcm file created by the ATLAS software and uses it to configure itself to acquire data from the ATLAS hardware.

The ADAS II Measured Signal Configuration window is shown in Figure 3-30.

Once the program has been configured, you must specify the location and the time duration of the data files to be taken before the software is ready to acquire continuous data. All saved data files are stored with an accompanying header file, which contains all the pertinent information that belongs to that specific data file. The header file naming convention is identical to the convention of the data file. The only difference in the extension, which is a "*.hdr" instead of a "*.dat." The data and header files can then be read by many software packages for post-processing (NREL programs GPP, Crunch and Genstats, as well as the new SDAS). The Collect Data window, shown in Figure 3-31, is displayed during actual data acquisition. Within this window, you also have the capability to view the data in pseudo-real-time in any of several different chart formats.

Other important features of the ADAS II software are the triggering routine and the logbook. The triggering routine allows the user to specify specific quotas or conditions on the data. In other words, if the data does not meet the specific requirements, the data is not saved. For example: if the triggering conditions are set to take data when the wind speed is greater than $6 \mathrm{~m} / \mathrm{s}$, data will not be saved unless the wind speed exceeds $6 \mathrm{~m} / \mathrm{s}$.

The logbook feature maintains a record of any modifications, errors, or events that occur while the program is running. You may view this file at any time, which can be useful, especially if the program is operating in unattended mode. 


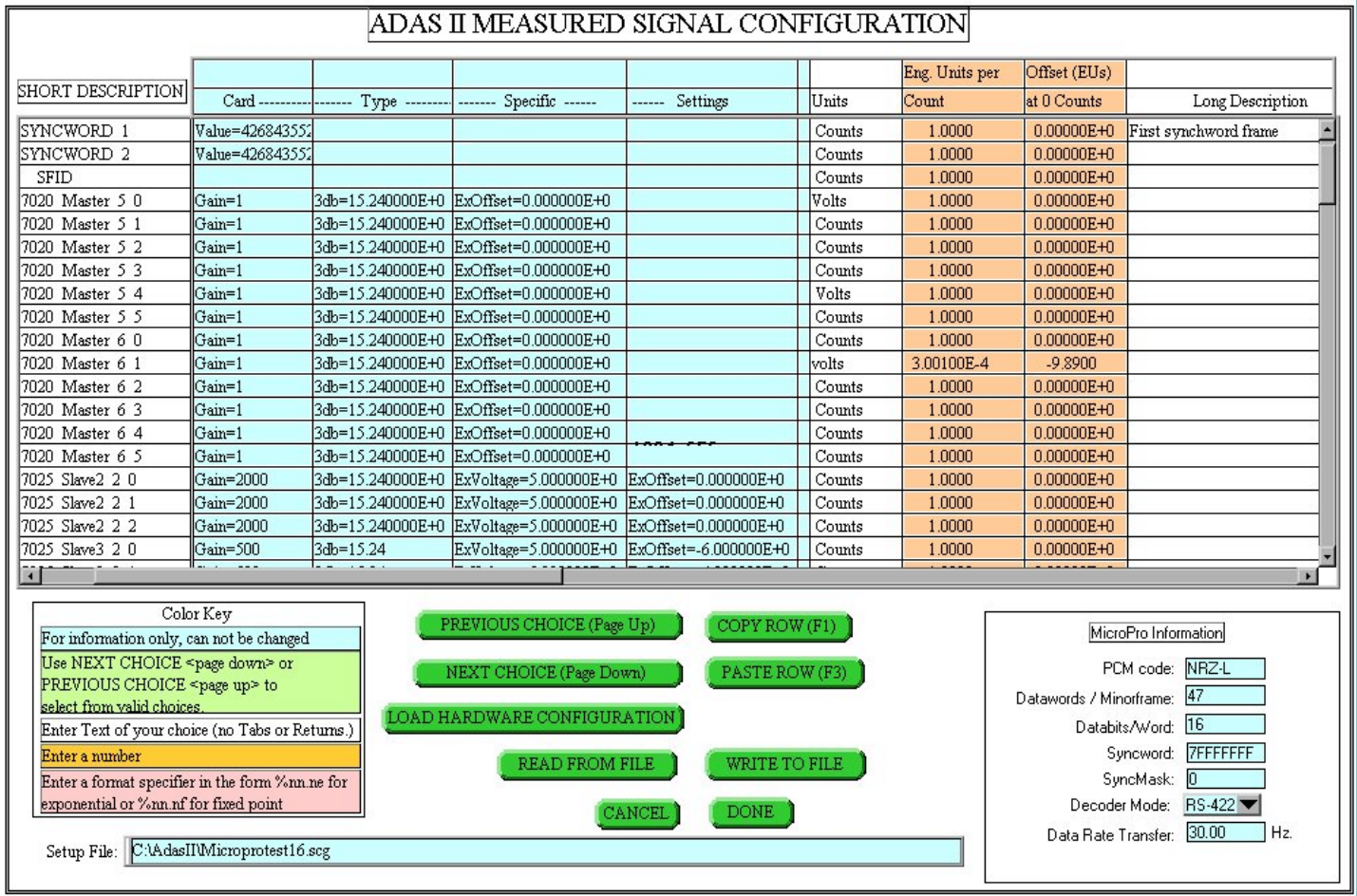

Figure 3-30. ADAS II Measured Signal Configuration Window.

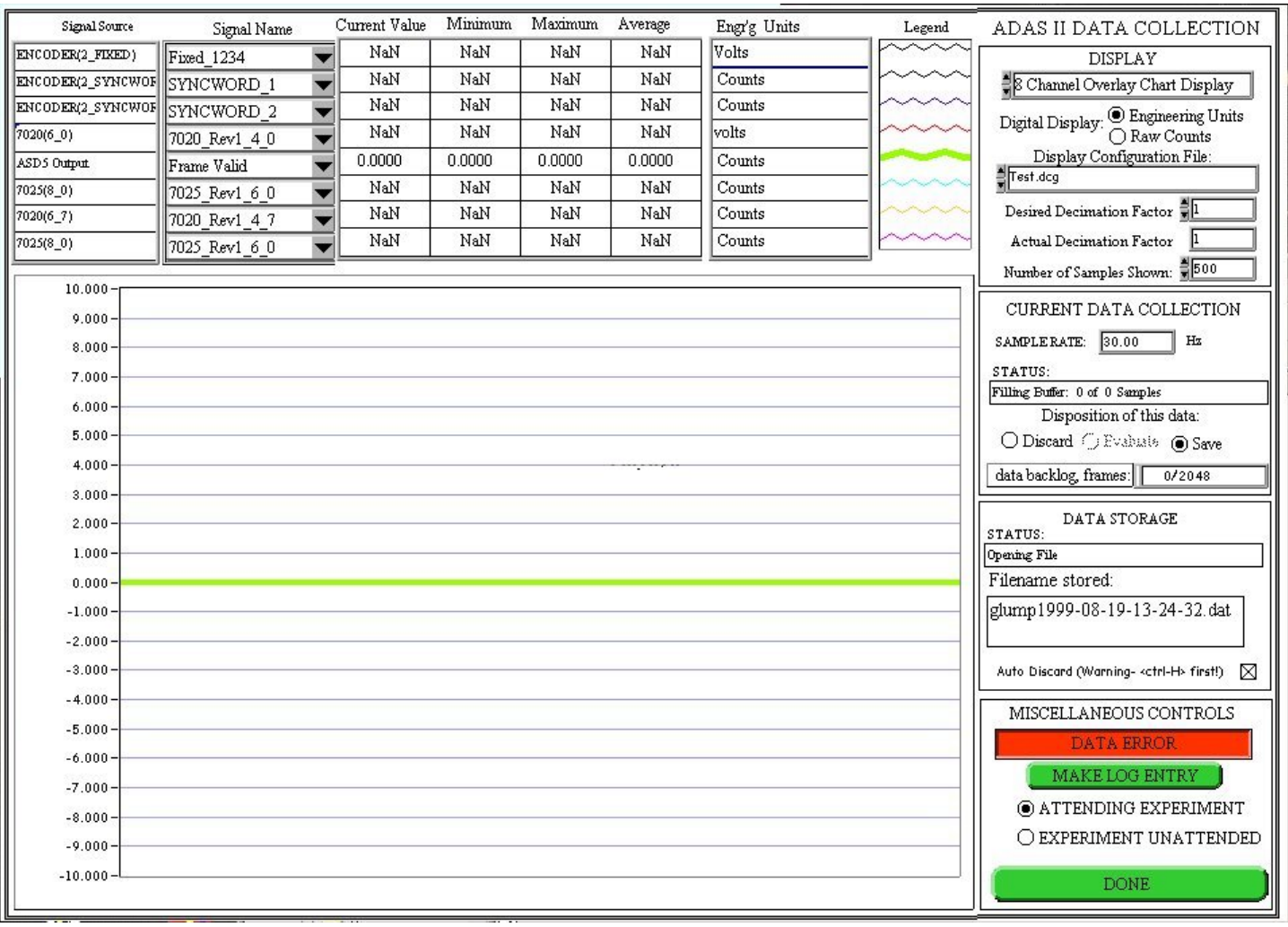

Figure 3-31. ADAS II Collect Data Window. 


\subsection{Smart Data Acquisition System}

\subsubsection{Smart Data Acquisition System Overview}

A new program called SDAS has been written to help researchers process the large amounts of data that are typically acquired in performing wind energy technology research. Data acquired and stored with the ADAS II software can be read directly into SDAS, enhancing the capabilities of the ADAS II program. The SDAS program is intended to complement other existing NREL analysis programs, such as GPP, Genstats, and Crunch, which can also read ADAS II time-series files. This section gives an overview and describes some of the capabilities of the SDAS program.

SDAS is a unique data acquisition program; instead of acquiring data from hardware, SDAS acquires data created (or acquired) by other programs, usually, but not necessarily, the ADAS II data acquisition program. SDAS has the ability to know what data have been acquired; in this way, SDAS maintains a global picture of the acquired data. SDAS is designed to receive a continuous stream of time-series files either from the ADAS II computer program in pseudo-real-time (typically, but not necessarily, every 10 minutes), or off-line from archived time-series files. SDAS can calculate and store an extensive set of user-selected statistics for every time-series file. All statistics are stored in a central database that the user can access later. SDAS will allow you to interactively interrogate the database or any time-series file that was previously processed by SDAS. This allows you to perform a large number of tasks, including looking at statistics, looking for trends, finding extremes, looking for particular events, performing Rainflow analysis, plotting channels or statistics against each other, investigating point-by-point details in time-series files, and determining file commonality (redundant time-series files).

\subsubsection{Smart Data Acquisition System Computer Requirements}

Because SDAS could be required to handle large data files, SDAS was written to optimize computer memory wherever possible. SDAS is also graphics intensive. It will run on a computer with the following minimum capabilities:

- Pentium $200 \mathrm{MHz}$ or faster,

- $64 \mathrm{Mb}$ of RAM (128 Mb recommended),

- $25 \mathrm{Mb}$ disk space (plus necessary disk space for data storage),

- $1024 \times 768$-minimal resolution with Small Fonts,

- Windows ${ }^{\circledR} 95,98$, or NT.

Only one time-series file at a time is read into the SDAS memory during an SDAS acquisition, and up to four time-series files can be read at a time during post-processing. The only potentially large files that SDAS creates are the SDAS databases, which start out at 74 kilobytes each and grow at a rate of about 2 kilobytes for every time-series file acquired and processed. 


\subsubsection{Smart Data Acquisition System Status Window}

The main window in SDAS, called the SDAS Status window, is shown in Figure 3-32. The dynamic settings of SDAS, as they are set and changed, are displayed in this window. All of the functions available in SDAS can be reached from this window through the menu bar (File, Acquisition, Post Processing, View, Utilities, Options, and Help). As long as SDAS is running, this window will always be on the desktop.

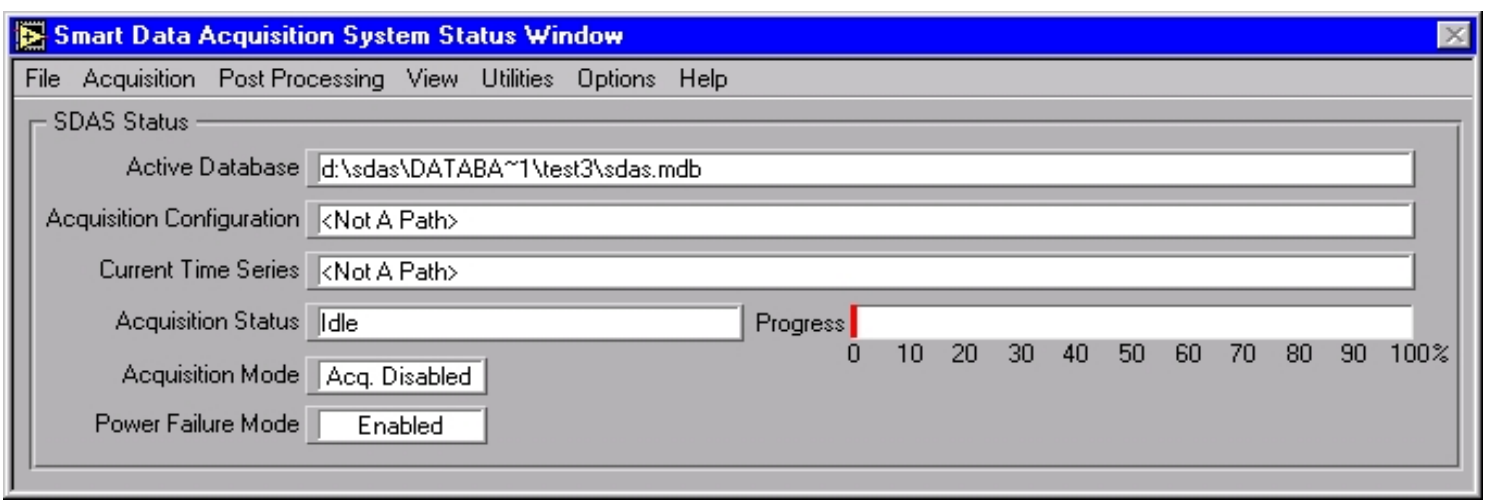

Figure 3-32. SDAS Status Window.

\subsubsection{Smart Data Acquisition System Statistics}

SDAS can calculate a large number of built-in user-selected statistics. Along with the minimum and maximum, the four statistical moments (mean, standard deviation, skewness, and kurtosis) can also be calculated for each data channel. There are also up to 12 special statistics, called Cross Channel Statistics, which can be calculated. Cross Channel Statistics are calculated using more than one data channel. These statistics are routinely calculated in wind energy research. The list of Cross Channel Statistics currently available within SDAS are capacity factor, horizontal sonic direction, horizontal sonic velocity, Obukhov length, Reynolds stress, Richardson number, total sonic velocity, vertical sonic velocity, wind direction, wind shear, yaw error, and yaw rate.

\subsubsection{Smart Data Acquisition System Configuration}

Before any data can be processed by SDAS, SDAS needs to know what data channels are available and what statistics are to be calculated and stored in the database for each channel. The Statistical Analysis Configuration window, shown in Figure 3-33, allows you to interactively point to a channel/statistic field (column/row) intersection and select or deselect the statistics to be calculated and stored for any raw data or calculated channel. An "X" indicates the statistic will be calculated and stored; the absence of an "X" indicates the statistic is not stored. The vertical list of channels in this window (except the yaw error) is read in from a time-series header file, or (with the yaw error) from a previously saved Statistical Analysis Configuration file. 


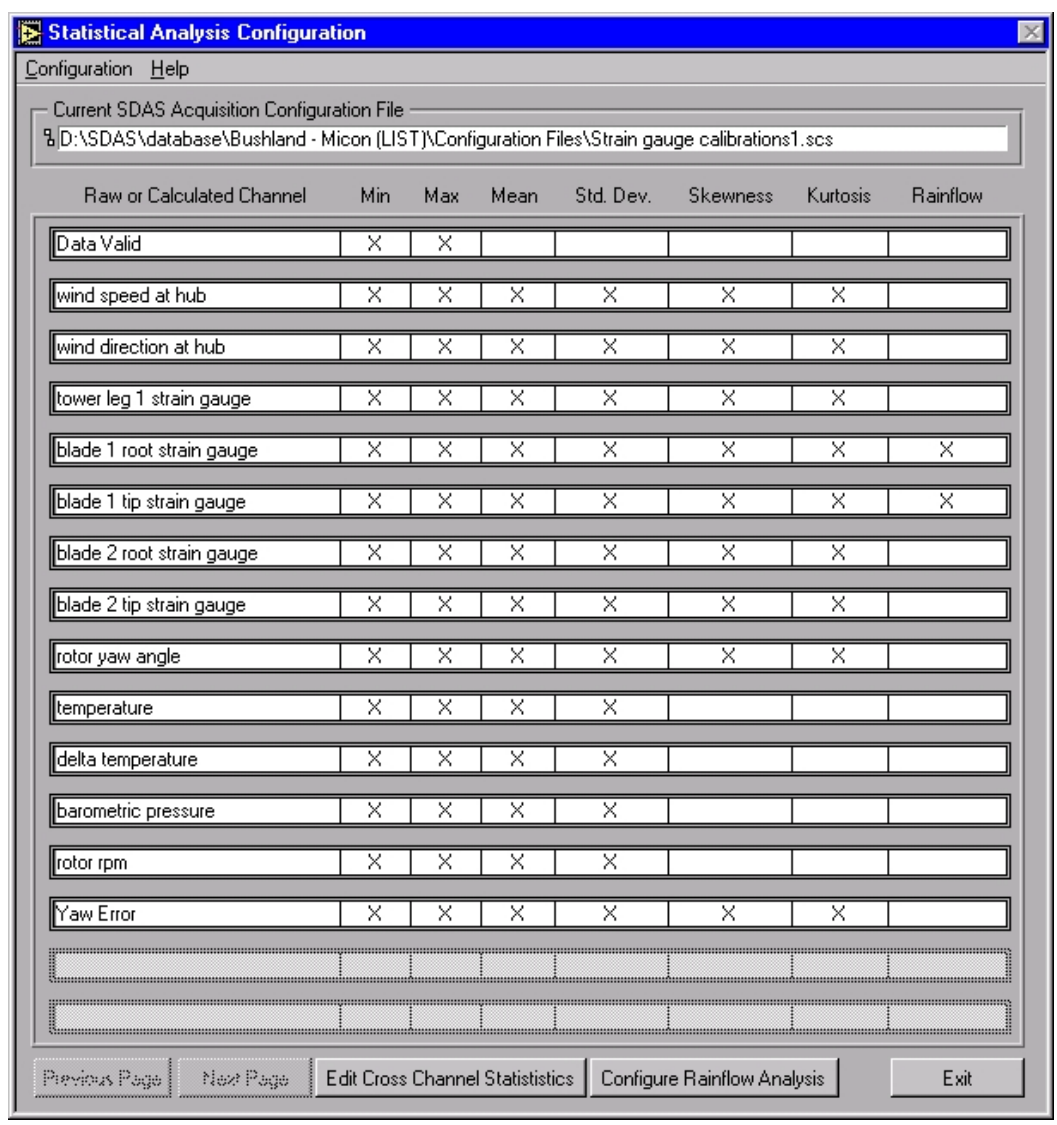

Figure 3-33. Statistical Analysis Configuration Window.

The Cross Channel Statistics are selected or deselected in the same manner as the simple statistics described above. As shown in Figure 3-34, the yaw error is the only Cross Channel Statistic selected. This window is reached by clicking on the button labeled "Edit Cross Channel Statistics" along the bottom of the Statistical Analysis Configuration window.

For the yaw error statistic to be calculated, SDAS needs to map two variables to two data channels. This is done in the SDAS Cross Channel Statistics Configuration window shown in Figure 3-35. Notice the yaw error variable "wind direction (degrees)" has not been assigned to a data channel yet, but the yaw error variable "yaw angle (degrees)" is about to be assigned to the data channel "rotor yaw angle (degrees)" from the pull-down menu that lists all the available data channels. After the yaw error statistic has been configured, the yaw error will now appear in the Statistical Analysis Configuration window as just another statistic. See the bottom entry in Figure 3-33. At this point, any simple statistics can be selected/deselected for the yaw error statistic.

This window allows you to define the statistics to be calculated for each data and calculated channel. 


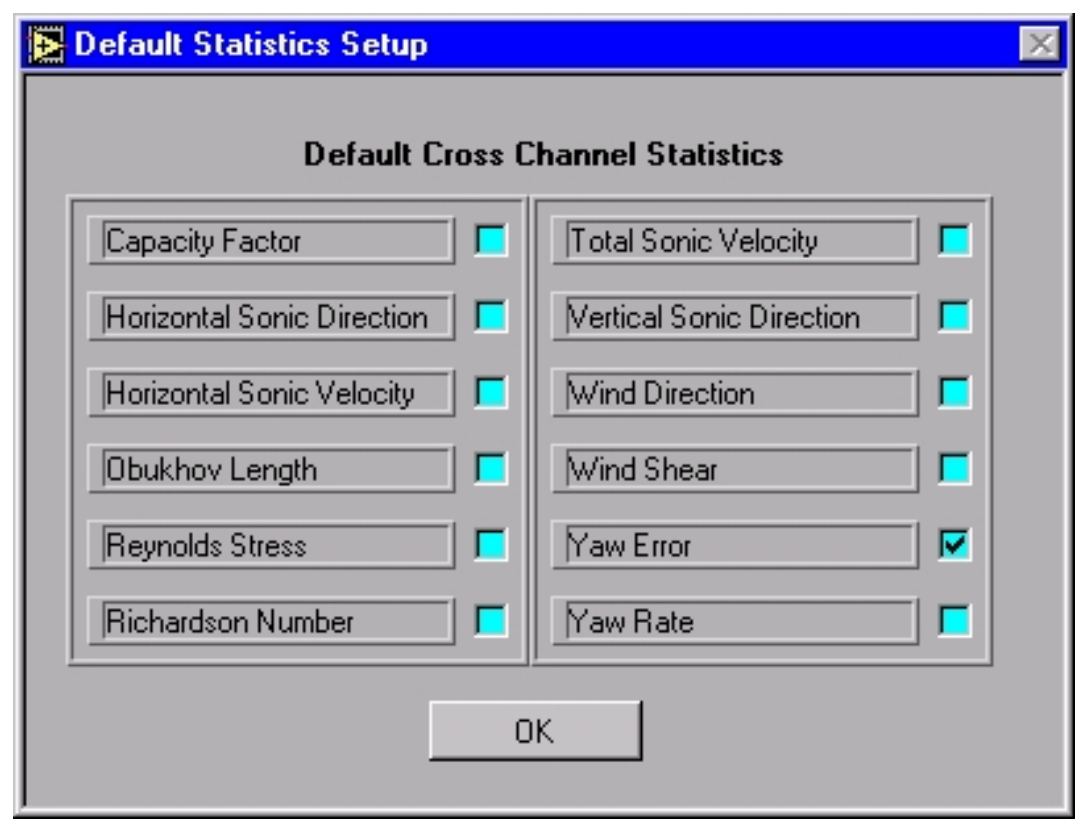

Figure 3-34. SDAS Default Cross Channel Statistics Window. This window allows you to define the cross channel statistic(s) to be calculated.

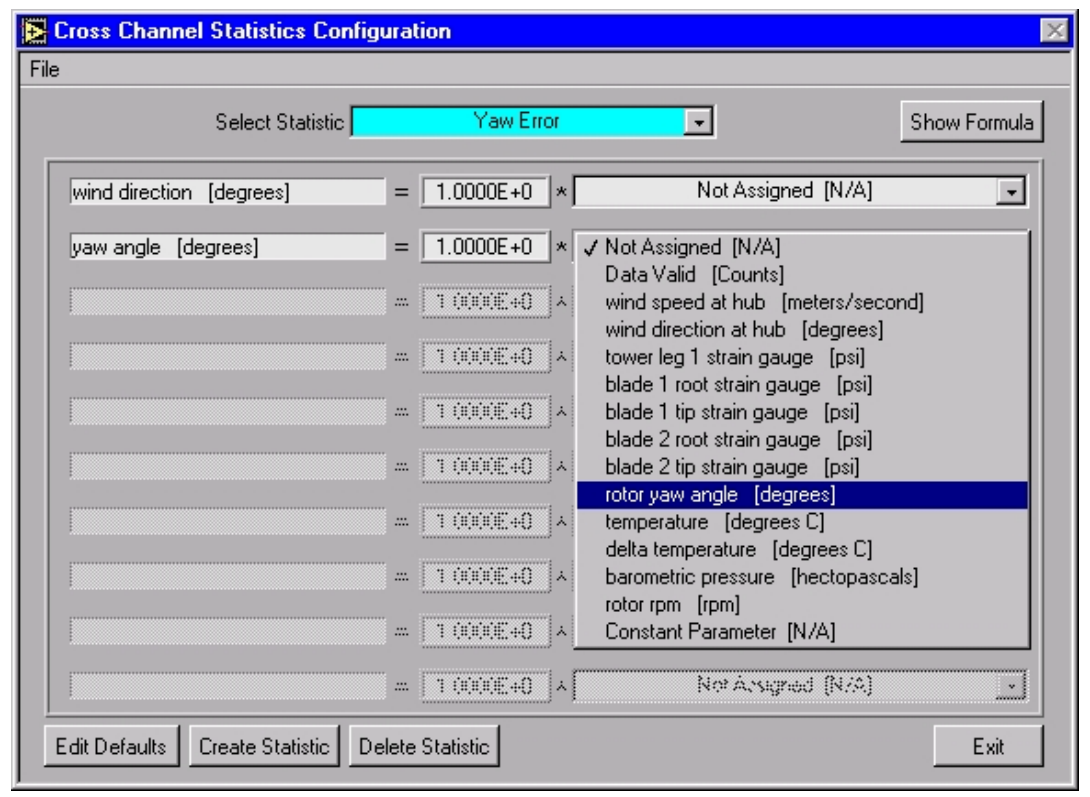

Figure 3-35. Cross Channel Statistics Configuration Window.

Notice also in Figure 3-33 that two boxes in the Rainflow column have been selected (with an " $\mathrm{X}$ " in the last column) for the "blade I root strain gauge" and the "blade 1 tip strain gauge" channels. This means two data channels have been selected for Rainflow analysis, and must be configured. The Rainflow Analyses Configuration Screen Window appears in Figure 3-36. The fields in this window have been user-configured in the same way as described above. 


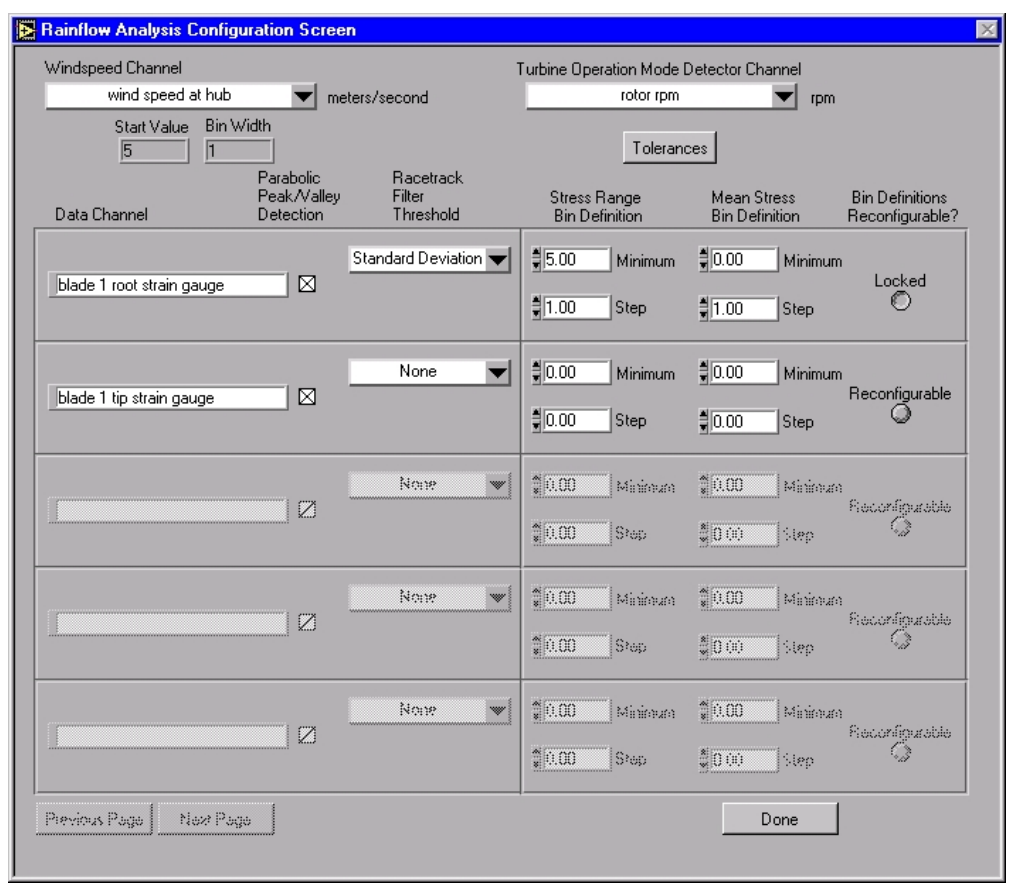

Figure 3-36. Rainflow Analysis Configuration Screen.

After you configure the SDAS acquisition by selecting and mapping the statistics, SDAS is ready to start acquiring time-series data. The time-series files can be acquired from a user-designated location on the local computer or over a network. The time-series files can be located in any computer folder (including where the ADAS II software is storing current time-series files), or on a CD-R or a floppy disk.

\subsubsection{Smart Data Acquisition System Database}

In SDAS, a database is the cumulative collection of information obtained by a sequence of acquisitions of time-series data files. For instance, if you had time-series data from a Bergey 850 and a Zond Z-56 wind turbine, the data could be separated into two groups, one for each turbine. SDAS gives you the ability to create and maintain any number of databases. However, only one SDAS database can be open at any given time while SDAS is running.

The SDAS database is based on the Microsoft ${ }^{\circledR}$ Access ${ }^{\circledR}$ database format, and thus can be read by Microsoft ${ }^{\circledR}$ Access ${ }^{\circledR}$. SDAS communicates with the database through the SQL and Microsoft ${ }^{\circledR}$ Open Database Connectivity (ODBC) driver interfaces. However, all of this is transparent to the user. There are no database query commands to remember, and Microsoft $^{\circledR}$ Access $^{\circledR}$ does not need to be installed on the computer in order to run SDAS.

\subsubsection{Smart Data Acquisition System Post-Processing}

SDAS has several post-processing capabilities or routines. The post-processing routines give you the ability to perform a large number of tasks, including looking at statistics, 
looking for trends, finding extremes, looking for particular events, performing Rainflow analysis, plotting channels or statistics against each other, investigating point-by-point details in time-series files, and determining file commonality (redundant time-series files).

Four different kinds of two-dimensional (XY) plots can be displayed, each with one to four channels per plot, and they can be interactively manipulated. The four postprocessing displays are Statistic versus Time, Channel versus Time, Statistic versus Statistic, and Channel versus Channel. An example of a Channel versus Channel plot, with four channels displayed, is shown in Figure 3-37.

All the powerful LabVIEW graphics functions are available to modify the view of any of the plots (zoom, panning, cursor measurement, auto-scaling, etc.). A Microsoft ${ }^{\circledR}$ Excel $^{\circledR}$ spreadsheet can be generated from the data in any plot. (Future enhancements to SDAS will allow you to create a new time-series data file from the "windowed" data.)

"Conditions filtering" is a powerful capability which is similar in function to the triggering capability of the ADAS II program. You can set criteria or limitations on the data displayed, in effect filtering information from the database. The filter criteria are userselectable and are based on a logical combination of any SDAS calculated statistic from any channel and the time the file was created.

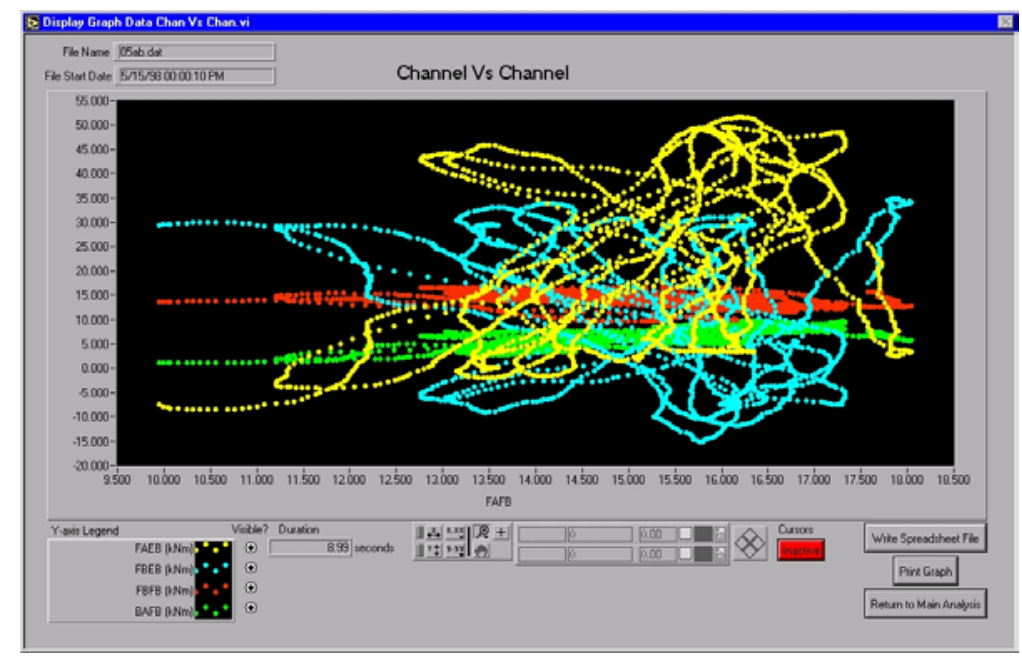

Figure 3-37. Channel Versus Channel Plot Showing Four Strain-Gauge Channels Plotted Against a Fifth Strain-Gauge Channel.

\subsubsection{Smart Data Acquisition System and Power Failures}

Because SDAS may be operated unattended for long periods of time, the program was written with the capability to gracefully handle utility power failures that could affect the integrity of the data acquisition. The ADAS and SDAS computer and ATLAS data acquisition hardware are all on an uninterruptible power supply (UPS). If a power failure occurs, the software that controls the UPS generates a text file in a user-defined folder. If 
SDAS detects the presence of this text file in the specified folder, it will finish all calculations on the current time-series file, store all calculations in the database, record all the user-defined SDAS settings, and gracefully terminate itself before the SDAS computer is shut down by the UPS. (Currently, the ADAS II software and ADAS computer do not have this power-failure shutdown capability.) When the utility power recovers, the SDAS computer is powered on by the UPS, it self boots, and SDAS is restarted. SDAS will reverse the shutdown process, reestablishing its acquisition configuration, resuming timeseries file acquisitions, performing statistical calculations, and storing results in the database as if nothing had happened. 


\section{Chapter 4. Maintenance}

\subsection{General Information}

The ATLAS hardware is quite complex and tracking down a problem when the system doesn't work can be extremely frustrating. The ATLAS software is extremely useful in troubleshooting. It's good to have a laptop computer set up with the ATLAS software so it's easy to connect directly to the mainframe that's causing the problem. In a Master/Slave system, the PCM stream output of each mainframe consists of frames the same size and format as those output by the Master, but only the data words collected by that particular mainframe are valid. Therefore, it's possible to monitor the data link of any mainframe in an ATLAS with the GBCU (or a laptop computer) without re-programming it.

\section{NOTE}

The ATLAS master data communications setting (set in the "DAS Settings" window of ATLAS) must be changed as necessary to match the data transfer link of the particular mainframe being monitored.

The best debugging procedure is to program the ATLAS hardware with a system and then access the "Acquire" window. The 'Link' indicator appears at the upper center of the ATLAS software data acquisition window (see Figure 3-24). It will display either a green 'Link' or a red 'No Link' message. If the message is 'Link,' PCM data is being received from the mainframe. If the message is 'No Link,' the data communications link between the mainframe and the GBCU is not working. Moving the laptop from mainframe to mainframe (connecting the RS-232 and the RS-422 or TTL lines between the mainframe and the laptop), adjusting the data communications setting as necessary, is a good way to verify that the mainframes are working properly.

Although a limited amount of trouble shooting can be accomplished with only a digital multimeter (DMM), a good quality (preferably digital) oscilloscope is essential for performing a more detailed checkout and troubleshooting.

\section{NOTE}

Be sure to turn off the mainframe power before inserting or removing any module or connector.

\subsection{Troubleshooting}

This section provides guidelines for solving some of the more common problems that might occur with ATLAS. The initial step in trying to resolve an operational problem should always be cycling the power (turn the power off, wait 15-30 seconds, turn the power on) to the Master and all Slave units, to any modems that are used, and to the 
GBCU. If the problem persists, try to locate the symptom in Table 4-1 and follow the instructions given there to identify and rectify the problem.

\section{Table 4-1. Troubleshooting Problems/Solutions for ATLAS}

\begin{tabular}{|c|c|c|}
\hline \multicolumn{3}{|c|}{ Troubleshooting Guide } \\
\hline Symptoms & Possible Cause & Background/Trouble Shooting Procedure \\
\hline $\begin{array}{l}\text { 'Link' indicator remains } \\
\text { red, with little or no } \\
\text { green, indicating no } \\
\text { reception of PCM data. }\end{array}$ & $\begin{array}{l}\text { Data communications } \\
\text { cable or modem not } \\
\text { functioning. } \\
\text { The PATSyM is not } \\
\text { generating the } \\
\text { appropriate clock and } \\
\text { sync pulse trains. }\end{array}$ & $\begin{array}{l}\text { The KAM-500 PCMCIA decoder expects to receive } \\
\text { data in precisely the format and at the speed specified in } \\
\text { the software setup files. If these files have changed } \\
\text { since the hardware was programmed, the PCMCIA } \\
\text { decoder may not be able to properly decode the } \\
\text { incoming data stream. } \\
\text { Make sure the correct software setup is being used for } \\
\text { the hardware, and then reprogram the KAM-500 } \\
\text { hardware using the ATLAS software (see the "Pro- } \\
\text { gramming the Hardware" section in Chapter } 3 \text { for } \\
\text { information on performing this function). } \\
\text { The data communications cable (or modem, if telemetry } \\
\text { is used) may be wired wrong or have one or more bad } \\
\text { connections. Replace the cable/modem and try again. } \\
\text { The PATSyM receives serial date and time information } \\
\text { and a 1PPS signal from the GPS receiver card. The date } \\
\text { and time information are placed on the KAM-500 bus } \\
\text { by the PATSyM. The GPS 1PPS output resets the } \\
\text { PATSyM output every second to keep it exactly time- } \\
\text { aligned with Universal Time and to initialize the } \\
\text { counting required to output the bit clock and sync pulse } \\
\text { trains to drive the KAM-500 data acquisition cycle. } \\
\text { Make sure the PATSyM is generating the normal } \\
\text { 'heartbeat,' utilizing three of the four on-board LEDs. If } \\
\text { the heartbeat is abnormal, proceed to Table } 4-2 \text { below. } \\
\text { If the PATSyM heartbeat looks good, reprogram the } \\
\text { systems. If the heartbeat continues to look good, but } \\
\text { there is still no link, use your oscilloscope to verify that } \\
\text { the Ex_Clk and Ex_Sync signals are in the range of } 0-5 \\
\text { VDC and at the right frequency (the Ex_Clk rate should } \\
\text { be the Bit Rate, and the Ex_Sync rate should be the } \\
\text { Data Rate specified in the "DAS Data Rates" routine of } \\
\text { ATLAS). If the signal level is low or either clock rate } \\
\text { is bad, the PATSyM is probably bad - replace it with } \\
\text { another one. If one or both clock rates still look bad, } \\
\text { replace the original PATSyM, replace the encoder, and } \\
\text { reprogram the system. If the signal levels and clock } \\
\text { rates look OK, check for encoder pin } 6 \text { wiring - it } \\
\text { should be pulled high to +5V. If it isn't, fix that } \\
\text { problem and then check the link again. }\end{array}$ \\
\hline
\end{tabular}


Table 4-1. Troubleshooting Problems/Solutions for ATLAS (continued)

\begin{tabular}{|c|c|c|}
\hline \multicolumn{3}{|c|}{ Troubleshooting Guide } \\
\hline Symptoms & Possible Cause & Background/Trouble Shooting Procedure \\
\hline \multirow[t]{3}{*}{$\begin{array}{l}\text { 'Link' indicator } \\
\text { remains red, with little } \\
\text { or no green, indicating } \\
\text { no reception of PCM } \\
\text { data (continued). }\end{array}$} & $\begin{array}{l}\text { The communication } \\
\text { mode being used for } \\
\text { PCM data transfer is } \\
\text { malfunctioning. }\end{array}$ & $\begin{array}{l}\text { Use the oscilloscope to check for proper clock signal } \\
\text { on the communications lines (for RS- } 422 \text {, check power } \\
\text { supply connector pins } 7 \& 8 \text {; for TTL, check encoder } \\
\text { connector pin } 11 \text { ). The clock signal on all of these } \\
\text { should be nice and clean, with the lower voltage } \\
\text { between }-7 \text { and }-2 \text { VDC and the upper voltage level } \\
\text { between } 2 \text { and } 7 \text { VDC for RS- } 422 \text { and with the lower } \\
\text { voltage between }-15 \text { and }-5 \text { VDC and the upper } \\
\text { voltage level between } 5 \text { and } 15 \text { VDC for TTL. If } \\
\text { there's something wrong with the signal on one or more } \\
\text { of these, there's a problem with the associated } \\
\text { communications hardware; either the encoder (if TTL) } \\
\text { or the mainframe (if RS- } 422 \text { ). Next, check data lines } \\
\text { (power supply pins } 3 \text { and } 4 \text { for RS- } 422 \text { and encoder pin } \\
12 \text { for TTL). All of these should have signals with } \\
\text { voltage levels similar to the clock, but without the } \\
\text { distinctive pulses - they should be blurred together, so } \\
\text { you can't really pin down the rate. If any of the } 422 \\
\text { clock or data signals are bad, replace the mainframe. If } \\
\text { either the TTL clock or data signal is bad, replace the } \\
\text { encoder (you will have to reprogram the mainframe } \\
\text { before you can proceed). }\end{array}$ \\
\hline & $\begin{array}{l}\text { The decoder card or } \\
\text { pigtail is not } \\
\text { functioning. }\end{array}$ & $\begin{array}{l}\text { Swap the communications mode (TTL or RS- } 422 \text { ) in } \\
\text { the ATLAS 'DAS Settings' routine and run 'Acquire' } \\
\text { again (be sure to connect the proper cable to the } \\
\text { decoder). If one communications mode works, but the } \\
\text { other does not, there's probably a problem in the pigtail } \\
\text { or the decoder. Replace these components, one at a } \\
\text { time. If changing the pigtail does not have any effect, } \\
\text { replace the original pigtail before changing out the } \\
\text { decoder. If changing out the decoder does not have any } \\
\text { effect, replace the original decoder. }\end{array}$ \\
\hline & $\begin{array}{l}\text { There is a more serious } \\
\text { problem. }\end{array}$ & Contact ACRA Control for assistance (see Chapter 6). \\
\hline $\begin{array}{l}\text { 'Link' indicator shows } \\
\text { lots of drop outs } \\
\text { (intermittent green and } \\
\text { red flashes) or 'No } \\
\text { Link' (solid red) for } \\
\text { hardwired PCM signal. }\end{array}$ & $\begin{array}{l}\text { Ground loop or floating } \\
\text { ground. }\end{array}$ & $\begin{array}{l}\text { The KAM- } 500 \text { case is not grounded to the back plane } \\
\text { into which the measurement modules are inserted, so it } \\
\text { is isolated from both the digital and analog grounds. } \\
\text { As a result, it sometimes floats at a rather high potential } \\
\text { with respect to ground, and this can cause communica- } \\
\text { tion problems. RS- } 422 \text { is more immune to ground } \\
\text { problems than TTL, so it may be beneficial to switch } \\
\text { the communication link format to RS- } 422 \text { if this contin- } \\
\text { ues to be a problem (see Section } 3.2 .3 .2 \text { for information } \\
\text { on how to set the communication link format). }\end{array}$ \\
\hline & & $\begin{array}{l}\text { Ground the KAM- } 500 \text { case to analog ground and } \\
\text { ensure that it is connected to the GBCU ground at one } \\
\text { (and only one) location. }\end{array}$ \\
\hline
\end{tabular}


Table 4-1. Troubleshooting Problems/Solutions for ATLAS (continued)

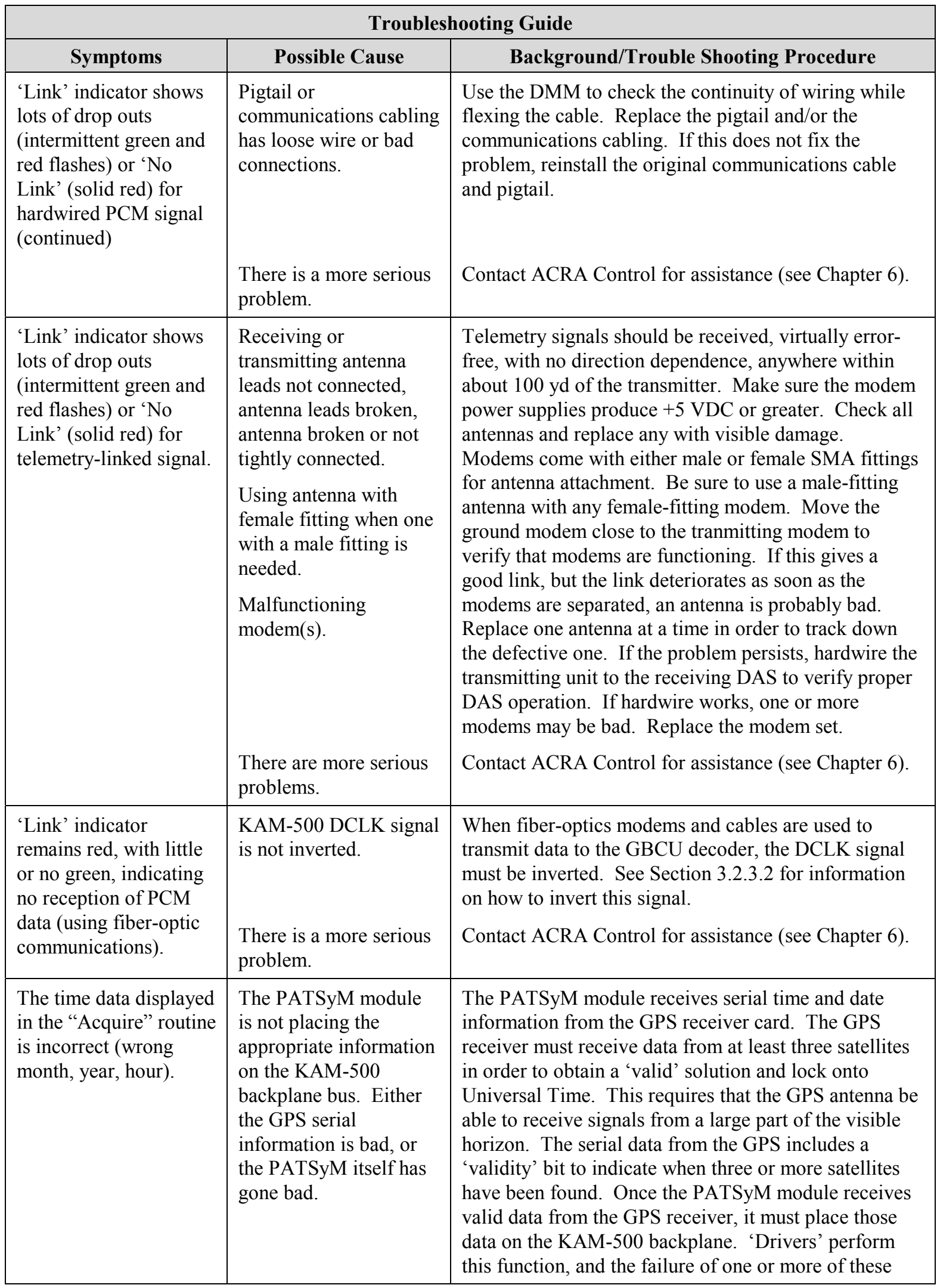


Table 4-1. Troubleshooting Problems/Solutions for ATLAS (continued)

\begin{tabular}{|c|c|c|}
\hline \multicolumn{3}{|c|}{ Troubleshooting Guide } \\
\hline Symptoms & Possible Cause & Background/Trouble Shooting Procedure \\
\hline $\begin{array}{l}\text { The time data displayed } \\
\text { in the "Acquire" routine } \\
\text { is incorrect (wrong } \\
\text { month, year, hour) } \\
\text { (continued). }\end{array}$ & $\begin{array}{l}\text { There is a more serious } \\
\text { problem. }\end{array}$ & $\begin{array}{l}\text { drivers will cause incorrect data to be written to the } \\
\text { bus. } \\
\text { Make sure the GPS antenna is attached and is placed } \\
\text { where it has a clear view of the sky. Monitor the GPS } \\
\text { serial data. If no serial data are received, the GPS } \\
\text { receiver may be bad and should be replaced. If the } \\
\text { same symptoms persist, reinstall the original GPS } \\
\text { receiver and replace the PATSyM. } \\
\text { Contact SNL for assistance (see Chapter 6). }\end{array}$ \\
\hline \multirow[t]{3}{*}{$\begin{array}{l}\text { "GPS Data" time } \\
\text { display does not update } \\
\text { to the appropriate time } \\
\text { and year, even after the } \\
\text { unit has been powered } \\
\text { on for } 10 \text { minutes or } \\
\text { more. }\end{array}$} & $\begin{array}{l}\text { GPS antenna does not } \\
\text { have a clear view of the } \\
\text { sky. }\end{array}$ & $\begin{array}{l}\text { The GPS receiver card is located in the weatherproof } \\
\text { box attached to the GPS antenna. The GPS receiver } \\
\text { must lock onto GPS satellites before it updates the } \\
\text { displayed time to the current time and year. This will } \\
\text { not happen if the GPS receiver does not receive data } \\
\text { from the GPS antenna. The GPS antenna must have an } \\
\text { unobstructed view of the sky to be able to receive GPS } \\
\text { signals. In general, the GPS antenna will not work } \\
\text { inside a building, although it may work if it is set close } \\
\text { to a window with a good view of a large portion of sky. } \\
\text { Place the antenna where it can see as much of the sky } \\
\text { as possible. Wait } 10 \text { minutes after moving the antenna } \\
\text { to see if the display updates. If this does not solve the } \\
\text { problem, the GPS receiver card may be bad and should } \\
\text { be replaced. }\end{array}$ \\
\hline & $\begin{array}{l}\text { The antenna cable } \\
\text { between GPS receiver } \\
\text { and GPS antenna is } \\
\text { disconnected. }\end{array}$ & $\begin{array}{l}\text { Make sure the cable is connected. Wait } 10 \text { minutes } \\
\text { after reconnecting to see if the date and time update. If } \\
\text { not, try a new cable. If this does not solve the problem, } \\
\text { the GPS receiver card may be bad and should be } \\
\text { replaced. }\end{array}$ \\
\hline & $\begin{array}{l}\text { There is a more serious } \\
\text { problem. }\end{array}$ & Contact SNL for assistance (see Chapter 6). \\
\hline \multirow{3}{*}{$\begin{array}{l}\text { "GPS Data" time } \\
\text { display is showing the } \\
\text { same information for } \\
\text { the Hr/Min and second } \\
\text { numeric displays. } \\
\text { None of the time } \\
\text { displays are showing } \\
\text { odd numbers. }\end{array}$} & $\begin{array}{l}\text { There is a bad } \\
\text { transciever U7 on the } \\
\text { PATSyM module. }\end{array}$ & $\begin{array}{l}\text { U7 is the transceiver chip that handles the low-order } 8 \\
\text { bits of the data and address lines. If bit } 0 \text { fails, only the } \\
\text { even board registers can be accessed and all displayed } \\
\text { values will be even. }\end{array}$ \\
\hline & & Replace the transciever or PATSyM. \\
\hline & $\begin{array}{l}\text { There is a more serious } \\
\text { problem. }\end{array}$ & Contact SNL for assistance (see Chapter 6). \\
\hline $\begin{array}{l}\text { Analog data appear to } \\
\text { be very noisy or not } \\
\text { responding to changes } \\
\text { in input signal. }\end{array}$ & $\begin{array}{l}\text { The DAM may have } \\
\text { failed or the filter cut- } \\
\text { off frequency may be } \\
\text { set too high. }\end{array}$ & $\begin{array}{l}\text { High-frequency noise generated by power-line } \\
\text { harmonics and other electrical noise can contaminate } \\
\text { the analog signals. Setting the filter cut-off frequency } \\
\text { below } 60 \mathrm{~Hz} \text { will attenuate this noise and yield a } \\
\text { cleaner signal. }\end{array}$ \\
\hline
\end{tabular}


Table 4-1. Troubleshooting Problems/Solutions for ATLAS (continued)

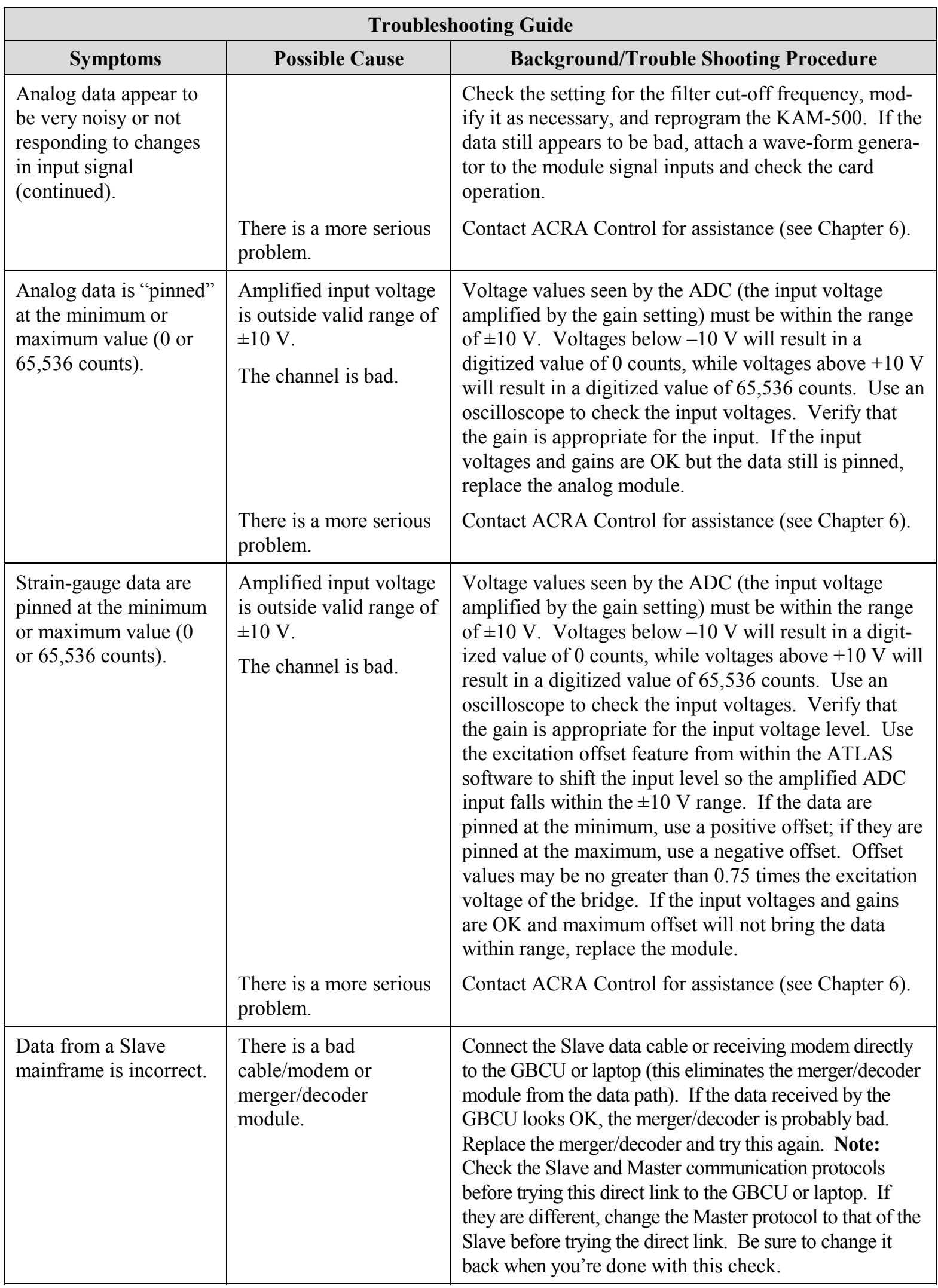


Table 4-1. Troubleshooting Problems/Solutions for ATLAS (continued)

\begin{tabular}{|l|l|l|}
\hline \multicolumn{1}{|c|}{ Troubleshooting Guide } \\
\hline \multicolumn{1}{|c|}{ Symptoms } & \multicolumn{1}{|c|}{ Possible Cause } & \multicolumn{1}{c|}{ Background/Trouble Shooting Procedure } \\
\hline $\begin{array}{l}\text { Data from a Slave } \\
\text { mainframe is incorrect } \\
\text { (continued). }\end{array}$ & $\begin{array}{l}\text { If the data still looks bad, replace any modem data link } \\
\text { with a hardwire link. If that results in a good 'Link' } \\
\text { with good data, the modem link was bad. Replace it } \\
\text { and try the original configuration again. } \\
\text { Connecting the Slave directly to the GBCU/laptop } \\
\text { makes the Slave look just like the Master to the } \\
\text { ATLAS software. If problems persist, follow the steps } \\
\text { given above to troubleshoot and resolve the problem(s). } \\
\text { Contact ACRA Control for assistance (see Chapter 6). }\end{array}$ \\
\hline $\begin{array}{l}\text { There is a more serious } \\
\text { problem. }\end{array}$ & \\
\hline
\end{tabular}

Table 4-2. Troubleshooting Problems/Solutions for PATSyM

\begin{tabular}{|l|l|l|}
\hline \multicolumn{2}{|c|}{ Troubleshooting Guide } \\
\hline \multicolumn{1}{|c|}{ Symptoms } & \multicolumn{1}{|c|}{ Possible Cause } & \multicolumn{1}{c|}{ Background/Trouble Shooting Procedure } \\
\hline $\begin{array}{l}\text { PATSyM lacks proper } \\
\text { heartbeat involving on- } \\
\text { board LEDs 1, 2, and } 4 \\
\text { (LED 3 may be off or } \\
\text { on). }\end{array}$ & $\begin{array}{l}\text { The PATSyM is not } \\
\text { generating the } \\
\text { appropriate clock and } \\
\text { sync pulse trains. }\end{array}$ & $\begin{array}{l}\text { The PATSyM receives serial date and time information } \\
\text { and a 1PPS signal from the GPS receiver card. The date } \\
\text { and time information are placed on the KAM-500 bus } \\
\text { by the PATSyM. The GPS 1PPS output resets the } \\
\text { PATSyM output every second to keep it exactly time- } \\
\text { aligned with Universal Time and to initialize the } \\
\text { counting required to output the bit clock and sync pulse } \\
\text { trains to drive the KAM-500 data acquisition cycle. } \\
\text { Supply voltages are too } \\
\text { First, remove all modules from the mainframe, except } \\
\text { for the encoder and PATSyM. If the heartbeat still } \\
\text { looks bad, make sure the power supplies are providing a } \\
\text { good solid 5 VDC and 12 VDC (too low a level on } \\
\text { either power supply may cause this). If the power } \\
\text { supply levels are OK, plug in one module at a time and } \\
\text { check the PATSyM heartbeat. If the heartbeat } \\
\text { disappears when one module is plugged in, remove that } \\
\text { one and try again. If the heartbeat disappears every time } \\
\text { the module is plugged in, the module may be bad. } \\
\text { Either leave that module out or replace it. Once all } \\
\text { modules are inserted in the mainframe and the heartbeat } \\
\text { is good, attach one connector at a time. If one connector } \\
\text { causes loss of heartbeat, the wiring for that connector is } \\
\text { suspect }- \text { check it out carefully, as it may well be mis- } \\
\text { wired or have lines shorted to ground, to high voltage, } \\
\text { or to each other. }\end{array}$ \\
\hline
\end{tabular}


Table 4-2. Troubleshooting Problems/Solutions for PATSyM (continued)

\begin{tabular}{|l|l|l|}
\hline \multicolumn{2}{|c|}{ Troubleshooting Guide } \\
\hline \multicolumn{1}{|c|}{ Symptoms } & \multicolumn{1}{|c|}{ Possible Cause } & \multicolumn{1}{c|}{ Background/Trouble Shooting Procedure } \\
\hline $\begin{array}{l}\text { PATSyM lacks proper } \\
\text { heartbeat involving on- } \\
\text { board LEDs 1, 2, and 4 } \\
\text { (LED 3 may be off or } \\
\text { on) (continued). }\end{array}$ & $\begin{array}{l}\text { There is no serial data } \\
\text { from GPS. }\end{array}$ & $\begin{array}{l}\text { If there is no obvious 1PPS LED flash (the leftmost of } \\
\text { the four LEDs), the 1PPS output of the GPS receiver } \\
\text { may have failed. Replace the GPS receiver and try } \\
\text { again. If this doesn't fix the problem, replace the } \\
\text { original GPS receiver and the PATSyM. If that doesn't } \\
\text { fix the problem, reinstall the original PATSyM. } \\
\text { If there is no heartbeat at all, use the oscilloscope to } \\
\text { check the GPS serial data receive line (pin 4 of the GPS } \\
\text { antenna/receiver cable or pin 34 of the PATSyM con- } \\
\text { nector). The low signal level should be between -15 } \\
\text { and -5 VDC and the high signal level should be } \\
\text { between 5 and 15 VDC. If no serial signals are present } \\
\text { or the levels are not as specified above, the GPS } \\
\text { receiver may be bad. Replace the GPS receiver and try } \\
\text { again. If this doesn't fix the problem, replace the } \\
\text { original GPS receiver and replace the PATSyM. If that } \\
\text { doesn't fix the problem, reinstall the original PATSyM } \\
\text { If serial data signals of the appropriate voltage are pres- } \\
\text { ent and there is a 1PPS LED flash, the GPS receiver is } \\
\text { probably OK. Replace the PATSyM. If that does not } \\
\text { fix the problem, reinstall the original PATSyM. } \\
\text { Contact SNL for assistance. }\end{array}$ \\
\hline $\begin{array}{l}\text { There is a more serious } \\
\text { problem. }\end{array}$ & \\
\hline
\end{tabular}

If the mainframe is still malfunctioning after working through the procedures given in these tables, turn off the mainframe power, disconnect all mainframe connectors, remove all mainframe modules, and follow the procedures given in Section 1.1.3 (Quick Check). This will program the mainframe with a very simple, stand-alone system. Once this is complete, attempt to troubleshoot the system following the tables given above. If you don't have the cables shown in Figure 1-9, you can build your own using the wiring schematic given in Figure 4-1. 


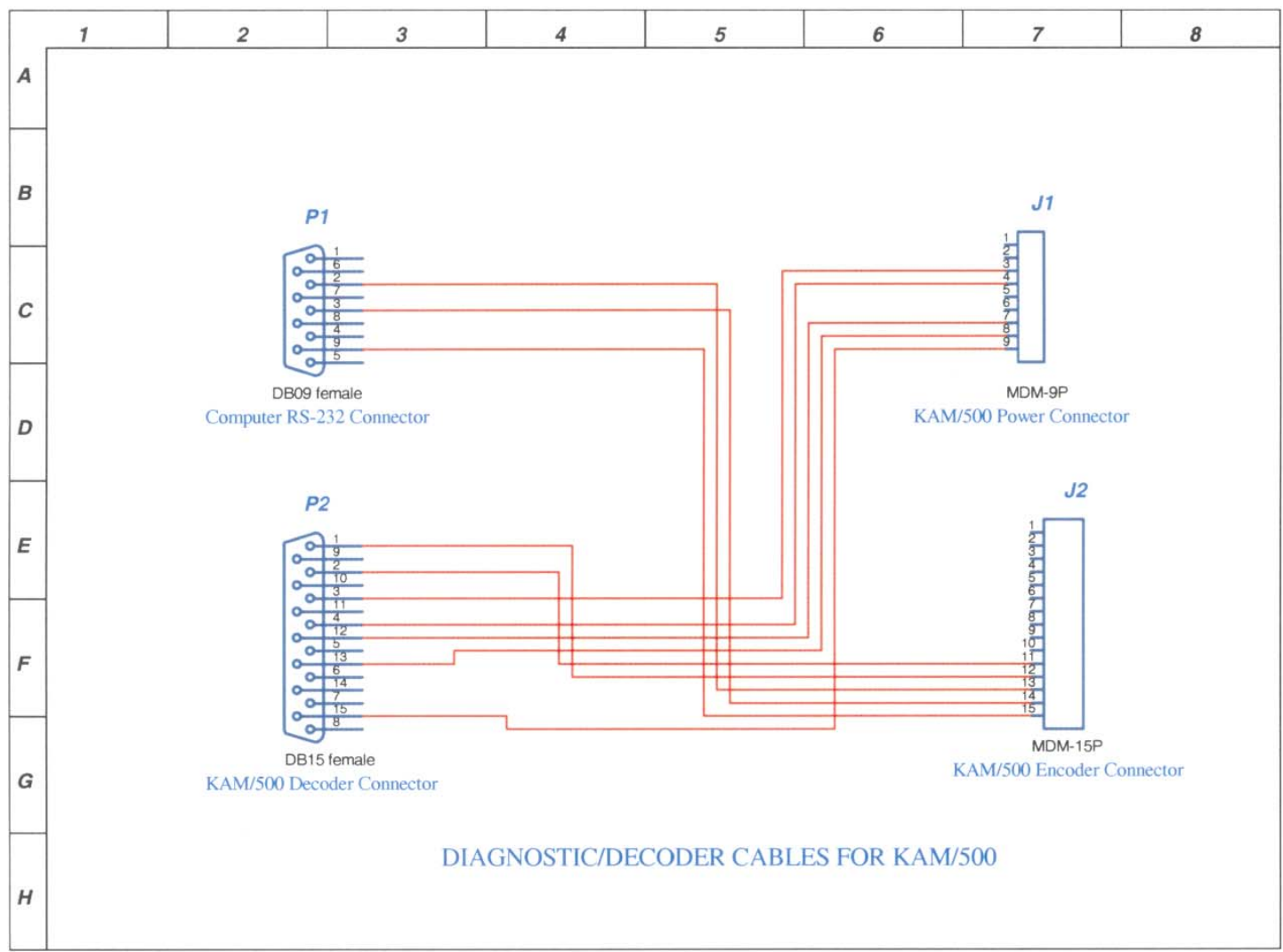

Figure 4-1. Diagnostic/Troubleshooting Cable Schematic. Connectors P1 and P2 are 9-pin and 15-pin D-shells with sockets. 
This page intentionally left blank. 


\section{Chapter 5. References}

Berg, D.E., Robertson, P.J., and Ortiz, M.F. 1998. Development and Application of a Light-Weight, Wind-Turbine Rotor-Based Data Acquisition System. Presented at Windpower '98, Bakersfield, CA, April 27-May 1, 1998. Sandia National Laboratories; Albuquerque, NM.

Berg, D.E., Rumsey, M., Robertson, P. 1998. Development of a Light-Weight, WindTurbine-Rotor-Based Data Acquisition System. Presented at 1998 ASME Wind Energy Symposium $/ 36^{\text {th }}$ AIAA Aerospace Sciences Meeting and Exhibit in Reno, NV, January 12-15, 1998. Sandia National Laboratories; Albuquerque, NM.

Berg, D.E., Robertson, P., and Zayas, J. 1999. ATLAS: A Small, Light Weight, TimeSynchronized Wind-Turbine Data Acquisition System. Presented at the 1999 ASME Wind Energy Symposium in Reno, NV, January 11-14, 1998. Sandia National Laboratories; Albuquerque, NM.

Berg, D.E., Rumsey, M.A., and Zayas, J.R. 2000. "Hardware and Software Developments for the Accurate Time-Linked Data Acquisition System," AIAA 2000-0052, Proceedings of the 2000 ASME Wind Energy Symposium, Reno, NV, January 10-13, 2000, pp. 306-316.

Berg, D.E., and Zayas, J.R. 2001. "Accurate Time-Linked Acquisition System Field Deployment and Operational Experience," AIAA 2001-0038, Proceedings of the 2001 ASME Wind Energy Symposium, Reno, NV, January 8-11, 2001.

Berg, D.E., and Robertson, P.J. 1998. "Precise Time Synchronization Data Acquisition with Remote Systems" Proceedings of 1998 International Telemetering Conference, San Diego, CA, October 26-29, 1998.

Nicolet Instrument Technologies, Inc. 1996. Nicolet MicroPro Remote Data Acquisition System Operation Manual, Version 1.40. P/N 269-923000. Madison, WI.

Robertson, P.J., Berg, D.E., Zayas, J.R., and Gass, K.L. 1999. Final Report and Documentation for the GPS-10K70 Board Design. Sandia National Laboratories; Albuquerque, NM.

Zond Systems, Inc. 1994. Advanced Data-Acquisition System. Tehachapi, CA. 
This page intentionally left blank. 


\section{Chapter 6. Technical Support}

ACRA Control, Inc.,

Landscape House

Landscape Road

Dublin, Ireland

01135312951234

Sandia National Laboratories

P.O. Box 5800

Albuquerque, NM 87185

Dale Berg

505-844-1030 
This page intentionally left blank. 


\section{Appendix A: Citel Protection Devices Specification Sheets}

\section{CITEL ${ }^{\text {inc }}$}

\section{Two Pair Plug-In Module for Telephone and Data Lines} E280

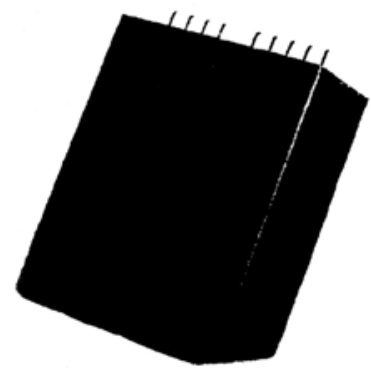

Citel E280 modules have been designed to dissipate the worst of power surges. They use a high speed gas tube/diode association that can arrest a surge in less than one nanosecond and provide high power handling with a tight clamping ratio.

All Citel plug - in modules protect two pairs(4 wires). They protect data lines such as RS422, RS423, RS485, RS232, DDS/56k lines, T1/E1 lines, ISDN, telephone lines, LANs on twisted pairs, Category 5 lines...etc.

E280 modules are used in conjunction with Citel bases: B10, FP10-110, B25, BN08, BN16, BN32 and F22S/MB. They permit on site repair or replacement by non-technical personnel. Each module is color coded for easy distinction between voltages or applications.

Ultra fast response time - less than 1 ns

Multi-stage circuitry

Modular presentation 


\section{CITEL inc}

\section{Electrical Specifications}

E280

\begin{tabular}{|c|c|c|c|c|c|}
\hline & E280T & E280 - 48V & E280 - 24V & $E 280-12 V$ & $E 280-6 \mathrm{~V}$ \\
\hline Application: & $\begin{array}{l}\text { Telephone } \\
\text { Lines }\end{array}$ & $\begin{array}{l}\text { Leased } \\
\text { Lines }\end{array}$ & $\begin{array}{l}4-20 \mathrm{~mA} \text { loop } \\
\text { Lines }\end{array}$ & Telemetry & RS485 \\
\hline $\begin{array}{l}\text { Series } \\
\text { Resistance: }\end{array}$ & $4.7 \mathrm{ohms}$ & $4.7 \mathrm{ohms}$ & $4.7 \mathrm{ohms}$ & $4.7 \mathrm{ohms}$ & $4.7 \mathrm{ohms}$ \\
\hline Capacitance: & $70 \mathrm{pF}$ & $200 \mathrm{pF}$ & $300 \mathrm{pF}$ & $400 \mathrm{pF}$ & $900 \mathrm{pF}$ \\
\hline $\begin{array}{l}\text { Maximum } \\
\text { Line Current: }\end{array}$ & $200 \mathrm{~mA}$ & $200 \mathrm{~mA}$ & $200 \mathrm{~mA}$ & $200 \mathrm{~mA}$ & $200 \mathrm{~mA}$ \\
\hline $\begin{array}{l}\text { Maximum } \\
\text { Line Voltage: }\end{array}$ & $170 \mathrm{~V}$ & $48 \mathrm{~V}$ & $24 \mathrm{~V}$ & $15 \mathrm{~V}$ & $6 \mathrm{~V}$ \\
\hline $\begin{array}{l}\text { Clamping } \\
\text { Voltage: }\end{array}$ & $190 \mathrm{~V}$ & $60 \mathrm{~V}$ & $30 \mathrm{~V}$ & $20 \mathrm{~V}$ & $10 \mathrm{~V}$ \\
\hline $\begin{array}{l}\text { Residual } \\
\text { Voltage: }\end{array}$ & $220 \mathrm{~V}$ & $70 \mathrm{~V}$ & $35 \mathrm{~V}$ & $30 \mathrm{~V}$ & $20 \mathrm{~V}$ \\
\hline $\begin{array}{l}\text { Power } \\
\text { Handling: } \\
\text { (8/20 } / 5 \text { - } 10 \text { x's) }\end{array}$ & $10 \mathrm{kA}$ & $10 \mathrm{kA}$ & $10 \mathrm{kA}$ & $10 \mathrm{kA}$ & $10 \mathrm{kA}$ \\
\hline $\begin{array}{l}\text { Electrical. } \\
\text { Diagrams: }\end{array}$ & 2 & 1 & 1 & 1 & 1 \\
\hline
\end{tabular}

\section{Electrical Diagrams}
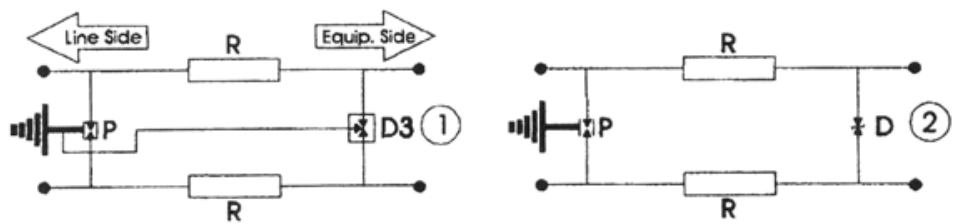

P: 3- Element Gas Tube

D: Clamping Diode

R: Resistor

R: Resistor
D3: 3 - Element Clamping Diode

\section{Mechanical Diagrams}

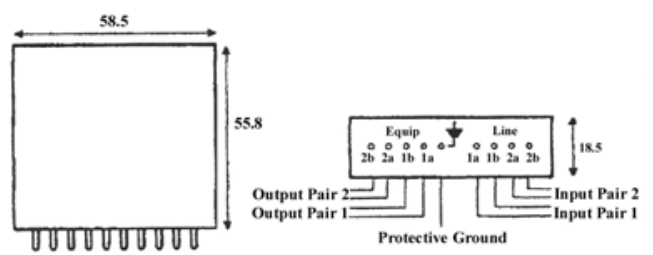




\section{Appendix B: GBU Wiring Schematics}


This page intentionally left blank. 


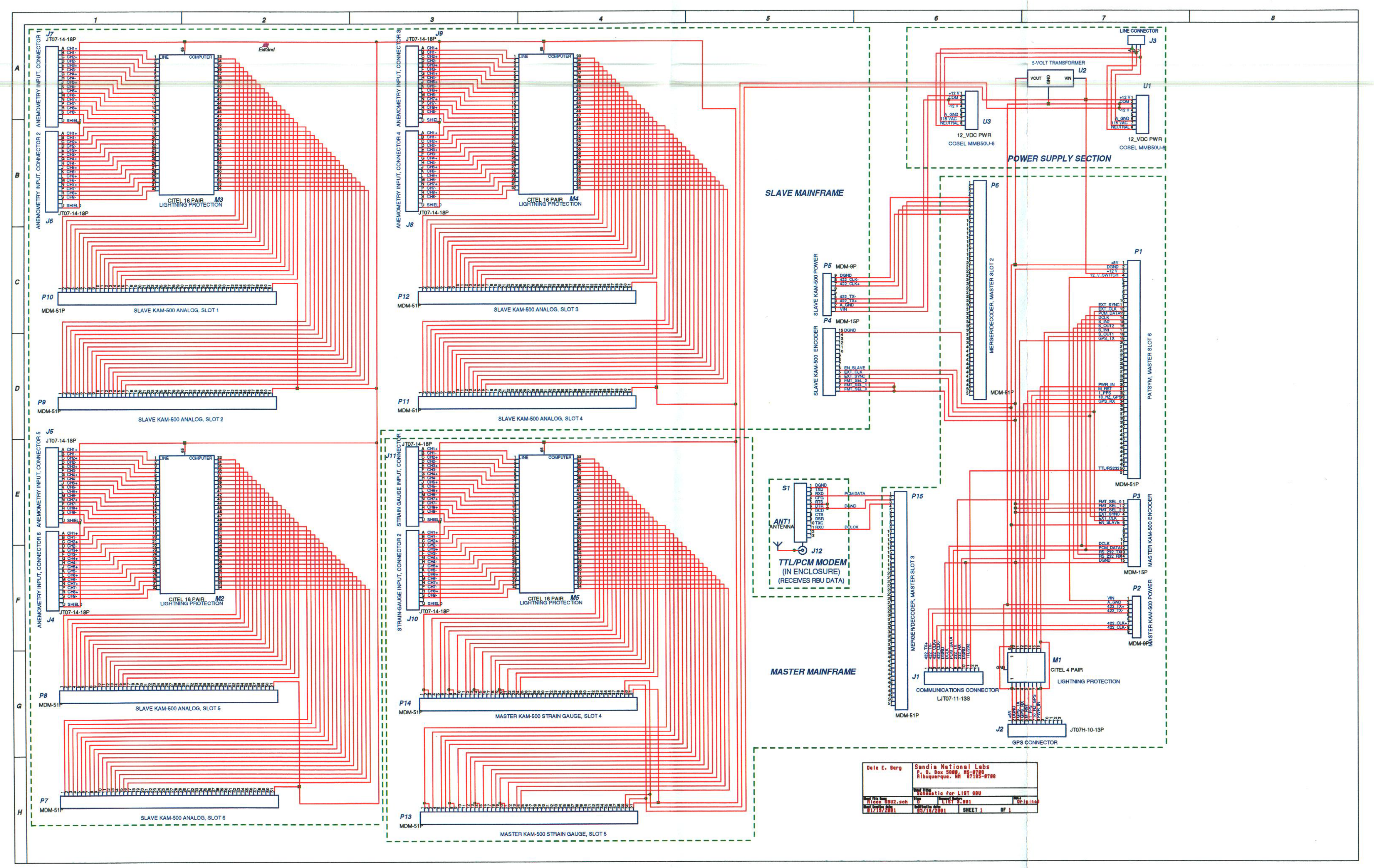




\section{Appendix C: RBU Wiring Schematics}

Wiring schematics for two of the RBUs that have been built are given below. 
This page intentionally left blank.

C-2 


\section{Windy 2}


This page intentionally left blank. 


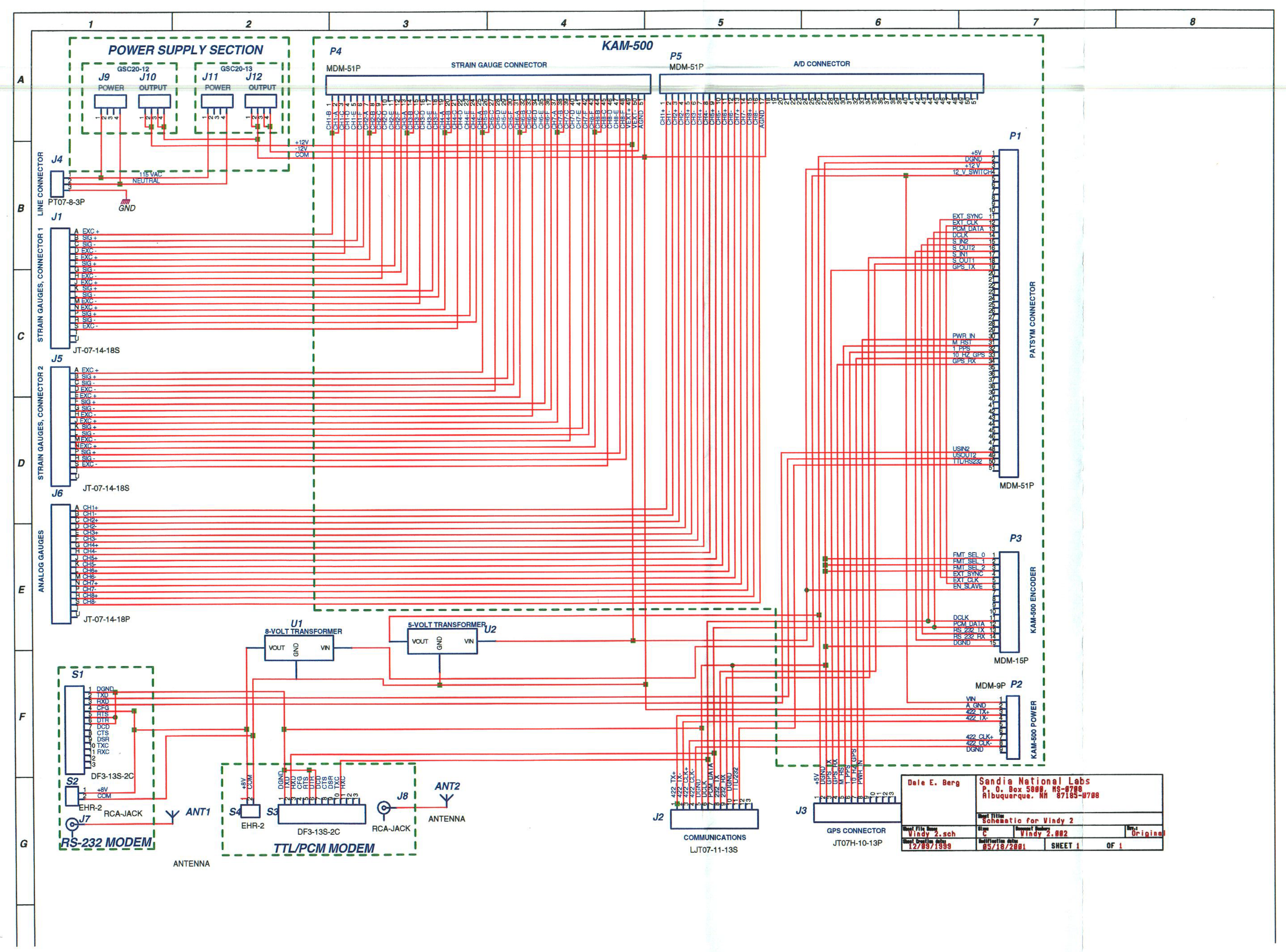




\section{Windy 3}


This page intentionally left blank. 


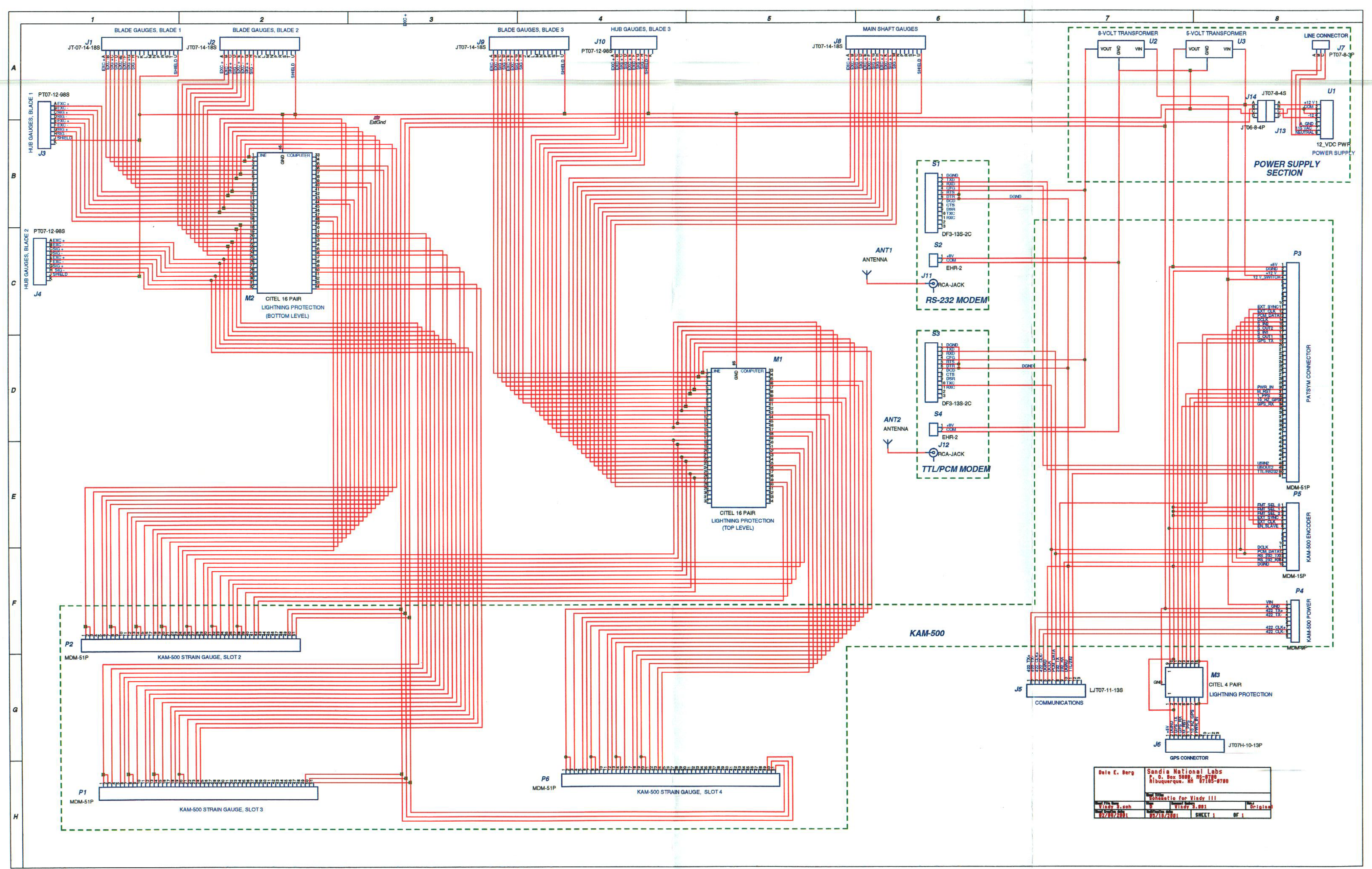




\section{Appendix D: Estimating MicroPro Power Requirements}

\begin{tabular}{|l|c|c|c|c|}
\hline \multicolumn{1}{|c|}{ Module } & $\begin{array}{c}\mathbf{+ 1 2 V} \\
\text { current } \\
(\mathbf{m A})\end{array}$ & $\begin{array}{c}\mathbf{- 1 2 V} \\
\mathbf{c u r r e n t} \\
\mathbf{( m A )}\end{array}$ & $\begin{array}{c}\mathbf{+ 5 V} \text { cur- } \\
\text { rent } \\
\mathbf{( m A )}\end{array}$ & $\begin{array}{c}\text { Power } \\
\mathbf{( W )}\end{array}$ \\
\hline $\begin{array}{l}\text { MicroPro Mainframe w/encoder module } \\
\text { (single power supply) }\end{array}$ & 0 & 0 & 180 & 1.7 \\
\hline Digital input module & 0 & 0 & 80 & 0.4 \\
\hline High level analog input module & 90 & 90 & 180 & 3.1 \\
\hline $\begin{array}{l}\text { Strain gauge input module } \\
\text { (not including bridge excitation) }\end{array}$ & 90 & 90 & 180 & 3.1 \\
\hline PATSyM module & 0 & 0 & $200 \mathrm{ma}$ & 1.0 \\
\hline $\begin{array}{l}8 \text { each 350 } \Omega \text { strain gauges, } \pm 5 \mathrm{~V} \\
\text { excitation }(\mathrm{i}=5 / 350)\end{array}$ & $8 \times 14.3$ & $8 \times 14.3$ & 0 & 1.1 \\
\hline $\begin{array}{l}8 \text { each } 1000 \Omega \text { strain gauges, } \pm 5 \mathrm{~V} \\
\text { excitation }(\mathrm{i}=5 / 1000)\end{array}$ & $8 \times 5.0$ & $8 \times 5.0$ & 0 & 0.4 \\
\hline
\end{tabular}

Because some losses will be incurred in the internal DC/DC convertors, the total estimated power from this table should be multiplied by a factor of 1.5 to determine the minimum power supply requirement. 
This page intentionally left blank.

$\mathrm{D}-2$ 


\section{Appendix E: GBU Photographs}

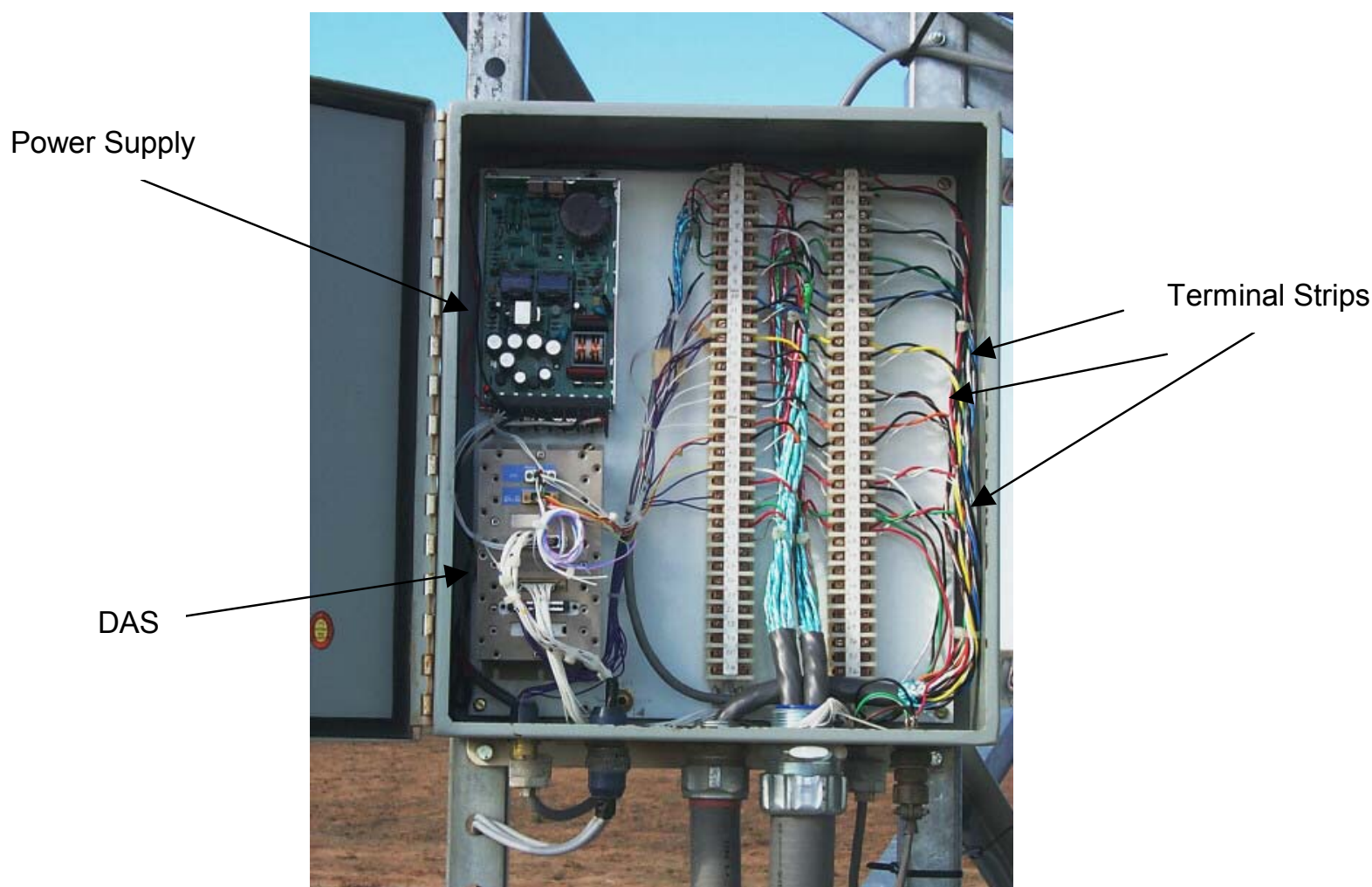

Figure E-1. Tower-Mounted GBU at Bushland.

Note that this installation does not include lightning protection. The instrumentation lines are the large cable entering the bottom of the enclosure just right of center. The right terminal strip connects to lines going back to the master GBU in the Wind Lab. Instrument lines going into the DAS and DAS RS-422 communications going to the master GBU are connected through the left terminal strip. 


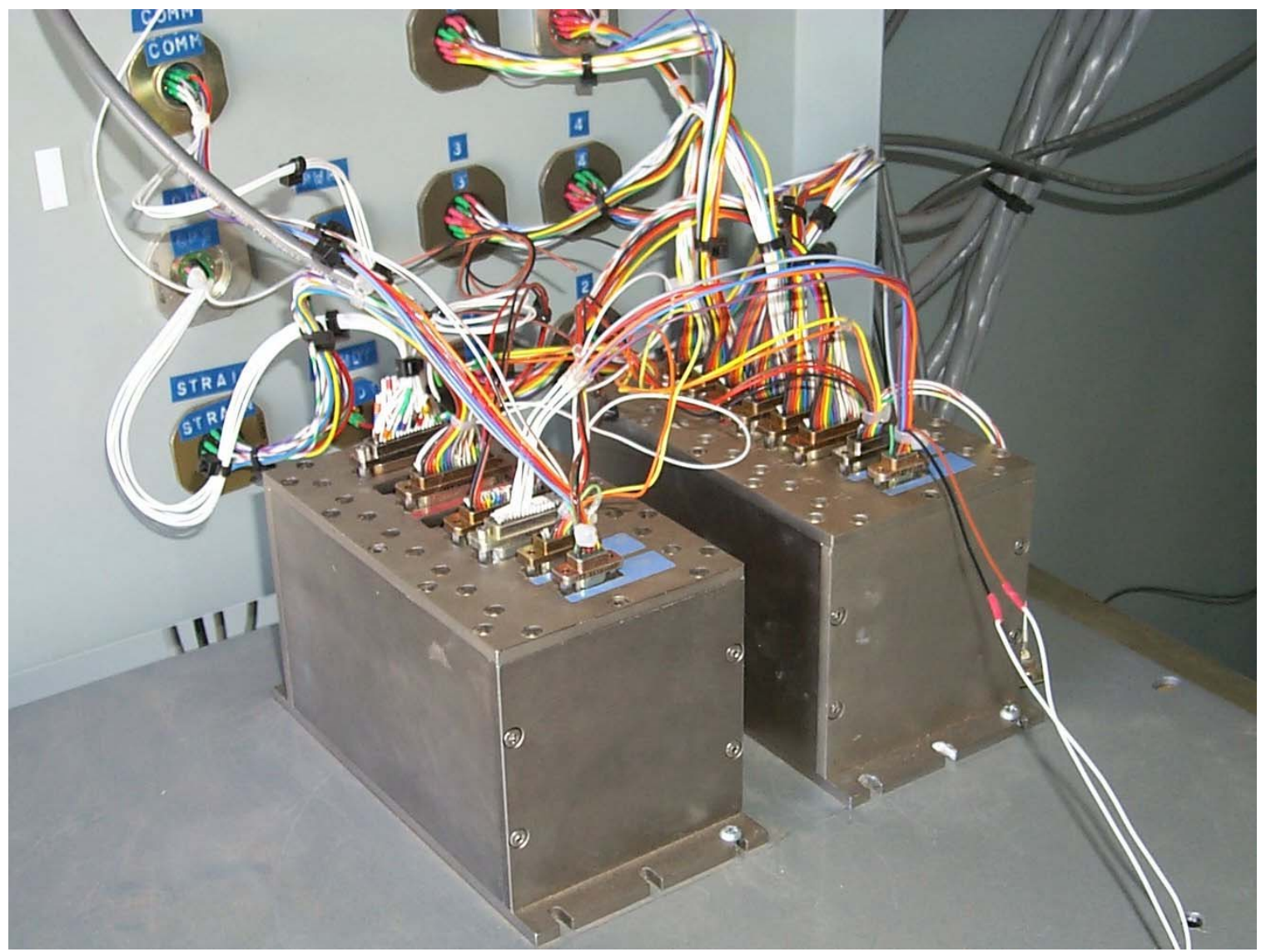

Figure E-2. Master and Slave GBUs for Bushland LIST Installation

The left unit is the Master GBU. The PATSyM in slot 6 (furthest to the rear) of the Master provides timing for both the Master and the Slave. The Master contains two Merger/Decoder modules in slots 1 and 2 to merge data streams from the Slave and from the RBU, respectively. The Master also contains a single strain-gauge input module in slot 4 to monitor strain and acceleration of the turbine tower. The Slave contains six high-level analog input modules to acquire anemometry and turbine operating parameters data. 


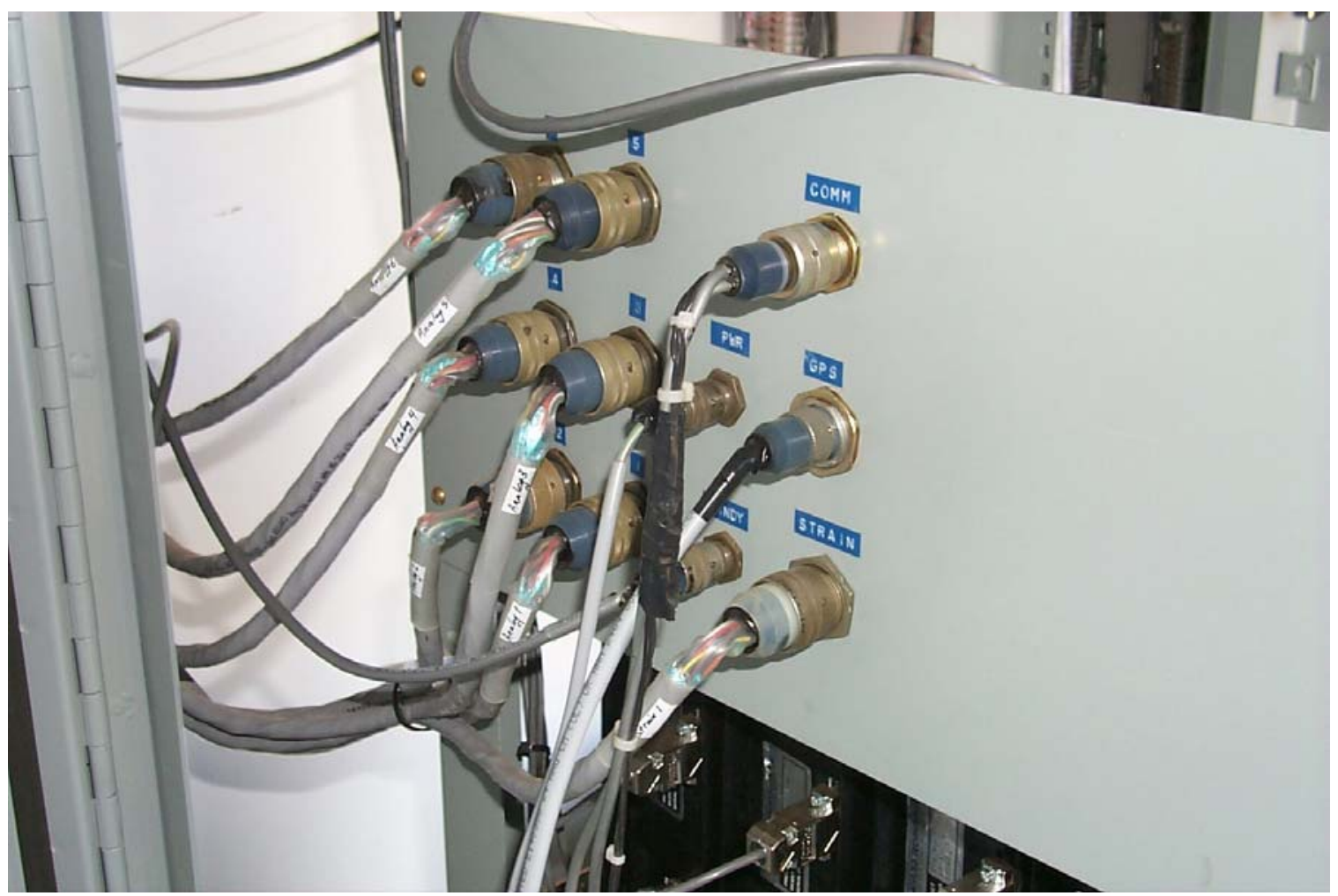

Figure E-3. Connector Bulkhead for Bushland LIST GBU Installation

All of the instrumentation, power, and communication lines into the Master/Slave GBU combination are passed through these connectors. The DAS units are mounted on the other side of this bulkhead (see Figure E-2). This facilitates wiring the lines and permits easy separation of DAS hardware and wiring for checkout purposes. All of these lines are protected by Citel devices between this point and where they enter the instrumentation building. 


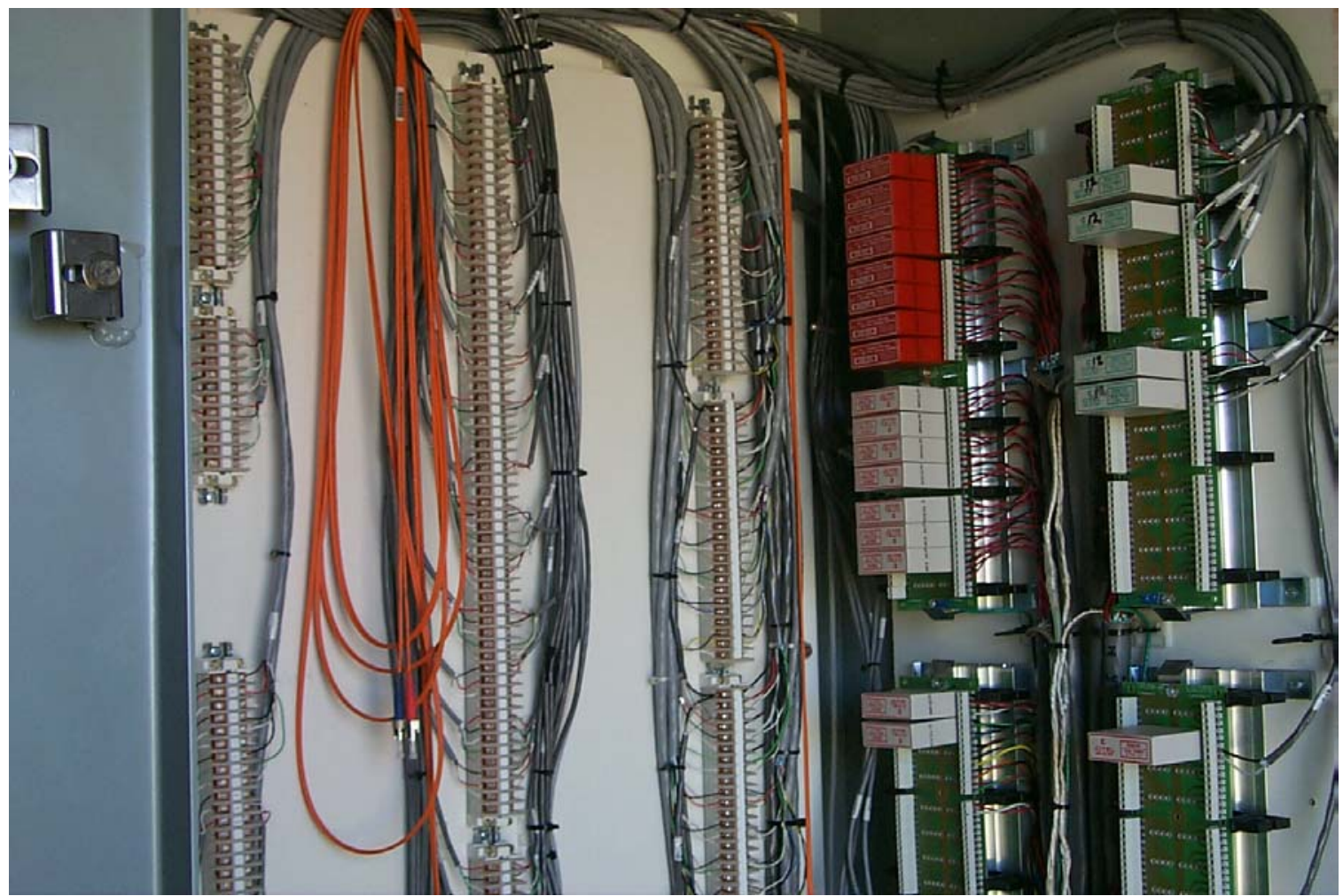

Figure E-4. Terminal Strips and Lightning Protection in Bushland LIST Instrumentation Building.

Instrumentation lines enter the building below the center of this photo (just to the left of the white and red Citel units). Those lines are connected to the terminal strips. From the terminal strips, the lines go through the lightning protection units at the right of the photo, back to other terminal strips, and then to the connector bulkhead shown in Figure E-3. This arrangement facilitates wiring checkouts and permits easy troubleshooting. 


\section{Appendix F: RBU Photographs}

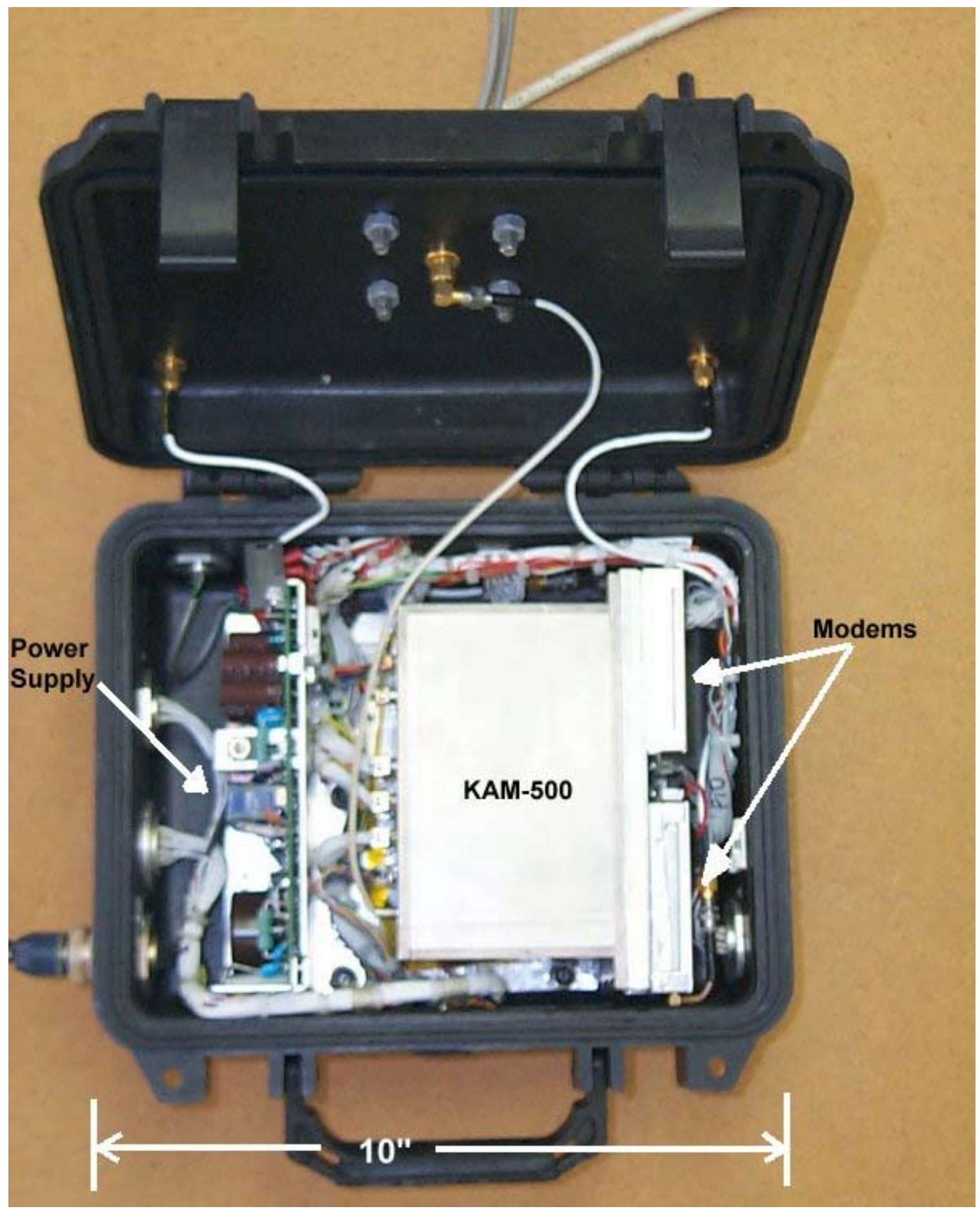

Figure F-1. Photo of Windy I Contents.

Note the location of the various components. The DAS is mounted on its side because of height limitations of the container. The PATSyM version used here placed the GPS receiver inside the DAS. Since the DAS is lying on its side, insertion or removal of any 
modules required the removal of the DAS from the container. All components are mounted on a 0.75 -in. thick aluminum plate passing through the back of the container.

The power supply occupies the left-hand side of the box, with the DAS (on its side) to the right. The two modems are mounted on the extreme right side of the box, and the GPS antenna is mounted on the top of the box. Notice that no lightning protection is included.

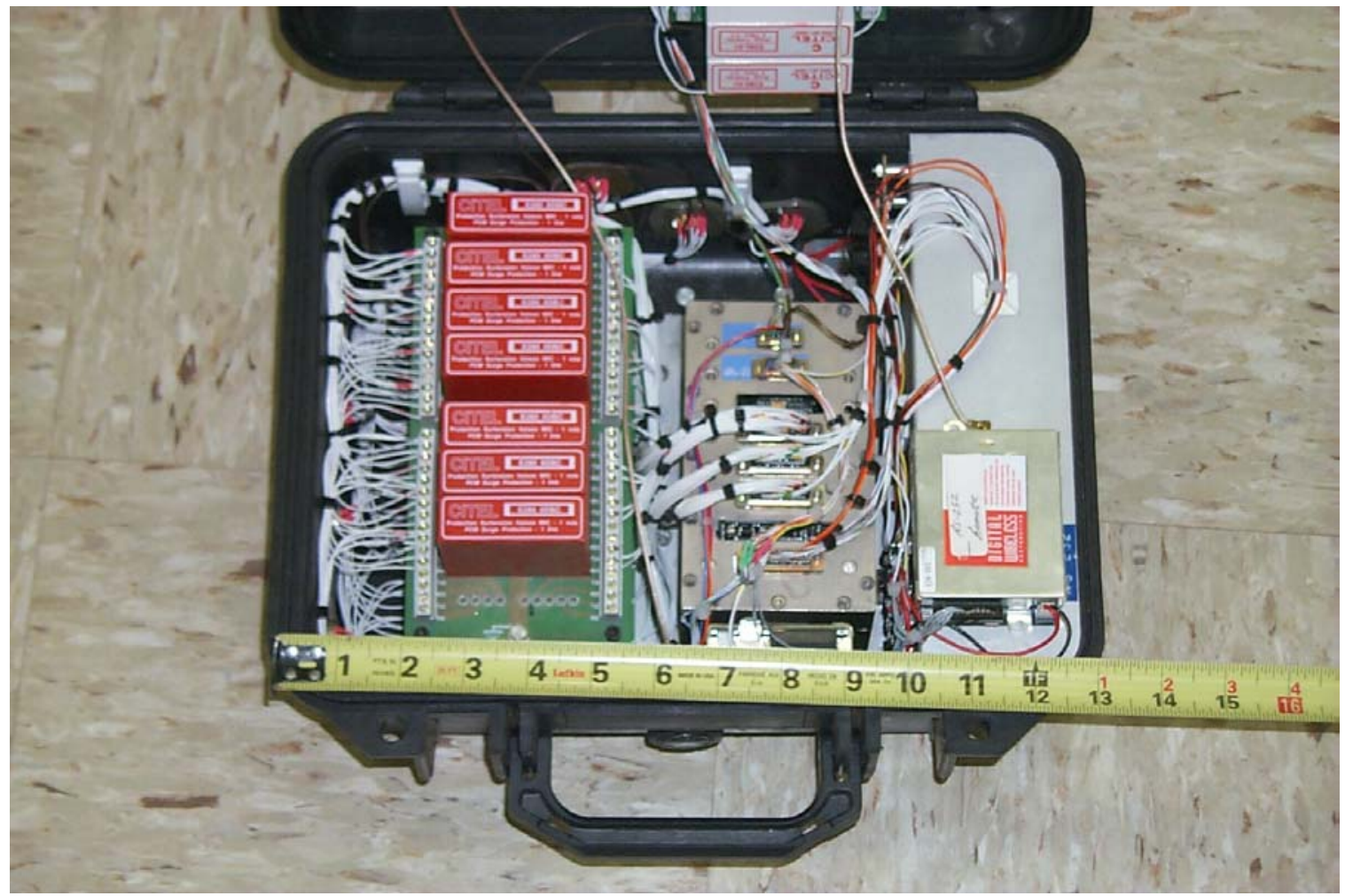

Figure F-3. Photograph of Windy III Contents.

Notice the increased size of this RBU, compared to Windy I. Again, all components are mounted to an aluminum plate passing through the bottom of the container. Two layers of Citel lightning protection devices are located at the left, the DAS (now mounted upright for easy access to the modules) is mounted in the center, and the power supply (covered by a grounded sheet-metal shield) is mounted to the right. One modem is mounted on top the power supply at the far right, and the other is mounted on the near end of the DAS, just above the number 8 on the ruler. The GPS antenna receiver is mounted on the hinged lid of the container, along with two Citel lightning protection devices (to protect the GPS lines) and the modem antennas. Instrumentation, power, and communication connectors are located on the left, top, and right sides of the container. 


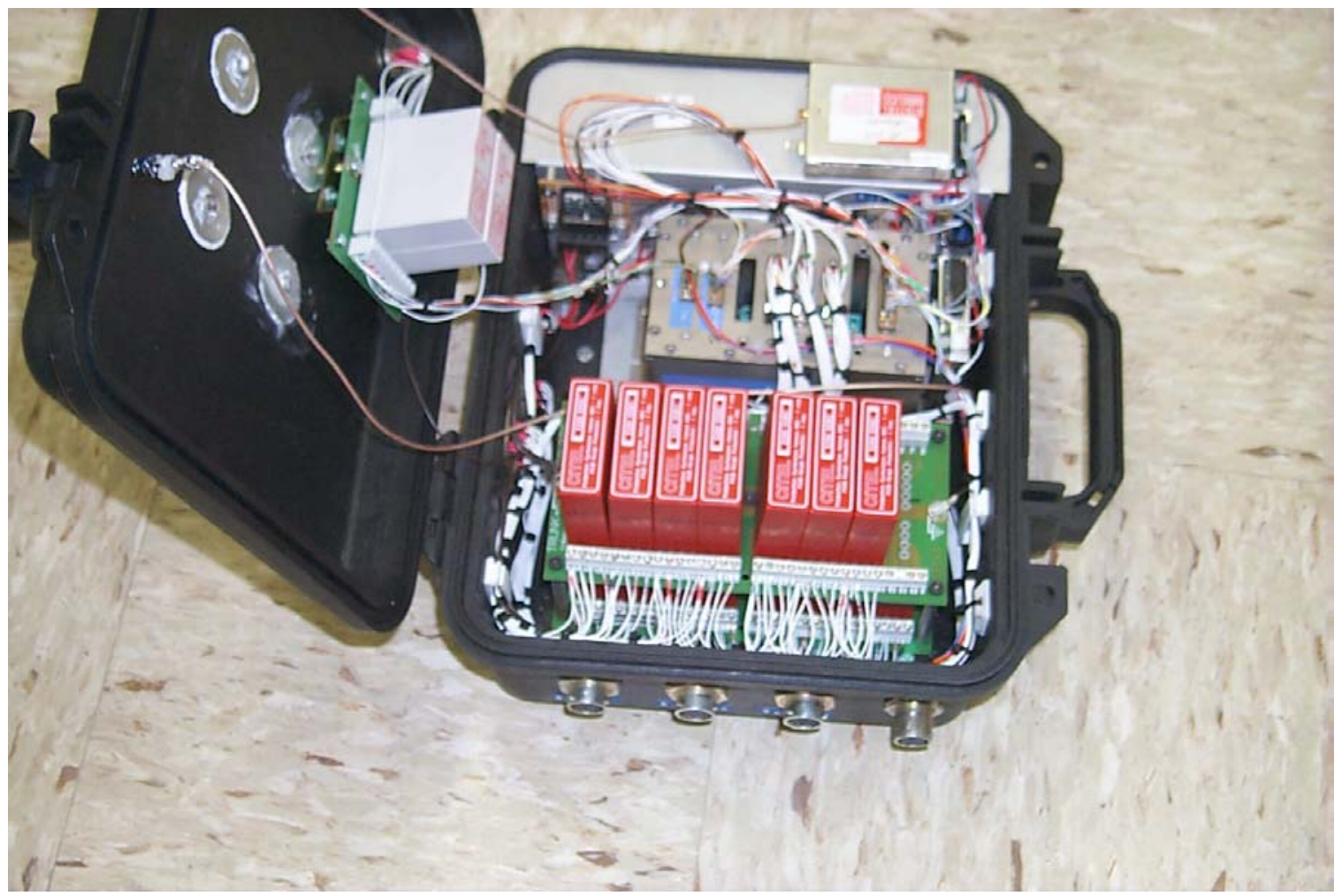

Figure F-4. Photograph of Windy III Contents.

Another perspective of Windy III shows several instrumentation connectors (left three) and the communications connector (right one) on the unit. Notice the container handle to the right. This makes carrying the assembled device very convenient. 
This page intentionally left blank. 


\section{Appendix G: Configuring Modems}

\section{G.1 Programming the Remote and Base Modems}

\section{G.1.2 Program the Remote RS-232 Modem}

The remote RS-232 modem handles all asynchronous communications on the rotor. It must be programmed once to set the communications protocol parameters properly. Although only the bare module will be used in the RBU, it must be mounted in a complete modem housing, with RS-232 interface and serial cable connection, to be programmed.

1. Connect the modem 9-pin connector to the computer serial port and the power cable to the $8 \mathrm{~V}$ power source (usually a 8 -VDC transformer that plugs into a $110 \mathrm{VAC}$ wall outlet).

2. Start the COM2400 program (a DOS program located in directory COM24) and set the communciation rate to 38,400 bps using the computer's $<\operatorname{PgUp}>$ or $<\operatorname{PgDn}>$ key. The communication rate is displayed on bottom left of the screen

3. Turn on the power to the modem.

4. The COM2400 program should display the modem firmware version and whether the modem is programmed as REMOTE or BASE. If the display is garbage characters, shift the program communication rate up or down and cycle the modem power again. The unit is probably programmed to operate at either $9,600,19,200,38,400$ or 57,600 .

5. After the version message is displayed, quickly press the F3 key to get the " $>$ " prompt. Then proceed to program the modem unit. Enter the following commands (followed by the Enter key) at successive > prompts:
a) wn0 (sets network number to 0)
b) wb0 (sets base/remote to remote)
c) wdaa (sets destination address to $\mathrm{AAH}$ )
d) wsaa (sets source address to AAH)
e) wt0 (sets channel access mode to CSMA)
f) wp1 (sets transmit power to $100 \mathrm{~mW}$ )
g) sy0 (sets sync/async to asynchronous mode)
h) $\operatorname{sd020~(sets~data~transmit~rate~to~} 38,400 \mathrm{bps}$ )

\section{NOTE}

Use the computer's $<\mathrm{PgUp}>$ or $<\mathrm{PgDn}>$ key to change the program communication speed to 38,400 before you continue - the speed is displayed at the bottom left of the screen. 

i) $\quad \mathrm{sp} 0 \quad$ (sets packet mode to point-to-point)
j) ph9c (sets hop duration to $9 \mathrm{CH}$ )
k) $\mathrm{pk} 0 \mathrm{a}$ (sets minimum packet length to $0 \mathrm{AH}$ )
1) plf0 (sets maximum packet length to $\mathrm{F} 0 \mathrm{H}$ )
m) $\mathrm{pt03}$ (sets packet timeout duration to $03 \mathrm{H}$ )
n) $\mathrm{pm} 40$ (sets packet link margin to $40 \mathrm{H}$ )
o) pr10 (sets ARQ retry limit to $10 \mathrm{H}$ )
p) py02 (sets ARQ per-hop limit to $2 \mathrm{H}$ )
q) pb08 (sets CSMA backoff constant to 08H)
r) pp20 (sets CSMA persistence to $20 \mathrm{H}$ )
s) $\mathrm{ps} 0 \mathrm{a} \quad$ (sets TDMA time slot to $0 \mathrm{AH}$ )
t) pd0 (disables diversity antenna switching)
u) $\mathrm{m}>\quad$ (stores configuration to memory)
v) $\mathrm{z}>\quad$ (exits modem control mode)

6. The modem module should now be programmed, in asynchronous mode, and capable of communication. To check configuration settings, press F1 twice (to toggle DTR off and back on), and then press F3 once (to transmit "wit:2400", which places the modem in configuration mode). Then check the settings programmed under Step 5, above. The current setting for each command can be displayed by typing the twoletter command followed by ? (i.e., sy?, to determine whether modem is set in sync or async mode).

\section{G.1.3 Program the Base RS-232 Modem}

The Base RS-232 modem handles all asynchronous communications on the ground. This modem module will be mounted in a modem case for normal use and will be located near the Master GBU.

1. Connect the modem 9-pin connector to the computer serial port and the power cable to a $110 \mathrm{VAC}$ power source.

2. Start the COM2400 program (a DOS program located in directory COM24) and set the communciation rate to 38,400 bps using the computer's $<\operatorname{PgUp}>$ or $<\operatorname{PgDn}>$ key. The communication rate is displayed at the bottom left of the screen.

3. Turn on the power to the modem.

4. The COM2400 program should display the modem firmware version and whether it is REMOTE or BASE. If the display is garbage characters, shift the program communication rate up or down and cycle the modem power again. The unit is probably programmed to operate at either $9,600,19,200,38,400$, or 57,600 .

5. After the version message is displayed, quickly press the F3 key to get the ">" prompt. Then proceed to program the modem unit. Enter the following commands (followed by the Enter key) at successive > prompts: 

a) wn0 (sets network number to 0 )
b) wb1 (sets base/remote to base)
c) wdaa (sets destination address to $\mathrm{AAH}$ )
d) wsaa (sets source address to AAH)
e) wt0 (sets channel access mode to CSMA)
f) wp1 (sets transmit power to $100 \mathrm{~mW}$ )
g) sy0 (sets sync/async to asynchronous mode)
h) $\operatorname{sd020~(sets~data~transmit~rate~to~} 38,000 \mathrm{bps}$ )

\section{NOTE}

Use the computer's $<\operatorname{PgUp}>$ or $<\operatorname{PgDn}>$ key to change the program communication speed to 38,400 before you continue - the speed is displayed at the bottom left of the screen.
i) $\mathrm{sp0}$ (sets packet mode to point-to-point)
j) ph9c (sets hop duration to $9 \mathrm{CH}$ )
k) pk0a (sets minimum packet length to $0 \mathrm{AH}$ )
1) plfo (sets maximum packet length to $\mathrm{FOH}$ )
m) pt03 (sets packet timeout duration to $03 \mathrm{H}$ )
n) $\mathrm{pm} 40$ (sets packet link margin to $40 \mathrm{H}$ )
o) $\operatorname{pr} 10 \quad$ (sets ARQ retry limit to $10 \mathrm{H}$ )
p) py02 (sets ARQ per-hop limit to $2 \mathrm{H}$ )
q) pb08 (sets CSMA backoff constant to $08 \mathrm{H}$ )
r) $\mathrm{pp} 20 \quad$ (sets CSMA persistence to $20 \mathrm{H}$ )
s) $\mathrm{ps} 0 \mathrm{a}$ (sets TDMA time slot to $\mathrm{OAH}$ )
t) $\operatorname{pd} 0 \quad$ (disables diversity antenna switching)
u) $\mathrm{m}>\quad$ (stores configuration to memory)
v) $\mathrm{z}>\quad$ (exits modem control mode)

6. The modem module should now be programmed, in asynchronous mode, and capable of communication. To check configuration settings, press F1 twice (to toggle DTR off and back on), and then press F3 once (to transmit "wit:2400", which places the modem in configuration mode). Then check the settings programmed under Step 5, above. The current setting for each command can be displayed by typing the twoletter command followed by? (i.e., sy?, to determine whether modem is set in sync or async mode). 


\section{G.2 Programming the Data Transmit and Receive Modems}

\section{G.2.1 Program the Transmit Data Modem to be Mounted in the RBU}

The transmit data modem transmits acquired data from the RBU. Although only the bare module will be used in the RBU, it must be mounted in a complete modem housing, with RS-232 interface and serial cable connection, to be programmed.

1. Connect the modem to the computer serial port and the power cable to the $110 \mathrm{~V}$ power source.

2. Connect module signal pin 4 (CFG) to signal pin 1 (GND) on the modem module 11pin connector. This jumper must be kept in place throughout the following procedure. This will require removal of the modem housing cover to allow access to the module connector.

3. Start the COM2400 program (a DOS program located in directory COM24) and set the communciation rate to 38,400 bps using the computer's $<\operatorname{PgUp}>$ or $<\operatorname{PgDn}>$ key. The communication rate is displayed at the bottom left of the screen.

4. Turn on the power to the modem.

5. The COM2400 program should display the modem firmware version and whether it is REMOTE or BASE. If the display is garbage characters, shift the program communication rate up or down and try again. It's probably programmed for 9600, 19,200, 38,400 , or 57,600 .

6. After the version message is displayed, quickly press the F3 key to get the " $>$ " prompt. Then proceed to program the modem unit. Enter the following commands (followed by the Enter key) at successive > prompts:
a) wn1 (sets network number to 1)
b) $\mathrm{wb} 0 \quad$ (sets base/remote to remote)
c) wdaa (sets destination address to $\mathrm{AAH}$ )
d) wsaa (sets source address to AAH)
e) wt0 (sets channel access mode to CSMA)
f) wp1 (sets transmit power to $100 \mathrm{~mW}$ )
g) sy1 (sets modem into synchronous mode - this will not be effective until $\mathrm{z}>$ is entered to terminate programming)
h) sd01f (sets data transmit rate to $38,400 \mathrm{bps}$ )

\section{NOTE}

Use the computer's $<\operatorname{PgUp}>$ or $<\operatorname{PgDn}>$ key to change the program communication speed to 38,400 before you con 
tinue - the speed is displayed at the bottom left of the screen.

i) sp0 (sets packet mode to point-to-point)

j) ph41 (sets hop duration to $41 \mathrm{H}$ )

k) $\mathrm{pk0 \textrm {a }}$ (sets minimum packet length to $0 \mathrm{AH}$ )

1) plff (sets maximum packet length to FFH)

m) pt03 (sets packet timeout duration)

n) $\mathrm{pm} 40$ (sets packet link margin)

o) pr10 (sets ARQ retry limit to $10 \mathrm{H}$ )

p) py02 (sets ARQ per-hop limit to $2 \mathrm{H}$ )

q) pb08 (sets CSMA backoff constant to $08 \mathrm{H}$ )

r) ppff (sets CSMA persistence to FFH)

s) $\mathrm{ps} 0 \mathrm{a}$ (sets TDMA time slot to $0 \mathrm{AH}$ )

t) $\operatorname{pd} 0 \quad$ (disables diversity antenna switching)

u) $\mathrm{m}>\quad$ (stores configuration to memory)

v) $\mathrm{z}>\quad$ (exits modem control mode)

7. Remove the jumper inserted in step 2, above.

8. The modem module should now be programmed and in synchronous mode and no longer capable of communication with the computer. To check configuration settings, power off the modem and then perform steps 2,4 , and 5 , above. The current setting for each command can be displayed by typing the two-letter command followed by ? (i.e., sy?, to determine whether the modem is set in synchronous or asynchronous mode).

\section{G.2.2 Program the Receive Data Modem}

The receive data modem receives the acquired data signal from the RBU installed on the rotor. It must be located next to the Master GBU. This unit will usually be situated in a modem case, so signal and power are already supplied to the module - just remove the top of the case to access the 13-pin data connector.

1. Jumper signal pin 4 (CFG) to signal pin 1 (GND) on the 13-pin connector. This jumper must be kept in place throughout the following procedure.

2. Start the COM 2400 program (a DOS program located in directory COM24) and set the communciation rate to 38,400 bps using the computer's $<\operatorname{PgUp}>$ or $<\mathrm{PgDn}>$ key. The communication rate is displayed at the bottom left of the screen.

3. Turn on the power to the modem.

4. The COM2400 program should display the modem firmware version and whether it is REMOTE or BASE. If the display is garbage characters, shift the program 
communication rate up or down and try again. It's probably programmed for 9600 , $19,200,38,400$, or 57,600 .

5. After the version message is displayed, quickly press the F3 key to get the ">" prompt. Then proceed to program the modem unit. Enter the following commands (followed by the Enter key) at successive > prompts:
a) wn1 (sets network number to 1)
b) wb1 (sets base/remote to base)
c) wdaa (sets destination address to $\mathrm{AAH}$ )
d) wsaa (sets source address to AAH)
e) wt0 (sets channel access mode to CSMA)
f) wp1 (sets transmit power to $100 \mathrm{~mW}$ )
g) syl (sets sync/async to synchronous mode - this will not be effective until $\mathrm{Z}>$ is entered to terminate programming)
h) sd014 (sets data transmit rate to $57,600 \mathrm{bps}$ )

\section{NOTE}

Use the computer's $<\operatorname{PgUp}>$ or $<\operatorname{PgDn}>$ key to change the program communication speed to 57,600 before you continue - the speed is displayed at the bottom left of the screen.
i) $\mathrm{sp} 0 \quad$ (sets packet mode to point-to-point)
j) $\mathrm{ph} 41$ (sets hop duration to $41 \mathrm{H}$ )
k) $\mathrm{pk0a}$ (sets minimum packet length to $0 \mathrm{AH}$ )
1) plff (sets maximum packet length to FFH)
m) $\mathrm{pt03}$ (sets packet timeout duration)
n) $\mathrm{pm} 40$ (sets packet link margin)
o) $\operatorname{pr} 10 \quad$ (sets ARQ retry limit to $10 \mathrm{H}$ )
p) py02 (sets ARQ per-hop limit to $2 \mathrm{H}$ )
q) pb08 (sets CSMA backoff constant to $08 \mathrm{H}$ )
r) ppff (sets CSMA persistence to $\mathrm{FFH}$ )
s) $\mathrm{ps} 0 \mathrm{a}$ (sets TDMA time slot to $0 \mathrm{AH}$ )
t) $\mathrm{pd} 0 \quad$ (disables diversity antenna switching)
u) $\mathrm{m}>\quad$ (stores configuration to memory)
v) $\mathrm{z}>\quad$ (exits modem control mode)

6. Remove the jumper inserted in Step 1, above.

7. The module should now be programmed and in synchronous mode, and no longer capable of communication with the computer. To check configuration settings, power off the modem, and perform steps 1, 3, and 4, above. The current setting for each command can be displayed by typing the two-letter command followed by ? (i.e., sy?, to determine whether the modem is set in sync or async mode). 


\section{Distribution List}

R. N. Clark

USDA

Agricultural Research Service

P.O. Drawer 10

Bushland, TX 79012

Dave Jager

NREL

1617 Cole Boulevard

Golden, CO 80401

Byron Neal (3)

USDA

Agricultural Research Service

P.O. Drawer 10

Bushland, TX 79012

Dave Simms (3)

NREL

1617 Cole Boulevard

Golden, CO 80401

$\begin{array}{ll}\text { MS-0708 } & \text { D. E. Berg, 6214 } \\ \text { MS 0708 } & \text { P. L. Jones, 6214 } \\ \text { MS-0708 } & \text { M. A. Rumsey, 6214 } \\ \text { MS 0708 } & \text { H. J. Sutherland, 6214 } \\ \text { MS 0708 } & \text { H. M. Dodd, 6214 (10) } \\ \text { MS 0708 } & \text { J. R. Zayas, 6214 } \\ \text { MS 0612 } & \text { Review \& Approval Desk, 9612 } \\ & \text { For DOE/OSTI } \\ \text { MS 0899 } & \text { Technical Library, 9616 (2) } \\ \text { MS 9018 } & \text { Central Technical Files, 8945-1 } \\ \text { MS 0161 } & \text { Patent \& Licensing Office, 11500 }\end{array}$

